\title{
Surge Protection in Low-Voltage AC Power Circuits - An Anthology Part 3 - Recorded Surge Occurrences, Surveys and Staged Tests
}

François D. Martzloff

U.S. DEPARTMENTOFCOMMERCE Technology Administration Electronics and Electrica! EngineeringLaburatory Electricity Division

Nationallnstitute of Standards and Tecnnology

Gaithersburg, MD 20899

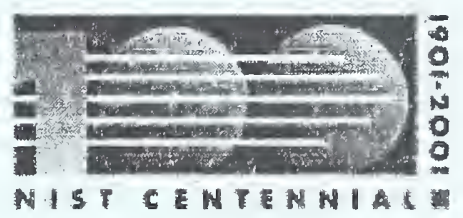





\section{Surge Protection in Low-Voltage AC Power Circuits - An Anthology Part 3 - Recorded Surge Occurrences, Surveys and Staged Tests}

François D. Martzloff

U.S. DEPARTMENTOFCOMMERCE

Technology Administration

Electronics and Electrical

EngineeringLaboratory

Electricity Division

Nationallnstitute of Standards

and Technology

Gaithersburg, MD 20899

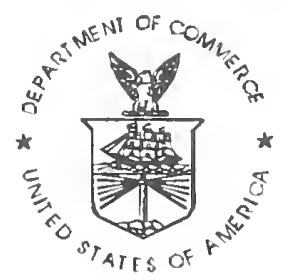

U.S. DEPARTMENT OF COMMERCE

Donald L. Evans, Secretary

TECHNOLOGY ADMINISTRATON

Phillip J.Bond, UnderSecretary for Technology

NATIONAL INSTITUTE OF STANDARDS

AND TECHNOLOGY

Arden L. B ement, Jr., Director 
Q 


\section{FOREWORD}

The papers included in this part of the Anthology report the occurrence of surges in low-voltage AC power circuits. Data on such occurrences were initially collected in the early sixties as the realization developed that the newly introduced solid-state devices were failing in the field, with the suspicion that surge voltages might be the cause. The investigations were conducted by the General Electric R\&D Center in support of product departments impacted by these failures or risks of failure. At the same time, industry 's interest in the matter also grew, to the point that the IEEE Surge Protective Devices Committee initiated a working group to study the matter, which became the forum of many papers by the researchers cited in Annex A. For obvious copyright limitations, these papers from other researchers cannot be reprinted here. The three papers in this Part 3 were copyrighted by the publisher, who graciously gave permission for reprinting. The two reports, initially internal proprietary reports, containing the source data for the IEEE papers, were now declassified by General Electric for the purpose of this anthology.

Part 1, Annotated Bibliography was initially compiled by the author as a contribution to the IEEE "SPD Trilogy" of the Surge-Protective Devices Committee (a set of three standards on the surge environment). This initial compilation is now complemented with additional relevant papers and reports written by the author. Undertaking a listing of "relevant papers" entails the risk of offending researchers whose papers might have been overlooked in the compilation, which should be seen as a limitation of the compilation effort for the Trilogy, not a deliberate rejection. However, in addition to this printed format (available from the U.S. Superintendent of Documents), this Part 3 is also available on the Web, thus opening the door for suggestions of additional entries for additions and periodic updates of the listing. The Web version includes an htm l file of the complete collection of the Part 3 papers, which is searchable for any word, with built-in links allowing display of the paper itself in pdf format. The site URL for the complete Anthology, in its several Parts. is: http://www.eeel.nist.gov/811/spd-anthology/ 
Q 


\section{Contents}

Surge Suppression in a Typical Home Wiring System . . . . . . . . . . . . . . . . . . . . Declassified GE TIS Report 63GL97, 1963.

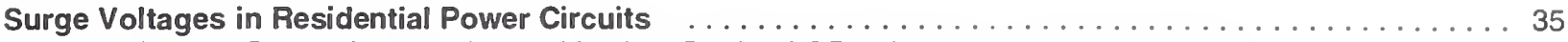

IEEE Conference Paper, Summer Power Meeting, Portland OR July 1967. Co-author: Hahn

Surge Voltages in Residential and Industrial Power Circuits

IEEE Transactions PAS-89, No. 6, July/Aug 1970. Co-author: Hahn

Transient Overvoltages in Secondary Systems

Unclassified GE TIS Report 81CRD121, 1981.

Varistor Versus Environment: Winning the Rematch

IEEE Transactions PWRD-1, No. 2, April 1986.

Annex A - Clock motor failure statistics

Excerpt from General Electric Clock \& Timer Dept memo

Annex B - Contributions by other researchers to documenting occurrences of surges (Listing and annotations of Part 3 from the complete Annotated Bibliography, Part 1) 
(Q) 


\title{
Surge Suppression in a Typical Home Wiring System
}

\author{
François Martzloff \\ General Electric Company \\ Schenectady NY \\ f.martzloff@ieee.org
}

Reprint of declassified General Electric Technical Information Series Report 63GL97

\section{Significance:}

Part 3 Recorded occurrences

The present interest in this report is historical as the experiments and devices it described represent initial efforts in addressing the emerging problems associated with the introduction of semiconductors in the consumer market.

This now declassified proprietary report was prepared to document experiments performed in the early sixties to assess the capability of devices available at that time for serving as surge-protective devices in residential circuits. The context was that the emerging electronic appliances were found vulnerable to transient overvoltages and therefore in need of some form of protection.

The technology at that time offered the well-proven selenium rectifier (under the General Electric trade name "Thyrector" among other similar offerings in the market), the well-known low-pass RC filter, and the emerging five-layer semiconductors. All these were then valid candidates but of course became completely supplanted ten years later when zinc-oxide based varistors were stumbled upon and quickly recognized as a promising technology.

Interesting observations on the occurrence and propagation of surges in a low-voltage ac power system are also documented in this report, and these are still applicable today. 


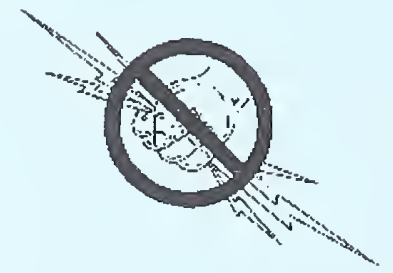




\title{
TECHNICAL INFORMATION SERIES
}

\author{
GENERAL ELECTRIC
}

ADVANICED

TECHNOLOGY

LABORATORIES

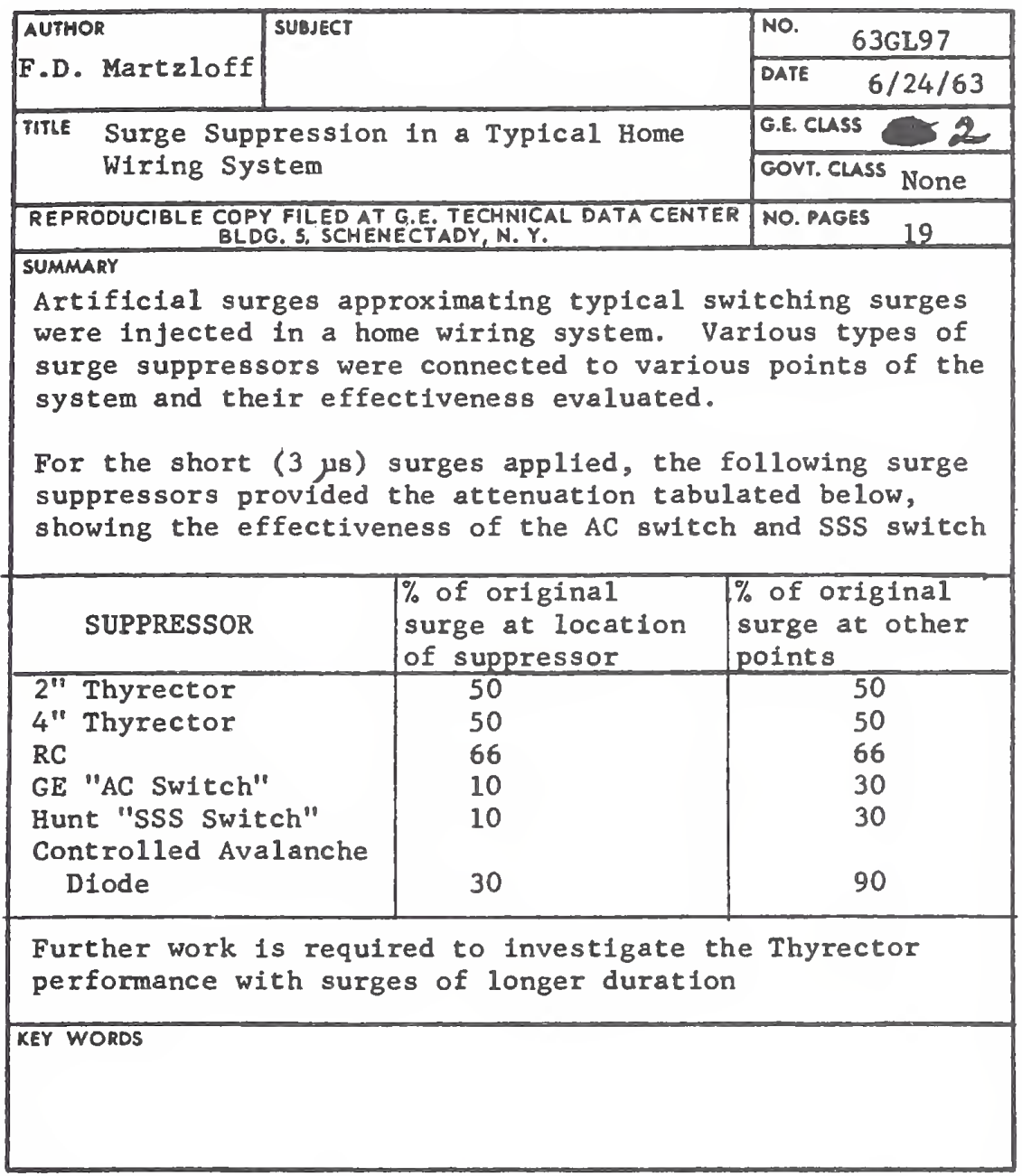

INFORMATION PREPARED FOR Transient Overvoltages Pooled Program

TESTS MADE BY S. Deiber - F. D. Martzloff

AUTHOR F. D. Martzloff Pmoat

COMPONENT APPROVED Converter Circults Engineering R. G. Hoft Que hrote $\geqslant / 8 / 63$ 
SUPPLEMENT TO TIS 63 GL97

Surge Suppression in a Typical Home Wiring System

August 2, 1963

\section{SUMMARY}

The surge suppression data for the selenium Thyrector devices originally reported in TIS 63GL97, dated 6/24/64 were based on a 10 cell/250 ACV unit applied to the $125 \mathrm{ACV}$ clrcult. The appropriate unit should have been a 5 cell/125 ACV model, which is the proper rating for the test conditions. The surge suppression provided by this unit is a significant improvement over the values previously reported. This summary supersedes the summary in the original report.

A comparison test was made in a laboratory model of a home wiring system, using both 10 and 5 cell Thyrectors as well as a 5 layer switch and the RC network.

Results of both tests are summarized below. These measurements are taken at the end of a line with the suppressor at central fuse box and surge applied on a second line end.

\begin{tabular}{|c|c|c|c|}
\hline \multirow[t]{2}{*}{ SUPPRESSOR } & \multicolumn{2}{|c|}{$\%$ of Original Surge at Iine Bn } & \\
\hline & Typical Home Test & \multicolumn{2}{|c|}{ Laboratory Model Test } \\
\hline \multirow[b]{2}{*}{ 1" Thyrector } & \multirow[b]{2}{*}{ No Test } & $\begin{array}{l}\text { Device Rated } \\
250 \text { Volts } \\
\end{array}$ & $\begin{array}{c}\text { Device Rated } \\
125 \text { Volts } \\
\end{array}$ \\
\hline & & 70 (with 10 cell) & 42 (with 5 cell) \\
\hline 2" Thyrector & 50 (with 10 cel1) & 50 (with $10 \mathrm{ce} 11)$ & 30 (with 5 cell) \\
\hline GE "AC Switch" & 30 & \multicolumn{2}{|c|}{28} \\
\hline RC & 66 & \multicolumn{2}{|c|}{66} \\
\hline
\end{tabular}




\section{INTRODUCTION}

The purpose of this test is to repeat, in the laboratory model of a house wiring system, the work reported in TIS 63 GL97 and to evaluate the effectiveness of proposed transient overvoltage suppressors. In the original report, the Thyrectors evaluated were 250 volt models (6RS21SA10D10, etc.). During the test program, the suppression devices were always located in the 120 volt circuit so the evaluation was repeated in the laboratory using the proper 120 volt Thyrector (6RS21SA5D5, etc.), the GE 5 layer AC switch, and the RC network. Surges were injected in the wiring system of the house and measurements recorded at an outlet with the suppression device located at the central fuse box.

This new study reflects the proper comparison of the effectiveness of the various devices studied and this additional data indicates that the 1" Thyrector (6RS21SA5D5) should be considered for household transient protection as well as the 2" Thyrector (6RS25SA5D5). This new look brings the $1^{\prime \prime}$ Thyrector price to about $\$ 1.00$ and the $2^{\prime \prime}$ Thyrector to $\$ 3.50$ which makes the Thyrector competitive valuewise. 


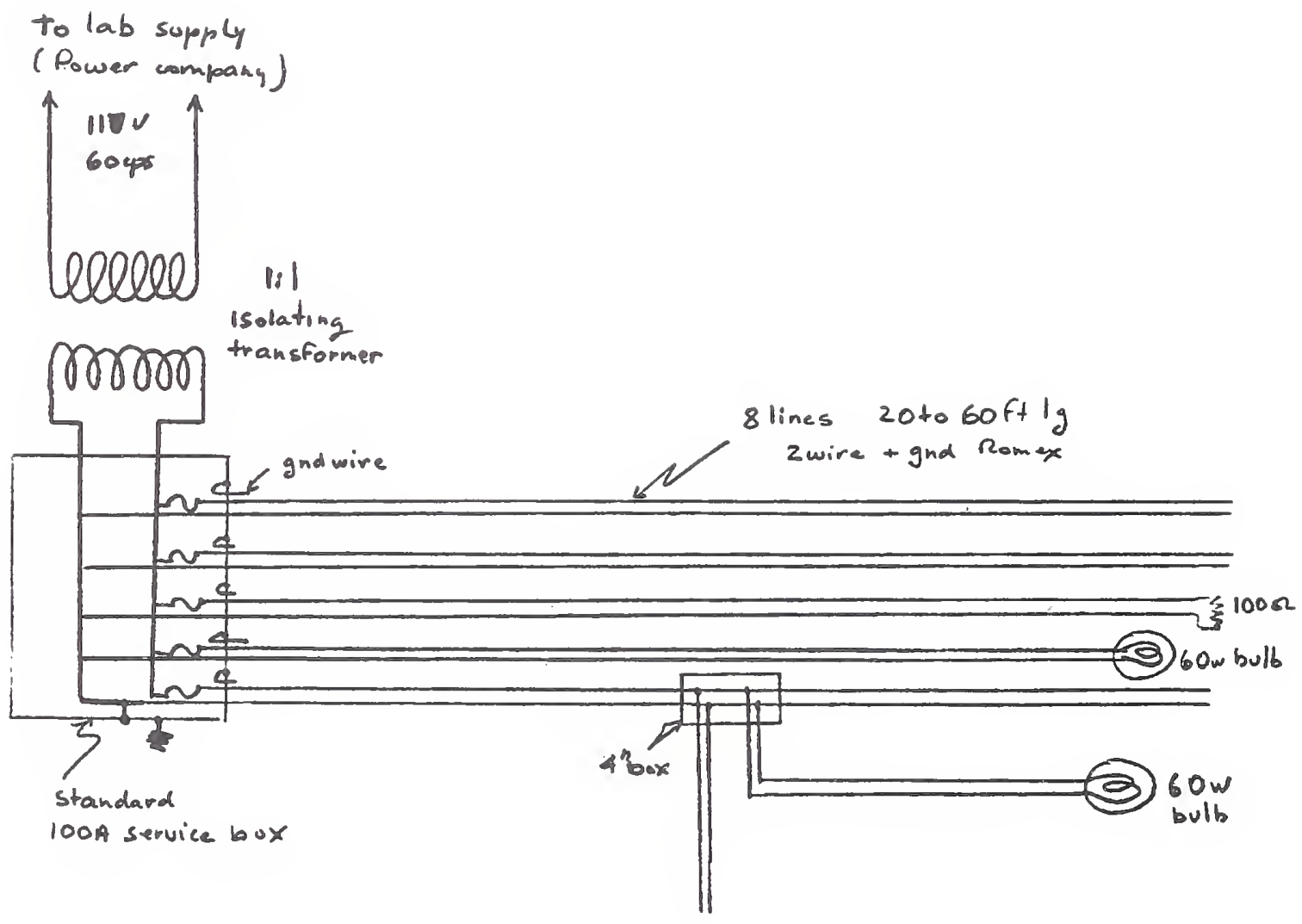

"Laboratory model" 
$-3-$

\section{TEST CONDITIONS}

The tests were made on a laboratory model of a house wiring system consisting of one standard service fuse box feeding 8 lines of Romex cable and 3 branch lines from one line, with length varying from 20 to 50 feet. The cable is strung in the room away from the ground in some locations and is close to the ground in some others. Light bulbs are connected at some line ends while others are left open. Single phase 117 volt $60 \mathrm{cps}$ power is applied to the service box from the low impedance laboratory supply through an isolating transformer.

Initial tests have shown that the portable surge generator used in the "typical house" can induce the same level and wave shape surges in this laboratory model which indicates that a reasonable degree of approximation has been obtained.

This was confirmed further by the similarity of the test results for the same devices between the "typical home" and the laboratory model.

All tests were made with the surge applied at one line end, the suppressor Installed with 6" leads at the fuse box, and the resultant surge at one other line end measured with a Tektronix 551 oscilloscope (this provides linear time base compared with the logarithmic time base of the automatic oscilloscopes used in the "typical home" test.

The laboratory model was built for further work in this program and will continue to be available.

\section{TEST RESULTS}

The two attached oscillogram sheets show a composite recording for 5 cell and 10 cell Thyrector units, both $1^{\prime \prime}$ and $2^{\prime \prime}$ Thyrectors as well as the original surge and they indicate the improved surge attenuation provided by the 5 cell unit. 
The GE flve-layer switch limits the voltage peak by abruptly turning on and with a subsequent low voltage, reducing the total surge energy delivered.to equipments connected to the wiring system.

\section{SUMMARY AND CONCLUSIONS}

Three types of surge suppressors, Thyrectors, RC's and five-1ayer switch, were investigated under conditions approximating typical switching surges generated within the home, which is the most frequent type of transient overvoltage in a house wiring system.

The crest of the surges was in the range of 1500 to 2000 volts with a duration in the order of 3 microseconds.

The resultant attenuation is tabulated below:

\begin{tabular}{|c|c|c|c|}
\hline \multicolumn{4}{|c|}{$\%$ of Original Surge at Line End } \\
\hline \multirow[b]{3}{*}{ 1" Thyrector } & Typical Home Test & \multicolumn{2}{|c|}{ Laboratory Model Test } \\
\hline & \multirow[b]{2}{*}{ No Test } & $\begin{array}{c}\text { Device Rated } \\
250 \text { Volts }\end{array}$ & $\begin{array}{c}\text { Device Rated } \\
125 \text { Volts }\end{array}$ \\
\hline & & 70 (with 10 cell) & 42 (with 5 cell) \\
\hline $2^{\prime \prime}$ Thyrector & 50 (with 10 cell) & 50 (with 10 cell) & 30 (with 5 cell) \\
\hline GE "AC Switch" & 30 & & \\
\hline RC & 66 & & \\
\hline
\end{tabular}

In terms of attenuation per dollar, the RC has the lowest cost, and the five-1ayer switch and the Thyrector have comparable costs. The limitations are most severe for the RC whose effectiveness is dependent upon circuit parameters and cannot attenuate long surges. The Thyrector effectiveness: in the initial period is determined by its junction capacitance and it has proven capability to absorb the energy of longer surges. A combination of Thyrector with RC can increase the initial effectiveness.

The five layer switch requires additional circuitry for DC applications and therefore is primarily attractive for AC circuits when loss of 60 cps 
power for a half cycle is not objectionable. It is the most effective and most promising surge suppressor in the present state of the art.

CEA/f,r)

C. E. Arnold

Rectifier Components Department

(4)rece.LL

F. D. Martzloff

Electrical Conversion Engineering Advanced Technology Laboratories 
Surge Suppresiton Measurement

in the Laboratory "house wiring system"

Comparison between performance of 5-cell thyrectors and 10-cell thyrectors, $1^{10}$ and $2^{\prime \prime}$.

Surge applied to one line end, propagating to central fuse box where the Thyrector is connected, and measured at one other line end.
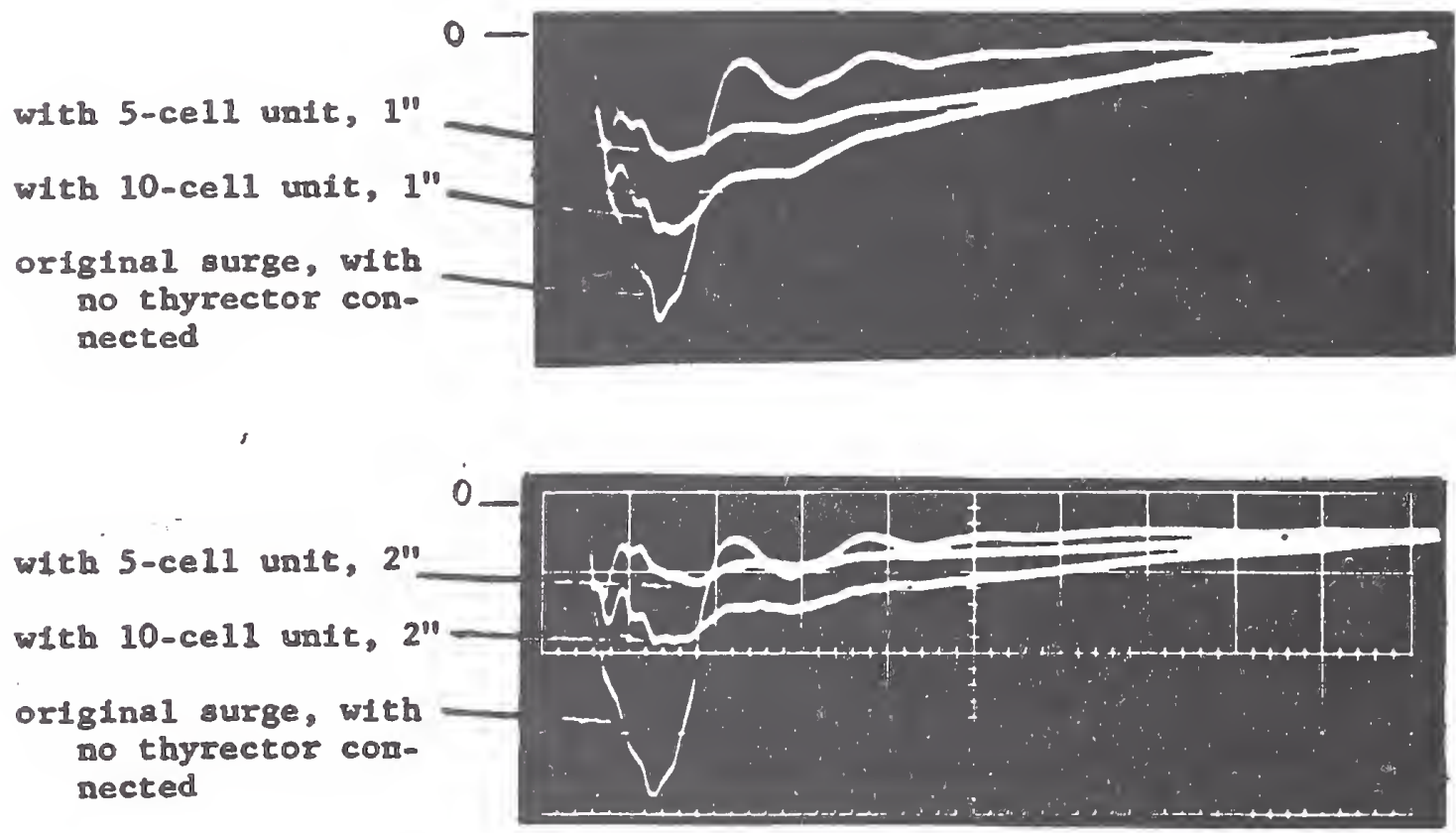

Botb osc1llograms: 500 volts/division

$1 \mu$ pldivision sweep 
Surge Suppression Measurement

ingthe Laboratory "house wiring system"

Surge suppression with RC and with 5 layer switch.

Surge applied to one 11 ne end, propagating to central fuse box

where suppressor 18 connected, and measured at one other line end.

ortginal surge, with

no suppressor con-

nected

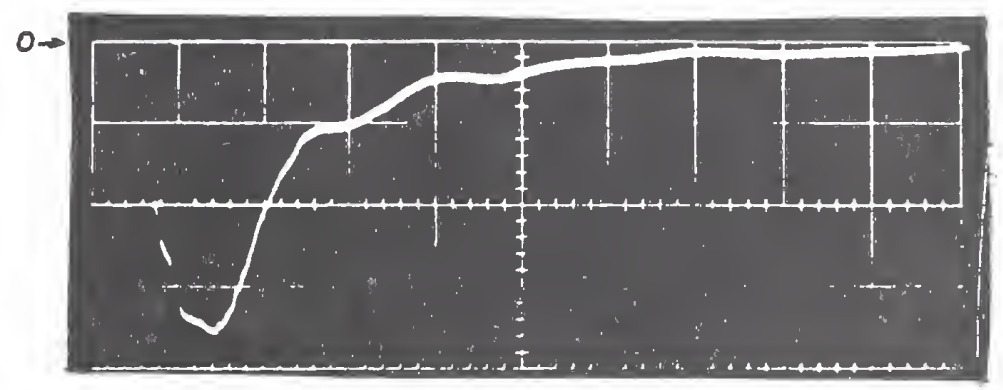

with GE 5 layer $A C$

switch and 1 "ohm

resistor

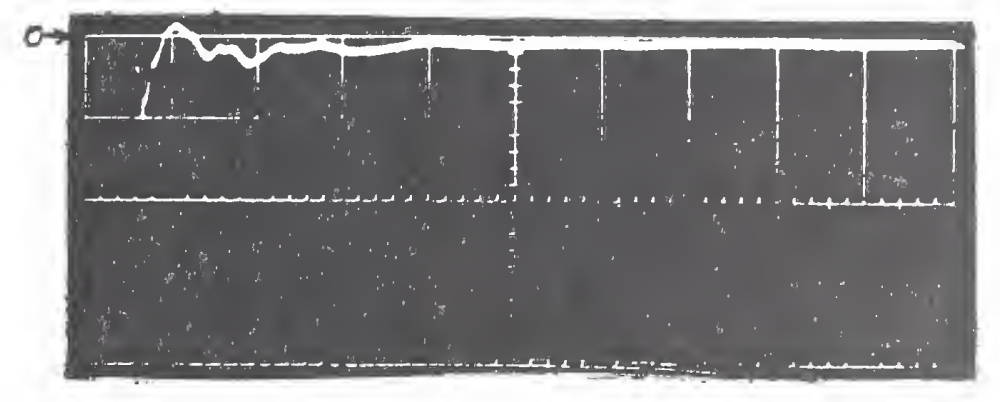

wth $0.05 \mu \mathrm{g}$ cepacitor

and 10 oben resistor

In series

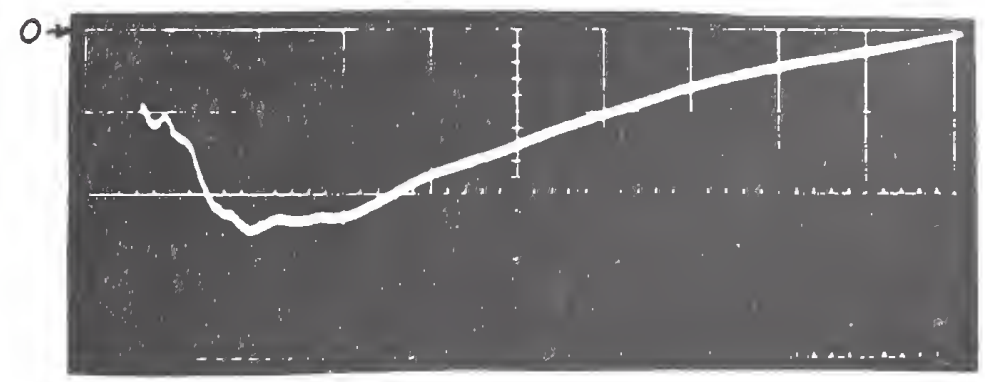

All oscillograms: 500 volts/division

$1 \mu \mathrm{s} / \mathrm{division}$ sweep 


\section{Introduction}

The purpose of the tests reported here was to evaluate the effectiveness of proposed transient overvoltage suppressors under conditions approaching those observed in actual field measurements.

The experiments were based on previous measurements in order to insure that the test conditions were representative of actual conditions, and also would not endanger the equipment of third persons; i.e. that of neighbors or the power company.

Surges were infected in the wiring system of a house and measurement of the surges at various points of the house were made with the proposed suppressor connected at a central (fuse box) location or at a single outlet.

Although the conclusions apply directly only to a particular house wiring system, worthwhile inferences can be drawn for other applications.

\section{Test Conditions}

\section{A. General Considerations}

Previous measurements and observations made during earlier parts of this program and reported under TIS 62 GL19I allow to make a reasonable approximation of typical switching surges occurring in a house wiring system. Examples of these are also shown in Figures 4 and 5 at the end of this report.

Because of the difficulty encountered in making transient current measurement in "non-laboratory" conditions, it is nearly impossible to evaluate directly the energy involved in voltage surges. Further work is required in this area.

More specifically, the following facts are known, and allow some conclusions to be drawn: 
1. Transients overvoltages in the 1500 volts range which occur "naturally" (1.e., not deliberately created for these tests) in a specific house (J. H. Ross, Schenectady) could not be detected at a significant level (over 400 volts) in the adjacent house (F. D. Martzloff, Schenectady). Thus we have an Indication that the attenuation through the meter coils, service entrance and division of the traveling wave at the service pole is sufficient to make harmless to neighbors the surges which would be deliberately injected in a test house.

2. Field measurements have shown that surges due to switching of loads within a house is the most frequent source of damaging transient overvoltages in a house wiring system; protection against these (and eventually only these) would therefore decrease by several orders of magnitude the possible frequency of damaged semiconductor equipments.

3. Several instances were found where voltage crests were in the 1500-2000 volt range, with the duration of the major loop of the oscillation about 1 to 4 microsecond. Thus, a "typical" surge wave form should approximate these values.

4. Surge impedance of a house wiring cable was found to be in the 10 to 100 ohm range. Thus, for short pulses, currents as high as $\frac{2000}{10}=200$ amperes may easily be involved.

\section{B. Test Procedure}

Therefore, based on the above facts, a series of tests were made at the residence of $R$. G. Hoft in Schenectady, where surge propagation measurements had been made in 1962. 


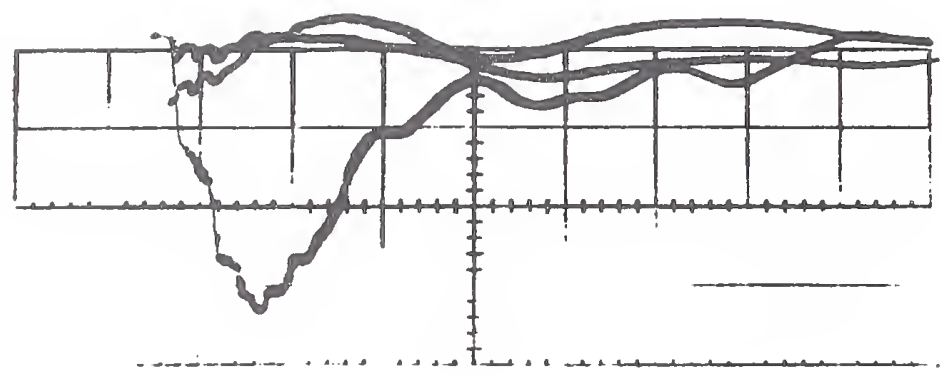

Voltage applied to one phase of house wiring (large pulse) and surge passing through isolating transformer into both phases of service entrance.

(500 volts/division, 1 us/division linear sweep)

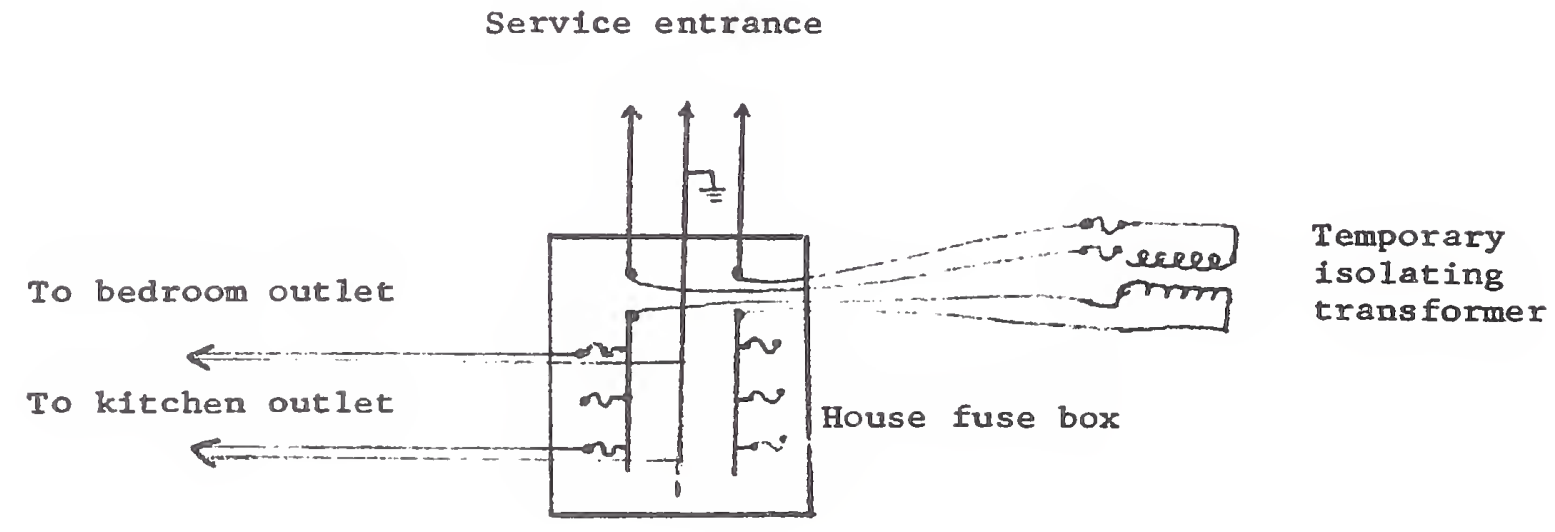

Circuit diagram showing surge injection into house and attenuation of surge for service entrance. 
The portable surge generator previously used in this work was used again. With additional capacitance added to the charging capacitor, it is capable of delivering single shot surges of 1500 volts crest and 3 microseconds duration into the house wiring system.

A temporary 1solating transformer was inserted between the service entrance and the house fuse box in order to attenuate the surge sent Into the service entrance, to provide further protection against surging adfacent houses.

Figure 1 shows the connections at the fuse box and oscillograms of the surge applied within the house compared to the surges transmitted to the service entrance.

Automatic recording oscilloscopes (those used for the field measurement of transient overvoltages) were used to make simultaneous recording of the surge at the sending and recelving end, and eventually at an intermediate point.

During the measurements, incadescent lamp loads were turned on, but other appliances were disconnected. Each branch circuit was generall: loaded with one or more 60 watt bulb; open end conditions existed at most wall recptacles, with the resulting reflection and voltage doubling effects.

Two test series were conducted; one with the surge injected at the fuse box and a proposed suppressor connected at a single outlet, presumed to protect whatever device may be connected at that outlet; the other test series was made with the surge injected at one outlet, and propagating to the fuse box where it met a proposed central suppressor installed there; from there the surge, or what was left of it, propagated through the rest of the branch circuits, and was measured at the same outlet as in the first series. 


\section{Proposed Suppressors}

The devices investigated in this test series were the following:

- I" Thyrector ce1I, cat 6RS21SA1OD10 rated 200 volts steady state

- 2" Thyrector cell, cat 6RS25SA10D10 rated 200 volts steady state

- 4" Thyrector cell, cat CRS15SA10D10 rated 200 volts steady state

- RC made of a $0.05 \mu F 1000$ volt paper capacitor and 10 ohm 1 watt carbon resistor in series

- General Electric AC switch (5 layer switch) in series with a current-1imiting resistor

- Hunt SSS switch (5 layer switch) in series with a current-limiting resistor

- General Electric controlled-avalanche rectifiers (back-to-back)

The Thyrector transient voltage suppressor has been available for

some time, but its response for fast and short transients is not well

defined. For very fast transients, it is expected that the junction

acts as a capacitor. Prices range from $\$ 2.00$ for the $1^{\prime \prime}$ cell to $\$ 24.00$

for the $4^{\prime \prime}$ cell in quantities above 1,000 .

An RC network is, of course, an obvious surge suppressor within the limits of its time constant. The values selected here were deliberately just short of the pulse duration in order to check the marginal case. Price of the two components is about $\$ 0.40$ above 1,000 pieces.

The five-layer switch is a relatively new solid state device ${ }^{1}$ which has the property of turning on, regardless of the polarity, when the voltage across its terminals exceeds a predetermined level. In the "off" state it presents a very high impedance right up to the turn-on voltage, contrary to the Thyrector which has a definite maximum steady state voltage rating determined by the leakage current.

The turn-on characteristics of the two five-layer units in this investigation have been measured and are included as Appendix I. It is 
significant that the characteristic is far more "flat" than other devices such as gaps or arresters; the curves published in the final report of the 1962 program are also reproduced for reference in the appendix, together with the turn-on time of the five-layer switches.

One unit was a Hunt SSS switch available from Hunt Electronics, Andjon Ave., Dallas, Texas. Its steady state rating is 8 amperes RMS. In lieu of specific surge data, it was decided to limit the half-cycle surge current to 80 amperes peak, so that a 2 ohm resistor was placed in series to limit the $60 \mathrm{cps}$ current following turn-on. Estimated price is $\$ 2.00$ in quantities to selected customers.

Another unit was an engineering sample of the General Electric AC switch developed by the Rectifier Component Department. It is rated 25 amperes RMS with a $\frac{1}{2}$ cycle rating estimated by ATL at 200 amperes, so that a 1 ohm limiting resistor was connected in series. No price information is yet avallable for this unit.

The controlled avalanche rectifier can also be used to a certain extent as a surge protector, although the purpose of connecting two diodes across the line in this test series was to compare the performance of a $7 \mathrm{AD}$ diode to that of the diode tested in 1962 for surge characteristics, both of which have fairly comparable mass and physical configuration.

\section{Test Results}

\section{A. First Series - Suppressor at Outlet}

The surge was applied between ground and one line at the fuse box, and the proposed suppressor installed at an outlet in the kitchen connected to the same line. Voltages were measured at both locations, the corresponding oscillograms are shown in Figure 2 for the various 
Sending end

20 us total sweep

$500 \mathrm{v} / \mathrm{division}$
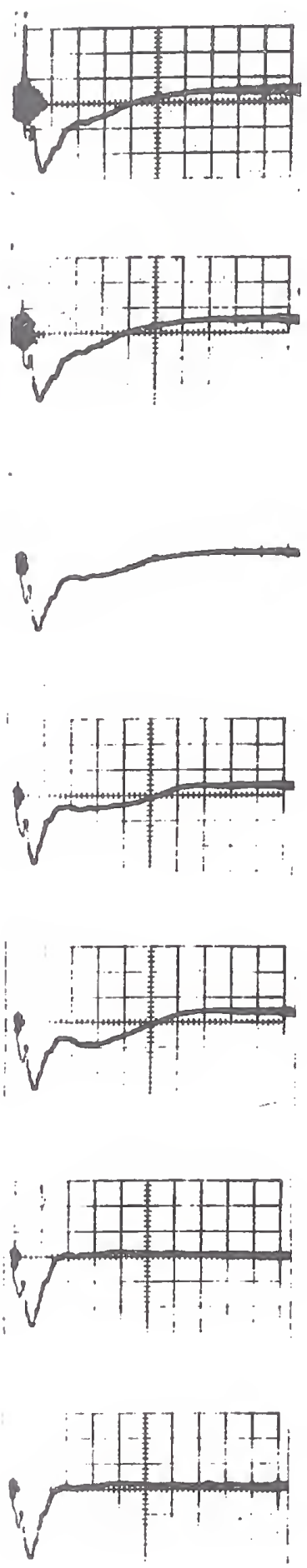

Receiving end

20 us total sweep

$1000 \mathrm{v} / \mathrm{division}$
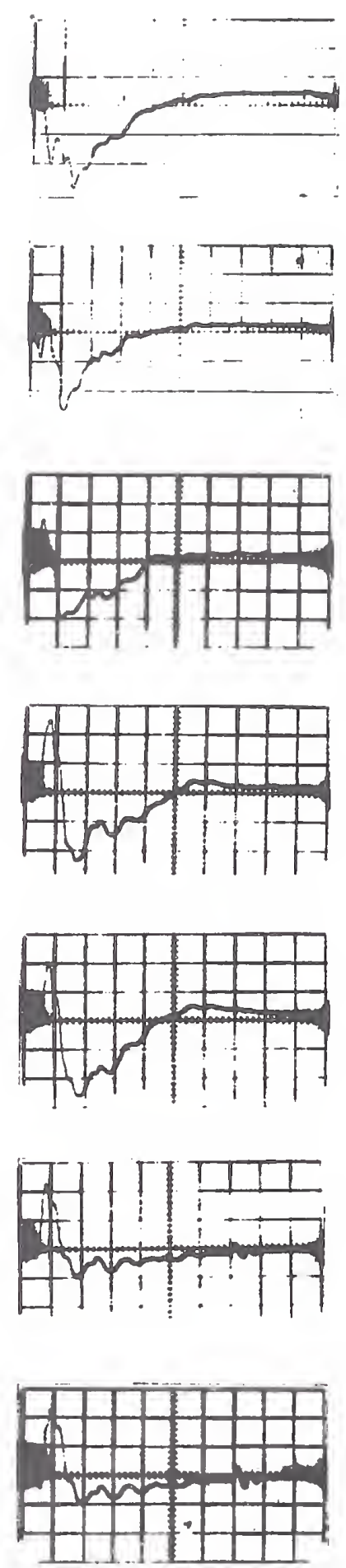

Additional device connected at receiving end

mone

1 "Thyrector 6RS21SA10D10

2" Thyrector 6RS25SAIOD10

\section{$4^{\prime \prime}$ Thyrector} 6RS15SAIOD10
$0.05 \mu \mathrm{F}$ and $10 \mathrm{ohms}$ in series

GE AC switch (25 Amp)

in series with 1 ohm

\footnotetext{
Hunt SSS switch ( 8 Amp)

in series with 2 ohms
}

FIGURE 2

Surge applied at fuse box, received at kitchen outlet 
Sending end

100 us total sweep

1000v/division
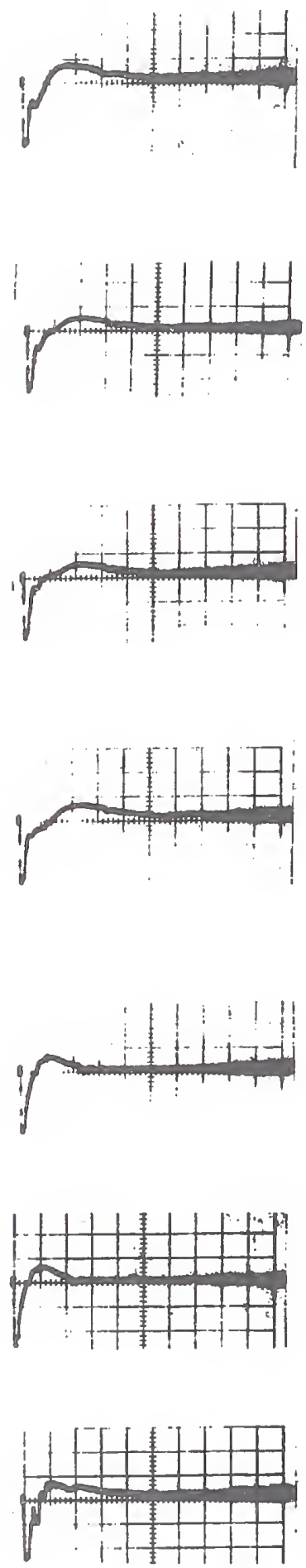

Fusebox

100 us total sweep

$500 \mathrm{v} / \mathrm{division}$

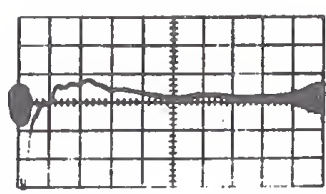

No suppressor

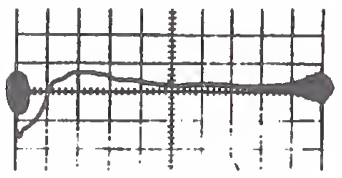

$2^{\prime \prime}$ Thyrector

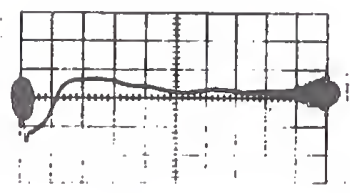

4" Thyrector

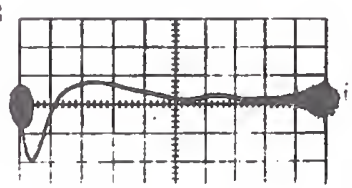

$0.05 \mu F=10$ ohms

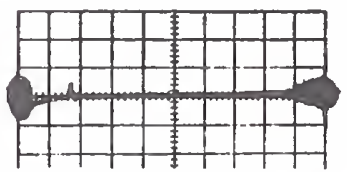

8A Hunt SSS with 2 ohms

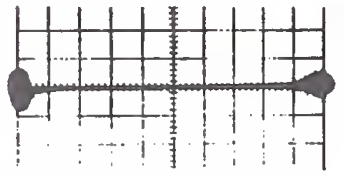

25A GE AC Swo with 1 ohm

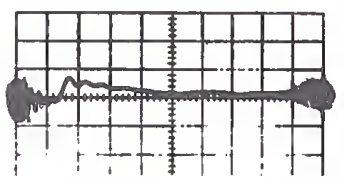

2 7AD back-to-back
Kitchen outlet

$100 \mu s$ total sweep

$1000 v / d i v i s i o n$
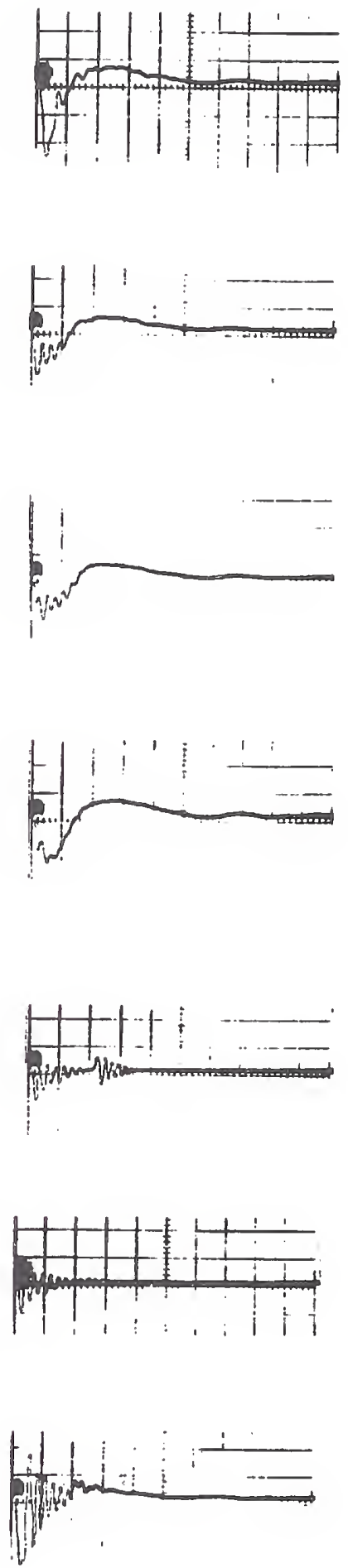

FIGURE 3

Surge applied to bedroom outlet, received at kitchen outlet, with suppressor installed at fuse box 
is not removed by the expected action of the switch, while the negative portion of the wave is limlted to a substantially lower level. Thus, the significance of the inftial positive crest is not quite clear. Because of the limitations of time, these readings could not be repeated. However, when compared to the next series, they give an additional indication of the performance of the suppressor. It is also apparent that the clamping effect of the switch is felt at the sending end after 3 microseconds.

\section{B. Second Series - Suppressor at Fuse Box}

The surge was applied at a bedroom outlet, between the ground side of the outlet and the other Iine at 115 volts. From these, the surge was transmitted to the fuse box, where a proposed suppressor was connected between the box ground and the same 115 volt line. From the fuse box, the residual surge resulting from division into the branch circuits and their action of the suppressor was transmitted through the house, and among other points to the same kitchen outlet used in the first series, where the incident surge, without any other suppressor, was measured. Voltage at the sending point as well as at the fuse box, directly across the suppressor, were also measured. The corresponding oscillograms are shown in Figure 3, and the following observations can be made:

a - No Suppressor

The surge applied at the bedroom outlet at 2500 volt crest appears only with a 1500 volt crest at the fuse box, as a result of the attenuation of the cable between the point of application to the fuse box as well as the division between the branches at the fuse box.

The surge leaving from the box and traveling towards the kitchen outlet appears there with a 2800 volt crest again as a result of the refelection at the high impedence line terminal. 
b - Thyrector Cells ( $2^{\prime \prime}$ and $\left.4^{\prime \prime}\right)$

The initial negative crest at the sending end is not appreciably affected by the presence of the Thyrector at the fuse box; the following positive oscillation however is reduced.

At the fuse box, the negative crest is reduced to half the value without the suppressor, and the positive oscillation is slightly reduced. The resulting surge at the kitchen outlet is also reduced to about half the original crest value, with some oscillations or reflections. c - RC

There again the simflarity between the effect of the Thyrector and the RC is apparent. The reduction for the small value of $\mathrm{RD}$ is slightly less than for the Thyrector, but the wave shapes are quite simflar, suggesting that for short transients, the Thyrector is effective inasmuch as the junction capacitance acts as an RD. It would be desirable to measure this capacitance; this will be attempted.

d - Five-layer Switches - GE and Hunt

For both switches, the initial negative crest at the sending end is not affected; the positive oscillation occurs sooner, as the clamping effect of the switch is transmitted back to the sending end; the clamping effect is then complete after 2.2 divisions of the oscillogram ( 3 us). At the fuse box the clamping effect of the switch is such that the inftial crest is lost within the beam halo, at less that 600 volts. The Hunt unit seems to take a slightly longer time - or higher voltage - to turn on, as indicated by the slope of the trace as it leaves the halo, and the short positive pulse at the probable polarity reversal of the surge.

The voltage at the kitchen outlet shows the resulting low amplitude oscillations or reflections for the surge existing at the fuse box. 
e - Controlled Avalanche Rectifiers

Two diodes connected back-to-back were also used as a possible suppressor, as a side effect of another test discussed later. The avalanche effect of the rectifier effectively limited the crest of the voltage surge at the fuse box, the maximum crest value for this 400 volt rated diode did not exceed 800 volts.

f - Controlled Avalanche versus Conventional Rectifiers

Attempts were made to correlate the test results of the 1 N679 diode investigation made in 1962 with the results under the simulated switching surge of this test series. The 1962 tests used a .1 $\times 5$ us wave shape while the present simulated surge had an approximate wave shape of $.2 \times 2$ us wave shape.

The 1 N679 diode (2 samples) survived a 2000 volt crest, while it failed at 3000 volts (average fallure level for similar conditions under $.1 \times 5$ us wave were 1500 volts). The difference is attributed to the shorter impulse duration.

On the other hand, the $7 \mathrm{AD}$ controlled avalanche rectifier (subminiature size) which proved an effective suppressor for the surge up to the 2000 volt level, also falled (by short circuit) for the energy level corresponding to the 3000 volt crest surge which was also fatal for the 1N679. Here again, because of time limitations in the nonlaboratory conditions, the test was not refined further.

\section{$\mathrm{V}$ Discussion of the Results}

The three types of suppressors investigated in this test series represent radically different approaches to surge protection, and thus their effectiveness and limitations, as well as cost, are widely different. The Thyrector has proven adequate capability of energy absorption; however, 
for fast transients, its action is limited to that of the equivalent junction capacitance, which is not to say that it is ineffective. The Thyrector will then have the same limitations as an RC for fast transient while of course having a higher price. On the other hand, for longer transients, when the RC becomes ineffective to absorb the energy, the Thyrector can dissipate it.

When fast transients are involved both the RC and the Thyrector act as capacitance dividers. Their effectiveness in limiting voltage transients thus depends on the load circuit parameters and will vary depending on the load conditions. This makes them questionable as universal surge protectors to be merely plugged in any circuit. For specific applications when the load is well defined, this objection does not apply.

Now, the five-layer devices operate as voltage sensitive switches. As long as there is enough current (miliamperes) available to turn them on, their clamping effect is independent from other cirucit parameters. Their action is also the fastest (200 to 500 nanoseconds) and the voltage they allow to pass the lowest. The junction capacitance of these devices is not known at this time; if anything, it contributes further to the surge suppression.

When applied on an AC line (obviously they could not be used in a DC circuit without forced commutation or other circuit complexity), the 60 cps power supply will be shorted from the moment of application of the surge to the next zero of the sine wave. This may or may not be an objection. Of course, a current-limiting resistor will be needed in series with the switch if the impedance of the AC supply is too low for the short-circuit current to remain below the $\frac{1}{2}$ cycle surge rating 
of the switch. The cost of the device is not yet very firm. There is a strong possibility that if other applications justify large production quantities, or if the use as an effective surge suppressor can become popular, the price may be lower than that of Thyrectors.

\section{Summary and Conclusions}

Three types of surge suppressors, Thyrector, RC's and five-layer switches, were investigated under conditions approximating typical switching surges generated within the home, which is the most frequent type of transient overvoltage in a house witing system (Figure 4 and 5). The crest of the surges was in the range of 1500 to 2000 volts with a duration in the order of 3 microseconds.

The resultant attenuation is tabulated below.

\begin{tabular}{|l|c|c|}
\hline SUPPRESSOR & $\begin{array}{c}\text { \% of original surge } \\
\text { at location of } \\
\text { suppressor }\end{array}$ & $\begin{array}{c}\text { of original surge } \\
\text { at other points }\end{array}$ \\
\hline 2" Thyrector & 50 & 50 \\
4" Thyrector & 50 & 50 \\
RC "AC Switch" & 66 & 66 \\
GE "AC & 10 & 30 \\
Hunt "SSS Switch" & 10 & 30 \\
Controlled Avalanche Diode & 30 & 90 \\
\hline
\end{tabular}

In terms of attenuation per dollar, the RC is the lowest cost, then the five-layer switch and last the Thyrector. The IImitations are most severe for the RC whose effectiveness is dependent upon the circuit parameters anc cannot attenuate long surges. The Thyrector effectiveness is limited in the initial period by the circuit parameters, and in order to have sufficient junction capacitance, an extremely large (and expensive) cell may be required. A combination of Thyrector with RC is more appropriate. The five-layer switch, primarly attractive for AC circuits is the most effective and the most promising universal surge suppressor which has been found in the present state of the art. 


\section{APPENDIX I \\ Turn-on Characteristics of \\ Five-Iayer Switches}

\section{Test Circuit}

A capacitor $C_{1}$ is charged at an adjustable voltage. It is discharged into a capacitor $C_{2}$ through resistor $R_{1}$ when the thyratron $T$ fires. The test piece, with or without additional parallel resistance is in parallel with $C_{2}$. The rate of voltage rise is controlled by $R_{1} C_{2}^{\prime}$ while the rate of decay is controlled by $R_{2}^{\prime} C_{1}$ where $R_{2}^{\prime}$ and $C_{2}^{\prime}$ are the equivalent values of all the resistance and capacitance across the terminals of the test circuit.

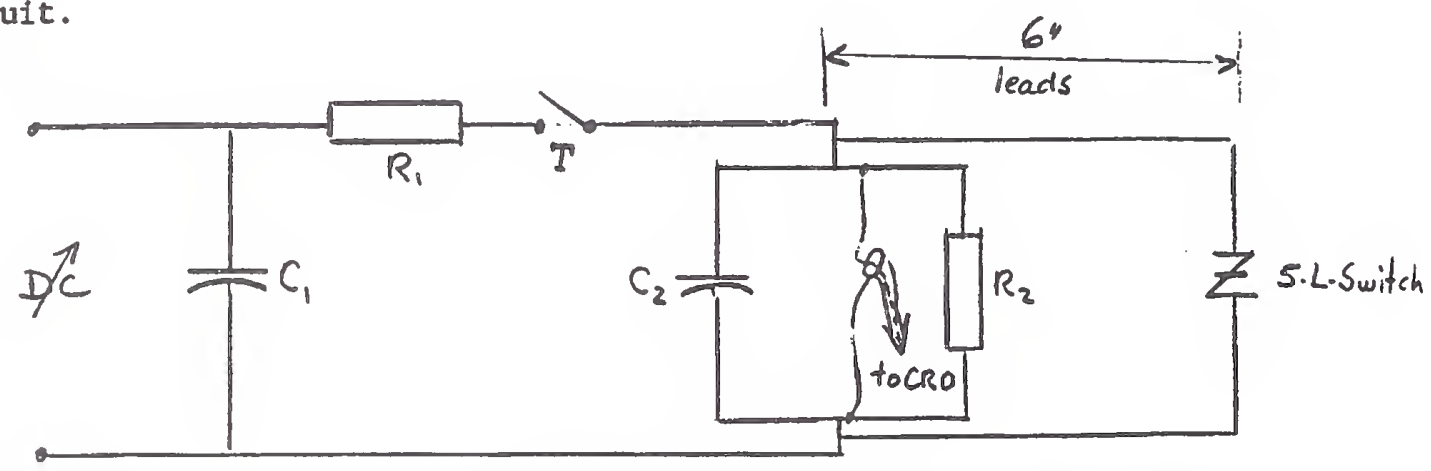

The values used for the data shown below are the following:

$\mathrm{R}_{1}=25$ ohms, non inductive

$R_{2}=750$ ohms, non inductive

$\mathrm{C}_{1}=0.01 \mu \mathrm{F} 15 \mathrm{KV}$ oil filled

$\mathrm{C}_{2}=0.001 \mu \mathrm{F} 15 \mathrm{KV}$ oll filled

Resulting in a. $.1 \times 5$ us double exponential wave where where $R_{1}$ and $C_{2}$ shape the tait of the wave

The wave shapes of the applied voltage and of the voltage measured with the five-layer switch connected across $C_{2}$ are plotted on the following page, from the oscilloscope readings. 
NOTES (continued)

not produce significant change in the time to turn on. The voltage $V_{R}$ was increased by about 20 to $30 \%$, as a result of the increased IR $+\mathrm{L} \frac{\mathrm{di}}{\mathrm{dt}}$ increase across the switch and leads.

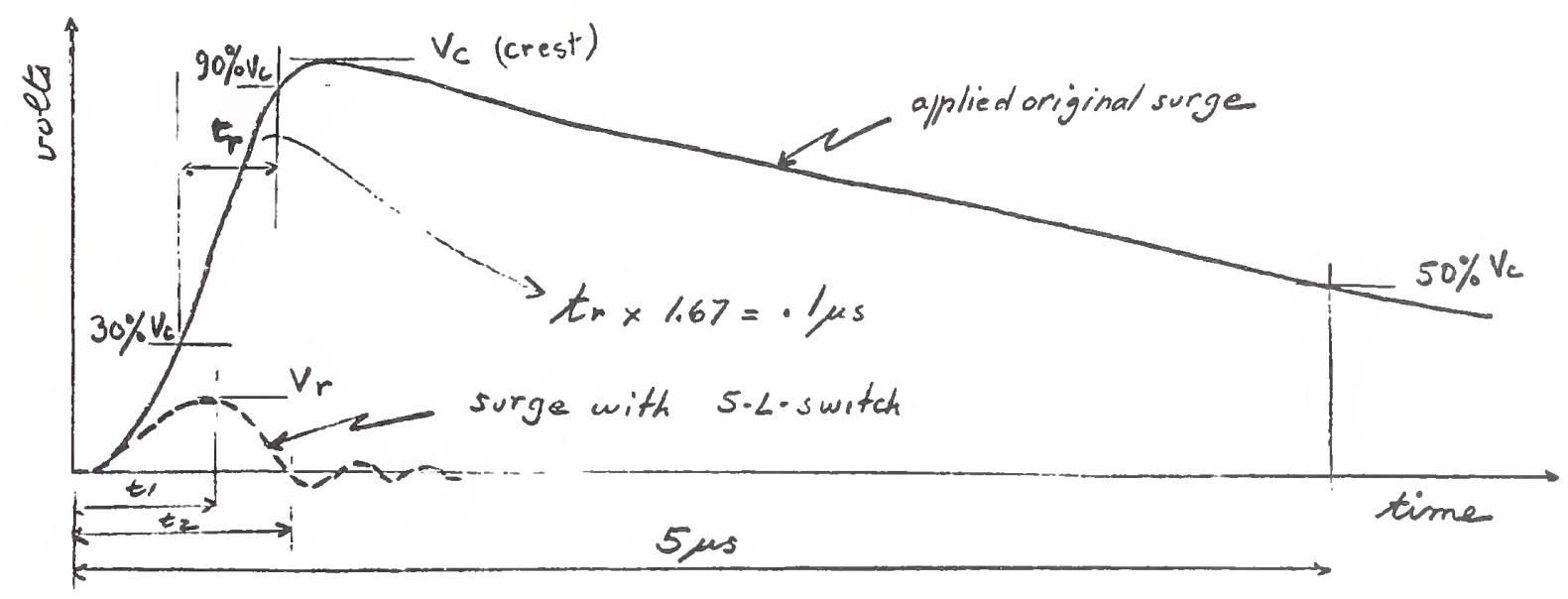

In order to apply increasing surge voltages, the DC voltage of the charging circuit was raised step by step, resulting in the crest volts values shown in Table $I$ without the five-layer switch across $C_{2}$. The Hunt unit and the GE unit were successively connected across $C_{2}$ with 6" leads simulating a practical connection to a circuit to be protected and the crest $V_{R}$ across the protected circuit read as well as the times $\mathrm{t}_{1}$ and $\mathrm{t}_{2}$, which are tabulated in Table $\mathrm{I}$.

\section{Conclusion}

The voltage clamping action of these devices is considerably faster than any other surge suppressor, and the time to clamp practically constant. The crest of the voltage allowed to pass does, however, increase with the crest of the initial surge; this corresponds to a simultaneous increase of the rate of voltage rise since the time to crest is held constant, as well as an Increased current through the device and the leads. 
TABLE I

Tura-on Characteristic of Five Layer'Switches With . 1 ×5 ps Voltage Wave

\begin{tabular}{|c|c|c|c|c|c|c|}
\hline \multirow{2}{*}{$\begin{array}{l}\text { Original } \\
\text { Crest Volts }\end{array}$} & \multicolumn{3}{|c|}{ Hunt URIt } & \multicolumn{3}{|c|}{ GE UnIt } \\
\hline & $\begin{array}{l}V_{\mathbb{R}} \\
\text { Crest } \\
\text { Volts }\end{array}$ & $\begin{array}{l}t_{1} \\
\mu s\end{array}$ & $\begin{array}{l}t_{2} \\
115\end{array}$ & $\begin{array}{c}V_{R} \\
\text { Crest } \\
\text { Volts }\end{array}$ & $\begin{array}{l}t_{1} \\
\mu s\end{array}$ & $\begin{array}{l}t_{2} \\
\mu s\end{array}$ \\
\hline 600 & 250 & .5 & .1 & 220 & .5 & .1 \\
\hline 800 & 300 & .5 & .1 & 220 & .5 & .1 \\
\hline 1000 & 350 & .5 & .1 & 225 & .5 & .1 \\
\hline 1500 & 420 & .5 & .1 & 250 & .5 & .2 \\
\hline 2000 & 500 & .5 & .1 & 300 & .5 & .1 \\
\hline 3000 & 750 & .5 & .1 & 350 & .5 & .1 \\
\hline 4000 & 1000 & .5 & .1 & 400 & .5 & .1 \\
\hline DC tura-on & 235 & & & 220 & & \\
\hline
\end{tabular}

NOTES- 1 The GE unit shows a lowex increase in the voltage $V_{R}$ as the original crest voltage is increased.

This may be due to a lower resistance across the tumed on switch or to a longer function capacitance ( $7 \frac{2}{2} \times 7 \frac{2}{3}$ m for the GE unit and $3 \times 3 \mathrm{~mm}$ for the Hunt unit). Part of the voltage $V_{R}$ is also due to inductive drop in the 6 " leads used to simulate a practical connection to the protected circuit.

2 An increase of one decade in the values of $C_{1}$ and a decrease of one decade in the value of $R_{2}$, resulting in the same wave shape with 10 times the energy flowing across the switch did 
$-14-$

Compared to other voltage sensitive devices, such as the gaps or arresters measured in $1962^{2}$, or a Thyrector under the same conditions, the surge suppression is considerably greater. 


$$
\text { - }
$$$$
\text { . }
$$$$
\text { ○ }
$$$$
\text { , }
$$$$
\text { ๑ }
$$$$
\infty
$$$$
\oplus
$$

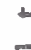$$
\circ
$$$$
\circ
$$$$
\text { a }
$$$$
3
$$

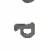

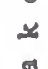$$
\text { ๑ }
$$$$
\omega
$$

$\infty$

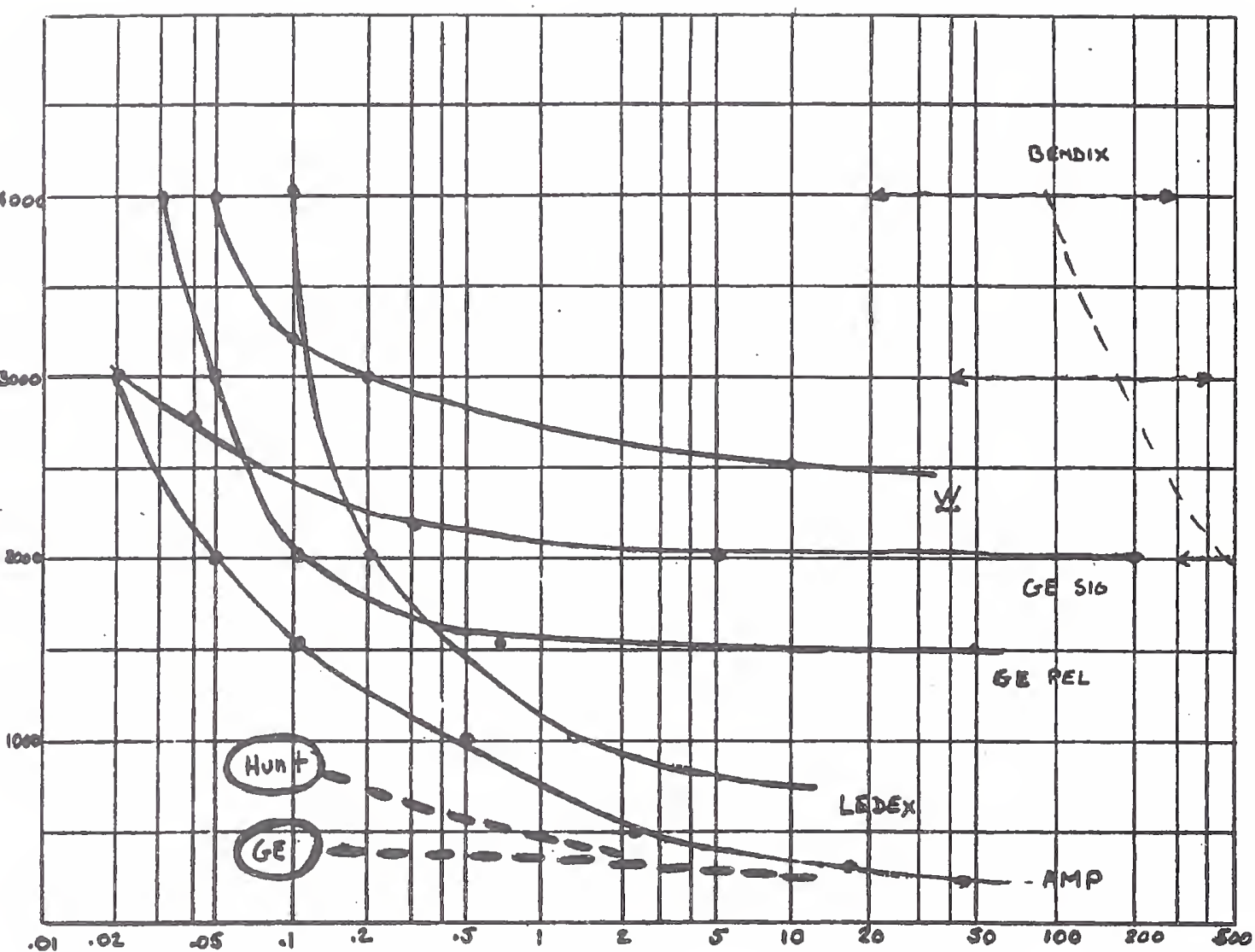

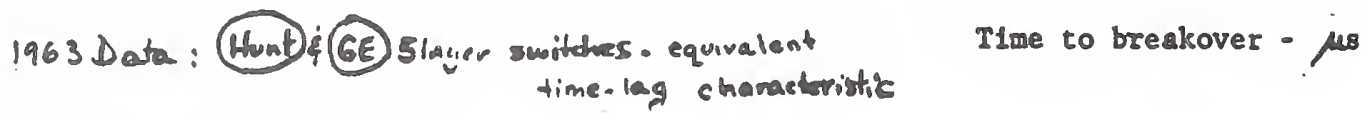
1962 Date: Gep Description

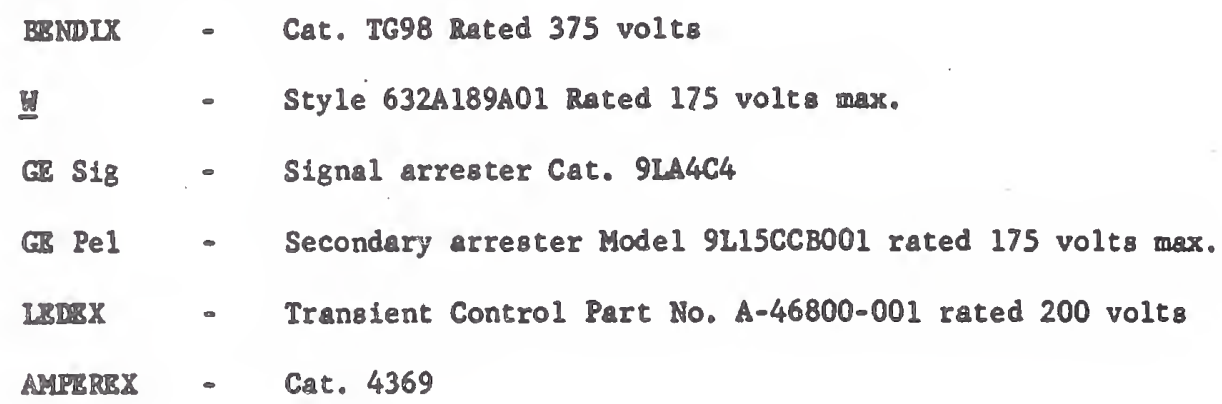

Points shown are average values of several single shot, except Bendix which was extremely erratic.

Time-1ag Characteristics of Various Gaps - 0.1 pa rise 
$-16-$

REFERENCES

1. Two-terminal Asymmetrical and Symmetrical Silicon Negative Resistance Switches, Journal of Applied Physics, Vol. 30 非11, November $1959, \mathrm{Pg} .1819$ - 1824.

2. TIS 62GL191 - Transient Overvoltages in Low Voltage Systems and Their Effect on Solid State Products.

\section{ACKNOWLEDGMENT}

The author wishes to acknowledge the contributions of J. D. Harnden, Jr., in establishing the program of this test series and in the presentation of the test results. 
Typical Surgea Recorded at

Mr. W. H. Bellany's House - Stewsrt Manor, L.I., N.Y.

Feb. 16-Feb. 21, 1963

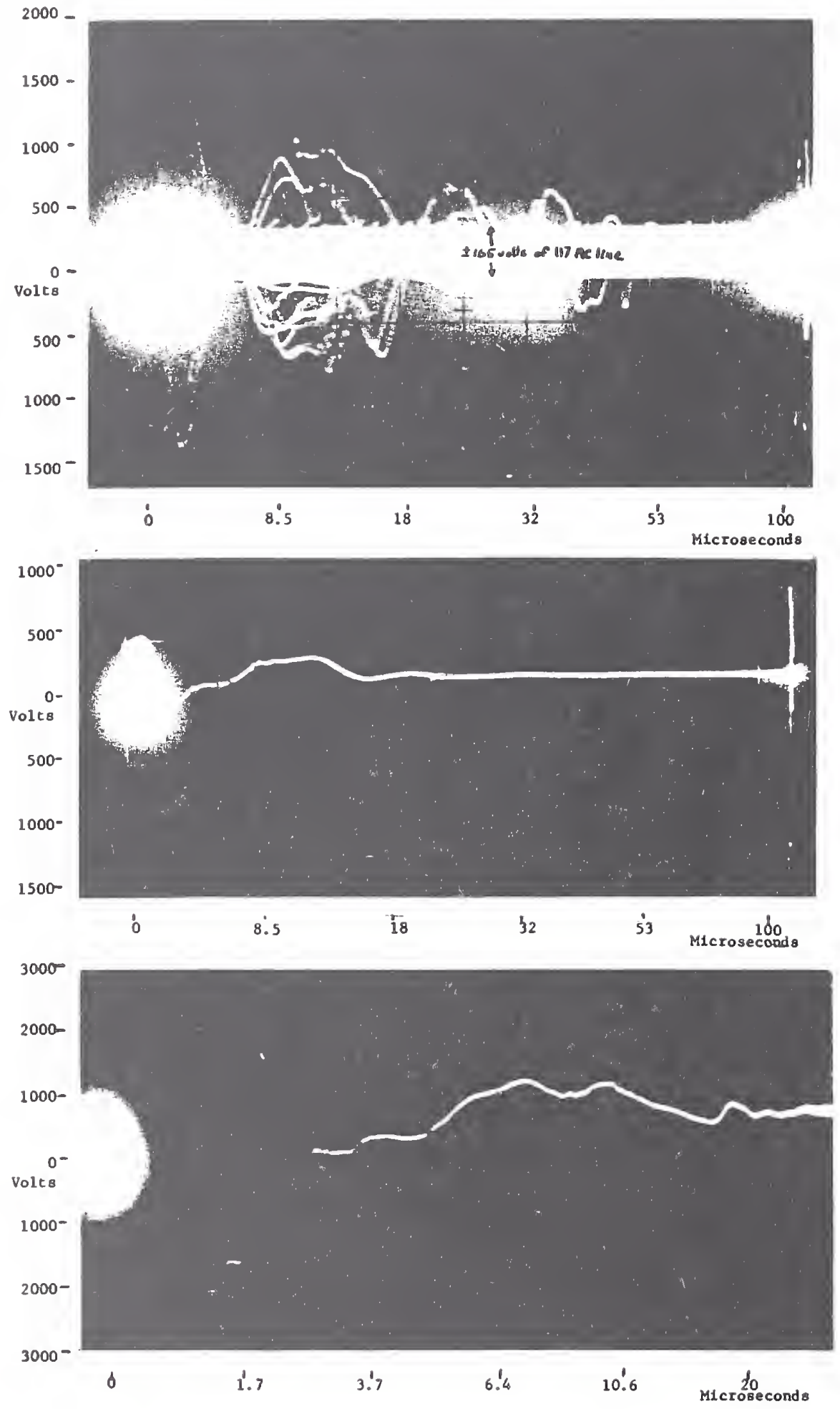

Composite record showing surge日 for 24 -hour period.

Oacilloscope to triggered for each surge, plus once every hour, resulting in \pm 165 volt band of steadystate $60 \mathrm{cps}$ voltage.

Recordings above $1800 \mathrm{~V}$ are blanked out by osc 11 loscope.
Single surge occurring 150 us efter intial,

low amplitude surge

triggered the oscilloscope.

Cause not determined.

Maximum recorded surge, at 2600 volts.

In a 5-dsy period surges of this wave shape were recorded is follows: Number Voltage Range of surges

$\begin{array}{rr}1 & 2500=3000 \\ 21 & 2000=2500 \\ 18 & 1500=2000 \\ 13 & 1000=1500\end{array}$

Cause: H.V. transformer for oll furnace interru 
TYPICAL SUREES RECORDED

AT H, R. SELIERS, UTICA, N. Y。 JANIARY 1963

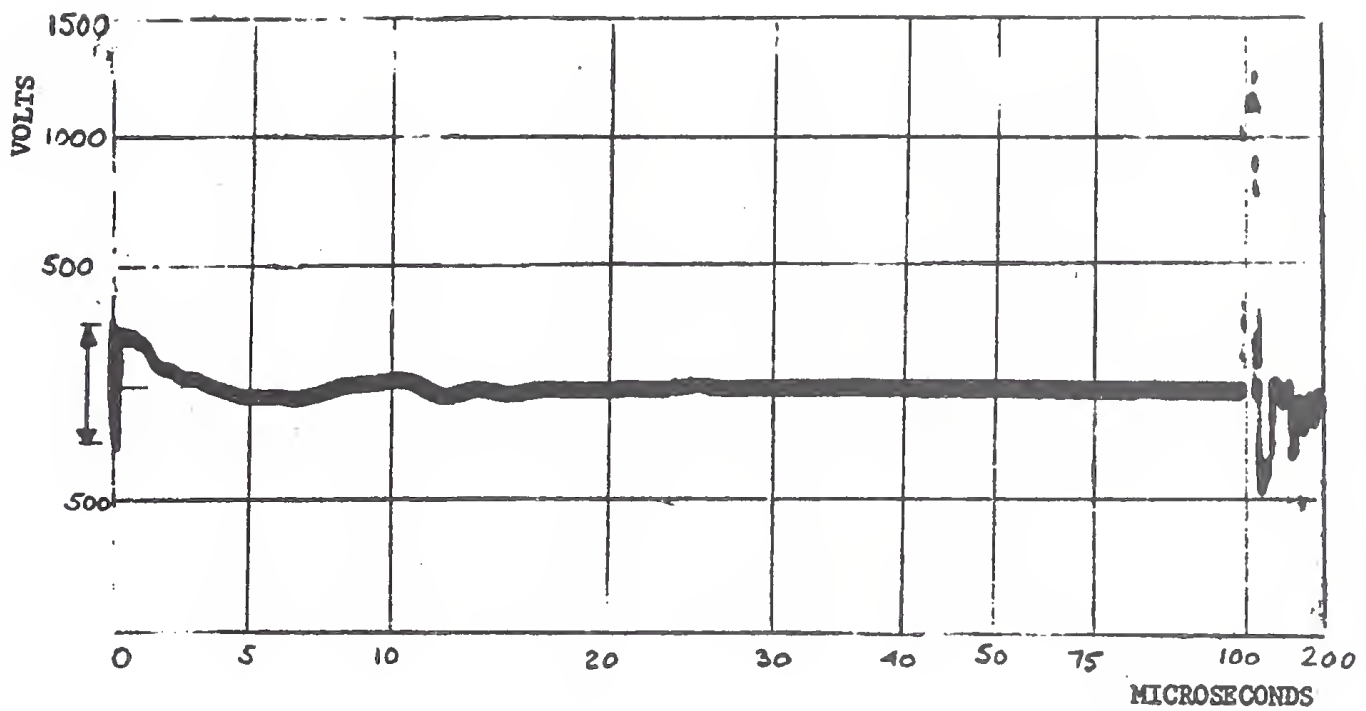

FRAR-TO- FEAK

OF 117 VOLTS $A C$

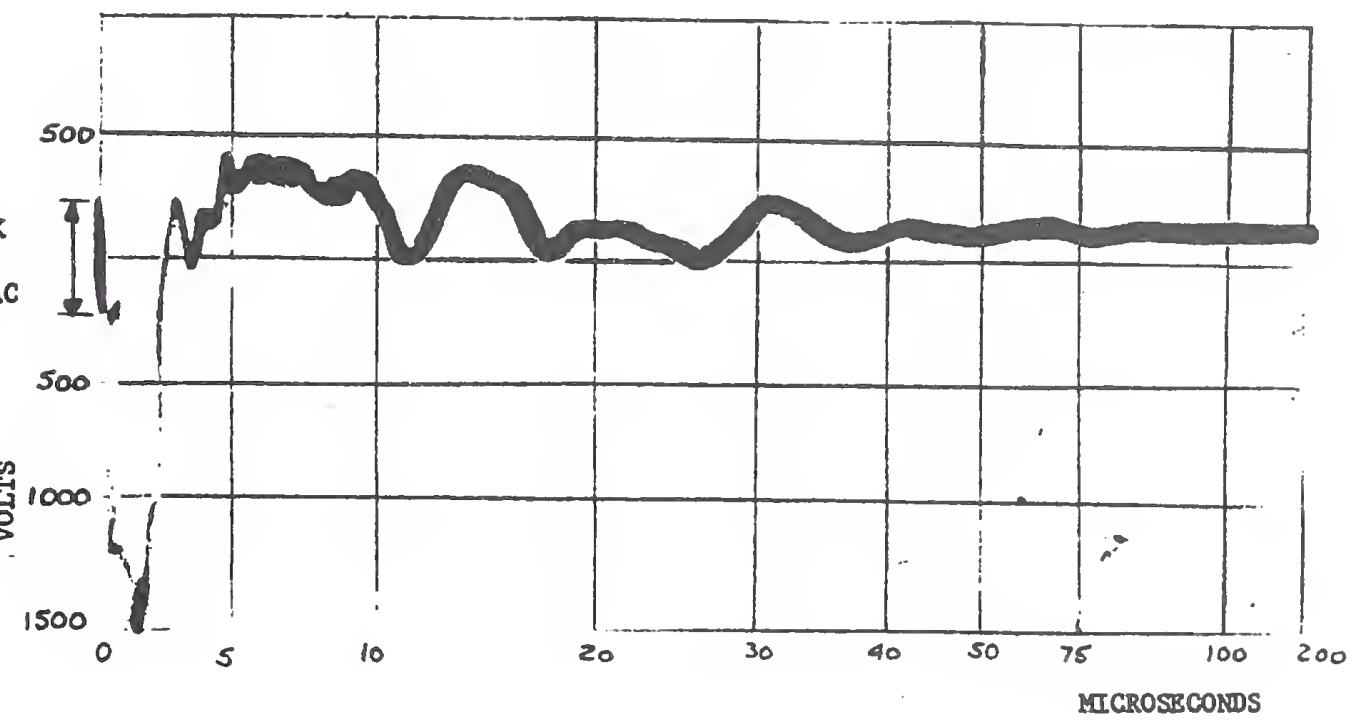

PIGURE 5 


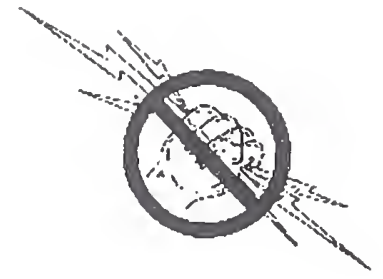




\section{Surge Voltages in Residential Power Circuits}

\author{
G.J. Hahn \\ General Electric Company \\ Schenectady NY
}

\author{
François Martzloff \\ General Electric Company \\ Schenectady NY \\ f.martzloff@ieee.org
}

All rights reserved IEEE

Reprinted, with permission, from

IEEE Conference paper $31 \mathrm{CP} 67-430^{1}$

\section{Significance:}

Part 3 Recorded occurrences

One of the first papers reporting surge recording in low-voltage ac power circuits.

Both waveform information and frequency of occurrence marked the beginning of the IEEE effort toward characterizing surge voltages in low-voltage ac power circuits, a departure from the traditional unidirectional and separate $1.2 / 50$ and $8 / 20$ waveforms in use for high-voltage equipment testing.

In the mid-sixties, when these recordings took place, there were very few, if any, surge-protective devices (SPDs) installed in residential power circuits. After the emergence of ubiquitous consumer-type SPDs, the results of subsequent monitoring campaigns were drastically changed (See "Galore" in Part 2) but the information is still valid for the frequency of occurrences to the extent that the origins of surges have not changed, only the observed levels are now considerably reduced by the proliferation of SPDs.

1967 IEEE Conference papers were available at the meeting for $\$ 0.75$ and later for $\$ 1.00$. However, they became no longer a vailable some time thereafter. 



\section{Conference Paper}

SURGE VOLTAGES IN RESIDENTIAL POWER CIRCUITS

G. J. Hahn

F. D. Martzloff

Member IEEE
Both of:

General Electric Company

Schenectady, N. Y.

A paper recommended by the IEEE Protective Devices Camittee of the IEEE Power Group for presentation at the IEEE Sunmer Power Meeting, Portland, Ore., July 9-14, 1967. Manuscript submitted April 3, 1967 ; made available for printing May 3, 1967.

Price: $\$ 1.00$

(75c at meeting)

(15r per copy additional if first class mailing desired)

(25) per copy additional if air mail is desired)
All Rights Reserved by

The Institute of Electrical and Electronics Engineers, Inc.

345 East 47th Street

New York, N. Y. 10017

Litho in USA

Paper No.

31 CP $67-430$ 


\section{SURGE VOLTAGES IN RESIDENTIAL POWER CIRCUITS}

by

G.J. Hahn and F.D. Martzloff

Research and Development Center

General Electric Company

Schenectady, New York

\section{Abstract}

Special instrumentation was developed for monitoring the magnitude and frequency of occurrence of surge voltages in residential circuits.

Over a period of two years, more than 400 locations in 20 cities were surveyed. Monitoring was accomplished by automatic recording cathode ray oscilloscopes and simple surge counters.

Two significant sources of surge voltages were identified: load switching within the house, and external surges, most likely associated with lightning, coming through the service drop.

Internally generated surges as high as 2500 volts were recorded during this test program, and six of the 250 households (i.e., 2.4 percent) in the sample experienced surges of this type in excess of 1200 volts once or more per day. A statistical evaluation indicated that a 90 percent confidence interval for the true proportion of homes with such surge voltages is between 1.0 and 4.7 percent.

Surges due to lightning reaching 5600 volts have been recorded on a 120-volt overhead distribution line. Independent evidence shows the occurrence of a number of surges in excess of 2000 volts.

In this study, a total of. 8 surges in excess of 1200 volts were caused by lightning and recorded on 39 counters at room outlets in 14 localities over the summer montbs.

\section{Introduction}

The successful operation of semiconductors and new insulation systems in appliances and consumer electronic devices may be adversely affected by transient overvoltages occurring on the 120volt power supply. Detection and measurement of these transient surges permits a designer to provide suitable built-in tolerance, or at least to recognize that there is a need for appropriate suppression or protection:

Special instrumentation has been developed for detection and measurement of surge voltages. In the first phase of testing automatic recording cathode ray oscilloscopes provided complete information on wave shape, and on magnitude and frequency of occurrence at a small number of arbitrarily chosen locations. These data, though statistically restricted, were adequate to demonstrate the existence of the problem, define some sources, and indicate typical wave shapes. It also became clear that there was a need for a larger sample that would be more statistically valid.

In the second phase of testing, one hundred surge counters, simple in design and easy to install, were developed especially for this program. These counters were installed in several hundred homes in various cities located in the East and middle West of the United States.

The purpose of this paper is to discuss recordings obtained during the two phases of this program and the statistical aspects of the results. It is hoped that publication of this paper will encourage other investigators to publish their findings. This would provide a broader statistical base for verification of the frequency and magnitude of surge voltages.

\section{Instrumentation}

Recording surge voltages in the field poses special problems. For example, the instruments cannot be continually attended and the signals to be recorded are unpredictable in magnitude, polarity, and frequency of occurrence.

In cooperation with Tektronix, Incorporated, a type 515 cathode ray oscilloscope was modified to record transients on film, with automatic advance of the film after a recording.

The modifications involved a change in the trigger and sweep circuits, as well as removal of a11 knobs (an important detail for an instrument to be left in all types of locations).

Most oscilloscope trigger circuits are polarized. This often causes a loss of recording when the polarity of the initial signal is not known. For surge recording, the trigger circuit was modified by feeding to the time base trigger through two $O R$ logic diodes the push-pull signal that is applied to the input of the oscilloscope delay 1ine. With this modification, the sweep is started for either polarity, while the signal is delayed before reaching the deflection plate of the CRT. In addition, the conventional blanking circuit holds the beam in low intensity before the sweep starts.

A second modification changed the sweep from a constant speed to a logarithmic speed, fast at the start and slow toward the end. This allows the recording of an impulse front with good resolution, while providing sufficient duration of the sweep to record a long tail. 
Finally, a relay was added with its coil energized whenever the beam sweep is triggered. Through a set of contacts on this relay, the film advance sequence in the camera is activated.

The camera, attached to the scope bezel, is a Beattie-Coleman system, accommodating 100 feet of $35 \mathrm{~mm}$ film, with no shutter, and recording on a $24 \times 36 \mathrm{~mm}$ frame the trace displayed on the CRT. Following the sweep, the contact mentioned above closes the motor circuit, advancing the film to the next frame in a few seconds. This film transport duration is matched in the oscilloscope trigger circuit by a hold-off so that no sweep will occur during film advance.

In order to prevent the film from being fogged by extended exposure to the faint glow on the phosphor (caused by imperfect blanking of the beam, cathode glow or light leaks) a built-in timer in the oscilloscope advances the film by one frame every hour. This provides an approximate method for timing the occurrence of surges. Since the surge-voltage tests were conducted, an automatic time recording feature has been added to give a more precise recording of time at each event.

Figure 1 is a photograph of this oscilloscope camera system. The relatively high cost of this system, its conspicuous presence (e.g., size, camera noise, etc.) in a home, and the amount of film to be scrutinized frame by frame limit the number of locations at which recordings can be made. However, for conclusions to rest on a sound statistical basis, it is necessary to investigate a large number of locations. To be acceptable to cooperative home owners, a transient detector should therefore lend itself to inconspicuous installation and simple data handing. Thus, a device which can merely be plugged into a wall receptacle, and that has a digital counter indicating the number of surges occurring above a specified threshold is satisfactory for widespread recording.

The circuit shown in Figure 2 was developed for the purpose, and packaged as shown in Figure 3. This device is connected to a wall receptacle by a conventional appliance cord, not a special probe. This connection is simple, establishes a typical final path for a surge impinging upon any appliance connected to this particular wall receptacle, and provides power for the high impedance rectifier circuit and a signal input to the trigger-sensor circuit.

A crudely compensated divider ( $\mathrm{R} 1 \mathrm{C} 1 / \mathrm{R} 2 \mathrm{C} 2$ ) attenuates the incoming surge before application to the Silicon Symmetrical Switch (SSS). This device has the characteristic of turning on abruptly whenever the voltage across it reaches a threshold, such as 250 volts. This threshold remains constant for durations as short as $0.1 \mu \mathrm{s}$. When the SSS turns on, the attenuated surge is applied to the gate of the very sensitive, fast switching Silicon Controlled Switch (SCS). If the polarity of this surge is positive, the SCs turns on, allowing the capacitor $\mathrm{C}$ to discharge through the coil of the solenoid-actuated counter S. A high impedance $(50,000 \mathrm{ohm})$ divider and half-wave rectifier provide a trickle charge 15-volt supply for the capacitor $C$. The resistance of this divider represents a negligible load for the house wiring system, yet is sufficiently low to allow some leakage in the electrolytic capacitor $C$. The long charging time (several seconds) of the capacitor is not objectionable, since the transients to be detected do not have a high repetition rate.

Calibration of the circuit is obtained by adjusting the value of the divider (RICl/R2C2). In these tests, the threshold level was set at 1200 volts for one group of counters and at 2000 volts for another group. A bench circuit was set up, whereby a surge with adjustable level and duration could be superimposed on a $60 \mathrm{~Hz}, 120$-volt power supply. Some consideration was given to the need to segregate, or filter out, the surge from the $60 \mathrm{~Hz}$ power voltage; in this case, however, with the minimum level at 1200 volts, the base 170 -volt crest represented a small contribution and was included in the signal detected by the circuit. Surges with approximately flat top and durations from several microseconds to 0.2 microsecond were applied to determine the variation of the threshold voltage as a function of surge duration. A typical response curve is shown in Figure 4. The response of this crest-indicating counter can be considered satisfactory, since the oscilloscope recordings in homes, as will be discussed later, have indicated that the shortest half-period of oscillatory surges is in the order of 2 microseconds.

\section{Recording Procedure}

In the first phase, oscilloscopes were installed at the basement service entrance of homes in the Schenectady, New York area. These locations do not represent a statistician's ideal sampling, but, during the initial phase of the program, the nature of transients rather than statistical accuracy was the major subject of interest. Later in the program, the range of locations was broadened to include homes in other urban and rural areas, particularly in Florida and South Carolina.

In the second phase, surge counters were installed at unspecified outlets in the homes of engineers in 20 cities in the northeast and midwest. Two distinct recording periods were scheduled: winter, because there is usually a minimum of lightning activity at that time of year, and summer, which ordinarily includes a maximum of lightning activity.

Since the oscilloscope input circuit operates at a level of a few volts, it is somewhat sensitive to direct radiation of electromagnetic noise in the preamplifier, even if there is no signal from the probe. In order to discriminate against this type of spurious indication, the recording procedure included a period during which the oscilloscope probe was shorted with the ground terminal remaining connected, so that spurious signals due 
to ground loops would be detected. In this manner, any noise entering the system could be recorded and later recognized for what it was in the analysis of the recordings made with the short circult removed from the probe.

The surge counters record only one polarity; in order to minimize record keeping by the homeowner, the connection of the cord was not polarized. In the event of an oscillatory surge (which is always quickly damped in these systems) two cases of counting can occur. For instance, the high side of the divider can be connected to the "hot" terminal of the receptacle (Figure 5). If the first half-cycle is positive and exceeds 1200 volts, a count is registered. If the first halfcycle is negative, and the second, positive half is highly damped, no count is registered. If the first half-cycle is well above 1200 volts causing the second half, in spite of some damping, to exceed 1200 volts, a count is registered. For the reverse connection, the same would occur for reverse polarity. Thus, the actual number of surge occurrences of both polarities in excess of 1200 volts is between 1 and 2 times the number indicated by the counter. The objective of the recording in this test series was only to determine whether or not surges occurred rather than their exact number. Consequently, the value of the multiplying factor is not very significant.

\section{Results of The Recordings - Oscilloscopes}

The first recording analysis revealed that some homes were subject to frequent surge voltages, some experienced only a few isolated surges, and others did not experience any surges in excess of the trigger level ( 300 to 400 volts). Furthermore, among those installations where surge voltages frequently occurred, the surges at some houses were relatively low (rarely in excess of 800 volts), while other houses had surges in the range of 1200 to 2500 volts.

Rates of surge occurrence ranged from zero (no surge in one to two weeks) to 0.5 per hour, with peak values from 400 volts (trigger threshold) to 5600 volts.

At the conclusion of the recording program, a total of 16 homes and two overhead distribution poles had been monitored for a total of 7000 hours. The peak of the surges was distributed as shown in Figure 6a; the most frequent and severe surges were distributed as shown in Figure 6b.

Further analysis of some recordings was made by deliberate switching of loads in the houses where frequent surges had been observed. In some cases, the operation of a specific device (e.g., oil burner, fluorescent lamp, pump motor, refrigerator, food mixer, etc.) was found to be the cause of the surges. In other cases, no amount of deliberate load switching could reproduce surges such as those recorded during unattended monitoring. The home owner was occasionally able to correlate surge recordings with lightning or power system disturbances.
A pattern emerged from all this information, showing two definite causes of surge voltages. In the homes:

1. Load switching in the house occasionally produced transient surges; these affected only that particular house. For any particular house, these transient surges had a wave shape which was consistently repeated with variations in amplitude along the entire film recording. This probably resulted from combination of switch characteristics and the impedance of the house wiring system; the varlations in amplitude were probably caused by variations of the switching angle and/or connected loads. Typical wave shapes of the recorded surges are shown in Figures $7 a, 7 b$, and $7 c$.

In one case, it was possible to install an oscilloscope in a house adjacent to that where repetitive surges up to 1700 volts were being recorded. The service drops were connected to the same pole, yet no surges occurring simultaneously were recorded in the second house.

2. Surge voltages not associated with load switching within the house were associated with lightning storms. In some cases, the home owner was able to correlate the film advance counts with the storm. Although recorded during lightning storms at two different locations, the surges shown in Figures $8 a$ and $8 b$ present the interesting characteristic of being oscillatory at a frequency in the range of $300 \mathrm{kHz}$. The surge shown in Figure $8 \mathrm{a}$ was recorded-at the overhead distribution line (oscilloscope mounted on the pole), while the surge of Figure $8 \mathrm{~b}$ was recorded at the service entrance in a home. The first exhibits far less damping than the second; this might be explained by the lower damping due to lower resistance of the system at the pole than at the end of a service drop.

Both of these surges, as well as most of the other surges recorded during lightning storms, exhibit this oscillatory characteristic at a frequency which is nearly constant for a particular locality. This constancy suggests that the oscillation of the system followed an excitation caused by the lightning stroke. A number of surges in the range of 800 to 1200 volts were observed during several storms. The maximum surge voltage recorded was 5600 volts; several other surges recorded during the same period were in excess of 4000 volts. 1

\section{Results of The Recordings - Counters}

With the two causes of transients identified by the oscilloscope measurements, the surge counters were applied in two separate programs. First, during the winter months, the counters were installed in a large number of houses for periods of one or two weeks; the objective was to 
determine how many houses sustained repetitive surges. Second, during spring, sumer, and fall, each counter was left at one or two locations for periods of 9 to 48 weeks; it was known from the first test that these homes were not subject to load switching surges. The objective was to determine the frequency and characteristics of externally generated surges, presumably caused by lightning.

The first period produced the data shown in Table 1, and the results obtained during the second period are shown in Table 2 .

\section{Statistical Analysis of The Recordings}

\section{Internally Generated Surges}

The data in Table 1 show that 6 houses, or 2.4 percent, were subjected to repetitive surges from among a total of 250 homes sampled. The true percentage doubtless differs somewhat from 2.4 percent due to statistical variations. How ever, one may be 90 percent confident that the true percentage is between 1.0 percent and 4.7 percent.* This band could be narrowed by taking additional samples. However, it should be noted that the precision is proportional to the square root of the sample size. Thus, four times the number sampled, or 1000 homes, would be necessary to cut the size of the statistical error band by approximately one-half. Since the above results refer to statistical variations only, they do not take into account possible biases due to such factors as restrictions in selecting members of the sample (principally engineers in a number of designated locations) or the time of year (winter months).

The probability of internally generated surges undoubtedly varies among economic groupings (1.e., the devices in use in homes probably vary with the economic status of the resident); however, devices found to generate surges (1.e., furnaces, refrigerators, etc.) exist in most homes.

\section{Excernally Generated Surges}

Results from the second testing perlod that was concerned with externally generated surges are shown in Table 2. From 39 counters installed in a total of 91 homes in 14 localities, a total of 8 occurrences in 6 separate localities were observed during an equivalent exposure time of 846 weeks. A ninth occurrence was disregarded in this analysis because it occurred in the same home during the same storm. Of the two palrs of occurrences which took place in the same location, one palr occurred during the same storm and the second involved two occurrences at different times.

*This result is obtained by the well-known method of setting confidence intervals for a sample percentage. Further deta1ls may be found in statis tical texts. $2,3,4$
Analyses could be conducted based on the following alternative assumptions:

1. Voltage surges above 1200 volts occur only during the period of the year that the counters were installed in the homes. Thus, although the counters were in homes for only part of the year, the time involved (1.e., the sumer months) was so chosen that no further surges would have been noted even if each counter had been run for 52 consecutive weeks. The average number of surges per year would then be $8 / 39$, or 0.205 .

2. Voltage surges occur randomly at a constant rate throughout the year. Thus, a counter which was in use 9 weeks, on the average, would be subject to a third as many surges as a counter in use for a period of 27 weeks. Under this assumption, a total of 8 surges observed in a total time equivalent to 16 years ( 846 weeks) ylelds an average of 0.5 surges per year.

Using these two extreme assumptions, a range could be established for the estimated number of surges per year in a larger sample, based on this specific sample. The above calculations refer only to single polarity surges. If all surges are being considered, the given values must be multiplied by a value corresponding to the additional proportion of opposite polarity surges above 1200 volts which do not also result in positive surges above 1200 volts. This rultiplying factor is probably about 1.6; it accounts for the damping between the first and second $1 / 2$ cycle of an oscillatory surge.

Lightning-induced surges are likely to affect more than one house when they occur. Local geographical and meteorological conditions are critical influences on these surges; however, these factors could not be considered in this preliminary investigation.

To relate the above data to risk of appliance fallure, the given values must be modified by the probability that a surge above 1200 volts would cause failure of operating appliances. Failure effects would vary with different appliances.

\section{Possible Further Analysis}

A more refined analysis for a probability measurement of voltage surges per lightning storm is possible if the geographical location of the homes, the occurrence rate of lightning storms during the testing period, and exact dates at which voltage surges occur is considered. The resulting values can then be used in conjunction with information given in Reference 5 to calculate the probability of a voltage surge in any specified geographic area, during a particular part of the year. Such an analysis would remove the need for making one of the two alternative assumptions stated above and lead to a single set of estimates. However, this would require more detailed data than could be collected in this program. 
Finally, it is noted that if one has knowledge of the actual voltage surges, rather than merely the information concerning whether or not a surge above 1200 volts occurred, a more sensitive analysis is possible. In this case, for example, probability plotting and other techniques based upon the statistical theory of extreme values ${ }^{4,6}$ might well be applicable.

\section{Effects of Surge-Voltages On Connected Electrical Devices}

The surges which have been recorded in this program occurred during normal operation of the household, with no knowledge of the connected load situation at the time of occurrence.

The question of energy involved in the surge is related to the impedance of the system, since these recordings provide voltage data only. Surge impedance measurements of house wiring cable indicate a value of 100 to 300 ohms for a typical branch circuit, so that the surge impedance at the service entrance could be in the order of 5 to 10 ohms. However, this low value exists only for the travel time (i.e., a fraction of a microsecond). Connected loads will have a lower impedance than that of the branch circuit. This value will be dependent upon frequency whenever inductive components are present. These loads will absorb part of the energy of the surges and thus lower their peak.

Devices such as motors and transformers have solid insulation and such a long history of successful application that their performance is not in question. Perhaps unusual failures can be explained by extreme values of surges as indicated by the data.

Defective wiring practices (e.g., pinched insulation, reduced air clearances in wall boxes, etc.) will cause air flashover with or without 60 $\mathrm{Hz}$ power follow. In fact, one house was brought to our attention because of complaints of sparking in a light fixture. With the switch in the ground wire and the frame attached to a grounded pipe, flashover at 1700 volts was observed in correlation with the start of an oil burner in the house. This defective light fixture was acting as a voltage limiting gap for the house.

Appliances containing semiconductors and direct $1 \mathrm{y}$ exposed to the 1 ine transients may be more vulnerable. Actually, the 1200-volt threshold level was selected as the result of this consideration. It is interesting to note that, although a number of surges above 2000 volts were recorded by the oscilloscopes, the few surge counters calibrated for 2000 rather than 1200 volts did not produce any recording above 2000 volts.

An independent study of clock motor failures produced information on failure rates versus withstand levels. This study was very pertinent to the surge counter program, since thousands of clocks are connected at all times to the power system. Over a period of three years, failure rates were correlated with insulation level of the coils. A very significant 100 to 1 drop in failure rate resulted from an increase in withstand voltage from approximately 2000 to approximately 6000 volts. This shows that, even though no surges over 2000 volts were recorded by the 2000volt counters, surges in excess of 2000 volts do indeed occur.

\section{Conclusions}

1. Residential power circuits are subjected to surge voltages due to two distinct causes: load switching within the house, and externally generated surges that are most likely associated with lightning.

2. Internally generated surges caused by load switching are likely to be repetitive. They can generally be associated with a specific device, probably operating erratically or exciting some natural frequency of the wiring system. They are not related to lightning or disturbances from the utility. Peaks as high as 2500 volts have been observed. The best single statistical estimate is that 2.4 percent of households of the type sampled experience these internaliy generated repetitive surges in excess of 1200 volts. However, because of the statistical variability in the sample, this value may be as low as 1 percent or as high as 4.7 percent. Surges may be repeated several times a day.

3. The frequency of surges caused by light ning is not affected by household electrical devices, but rather by local geographical and meteorological conditions. The limited data in this program reveal several 1ightning-caused surge occurrences above 3000 volts with one reaching 5600 volts.

4. Independent evidence shows that a significant number of surges above 2000 volts do occur periodically in residential power 1 ines.

\section{Acknowledgments}

The contribution of the hundreds of individuals involved in the data collection and the contribution of J.E. Lenz for the data on overhead distribution lines are gratefully acknowledged.

\section{References}

1. Lenz, James E., "Basic Impulse Insulation Levels of Mercury Lamp Ballast for Outdoor Applications," (Discussion), Illuminating Engineering, February 1964, pp. 133-140.

2. Dixon, W.J. and Massey, F.J., Jr., Introduction to Statistical Analysis, McGraw-Hill, New York, 1957.

3. Bowker, A.H. and Liberman, G.J., Engineering Statistics, Prentice-Ha11, New Jersey, 1959. 
4. Hahn, G.J. and Shapiro, S.S., Statistical Models in Engineering, John Wiley and Sons, New York, 1967.

5. Brownlee, K.A., Statistlcal Theory and Methodology in Science and Engineering, John Wiley and Sons, New York.

6. Gumbel, E.J., Statistics of Extremes, Columbia University Press, New York, 1958.

\section{Bibliography}

\section{Recording Techniques}

K.G. Beauchamp, "A Multiple Beam Oscilloscope for the Study of High Voltage Transient Discharges," Electronic Engineering, Vol. 30, June 1958, PP. $358-365$.

S.F. Pearce and J.H. Bull, "High-frequency Transients in Low-voltage Power Systems," The Electrical Research Association, Leatherhead, Surrey, 1962 .

P. Chowdhur1, "Portable Fast Response Transient Voltage Counter," Institute of Electrical and Electronics Engineers Transactions Power Appli ances and Systems, Vol. 84, May 1965, Pp. 417-422.

J. Czech, Oscilloscope Measuring Techniques, New York, Philips Technical Library, Springer-Verlag, 1965.

O.H. Davie and J. Wood, "An Automatic Cathode-ray Oscilloscope Beam Brightening Device for Transient Recordings," Journal of Scientific Instruments, Vo1. 33, No. 5, May 1956, p. 203.
F.A. Fisher, "Transient Response of Impulse Voltage Dividers," Transactions of American Institute of Electronics Engineers I, Vol. 77, 1958, Pp. 411420 .

C.W. Hargens, "Cathode-ray Recorder Compares Transients," Electronics, Vol. 31, No. 3, January 17, 1958 , PP. 84-87.

D.H. Kekas, "Trigger Generator Used in Recording Power-line Transients," Electro-Technology, July 1966 , p. 85.

H.W. Lord, "High Frequency Transient Voltage Measuring Techniques," Institute of Electrical and Electronics Englneers Transactions Communications and Electronics, November 1963, pp. 602-605.

\section{Results}

J.H. Bull and W. Nethercot, "The Frequency of Occurrence and the Magnitude of Short Duration Transients in Low-voltage Supply Mains," Radio and Electronic Engineer, September 1964.

S.F. Pearce and J.H. Bul1, "High Frequency Transients in Low Voltage Supply Systems," The Electri= cal Research Association, Leatherhead, Surrey, 1962 .

R.D. Goldblum, "Measuring DC Relay Coil Transients," Electronic Industries, Vol. 24, April 1965 , pp. 68-71. 


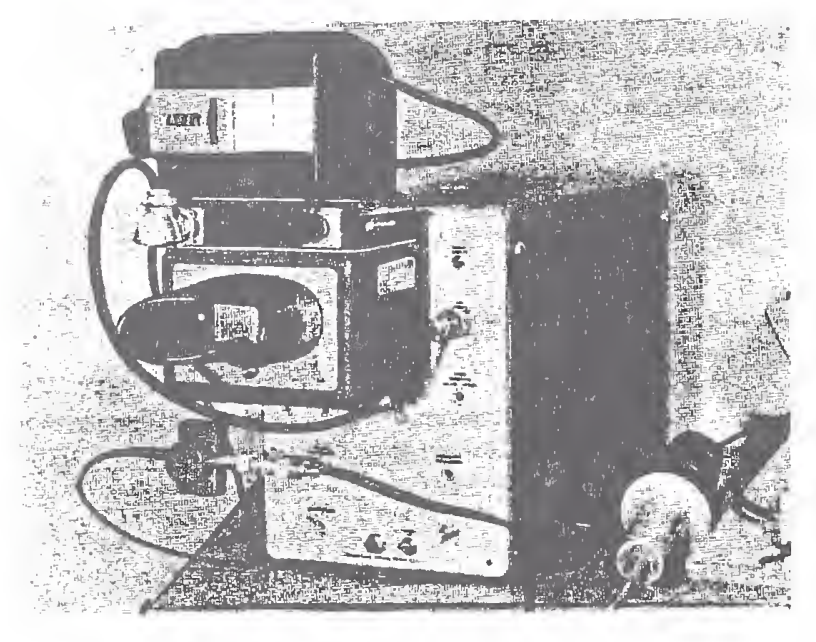

Figure 1. Oscilloscope and Camera

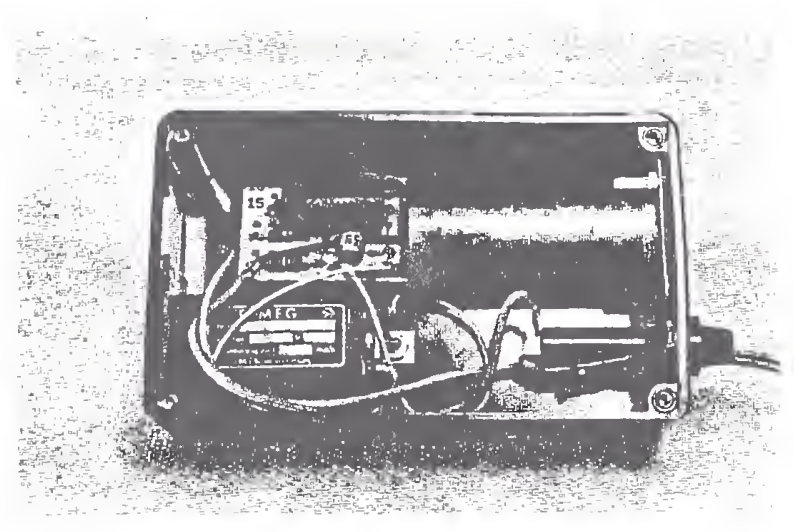

Figure 3a. Surge Counter--Cover Removed

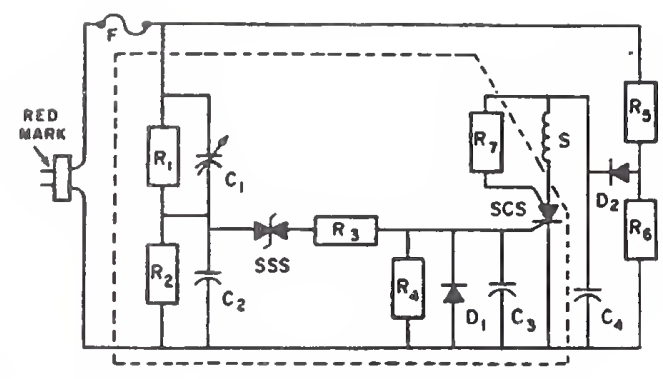

Figure 2. Surge Counter Circuit

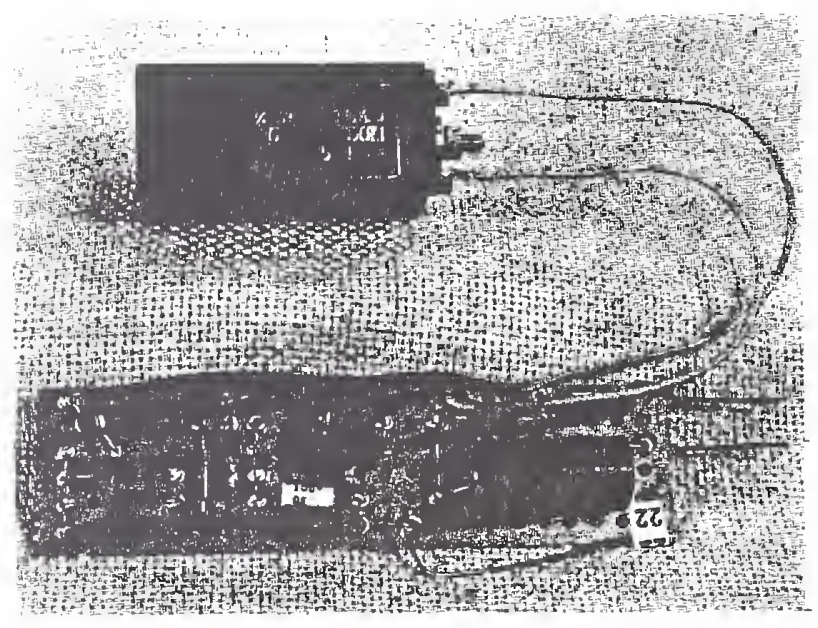

Figure 3b. Surge Counter Elements--Removed from Shileld

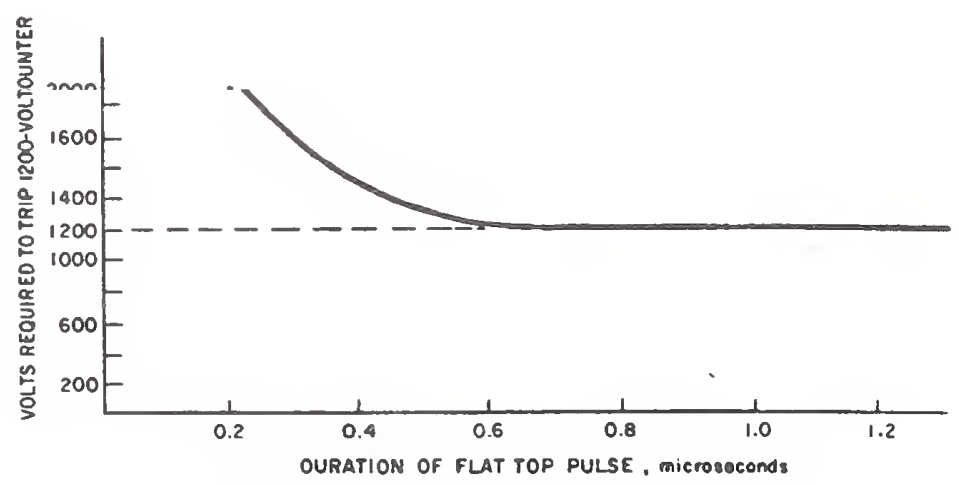

Figure 4. Response of Surge Counter 

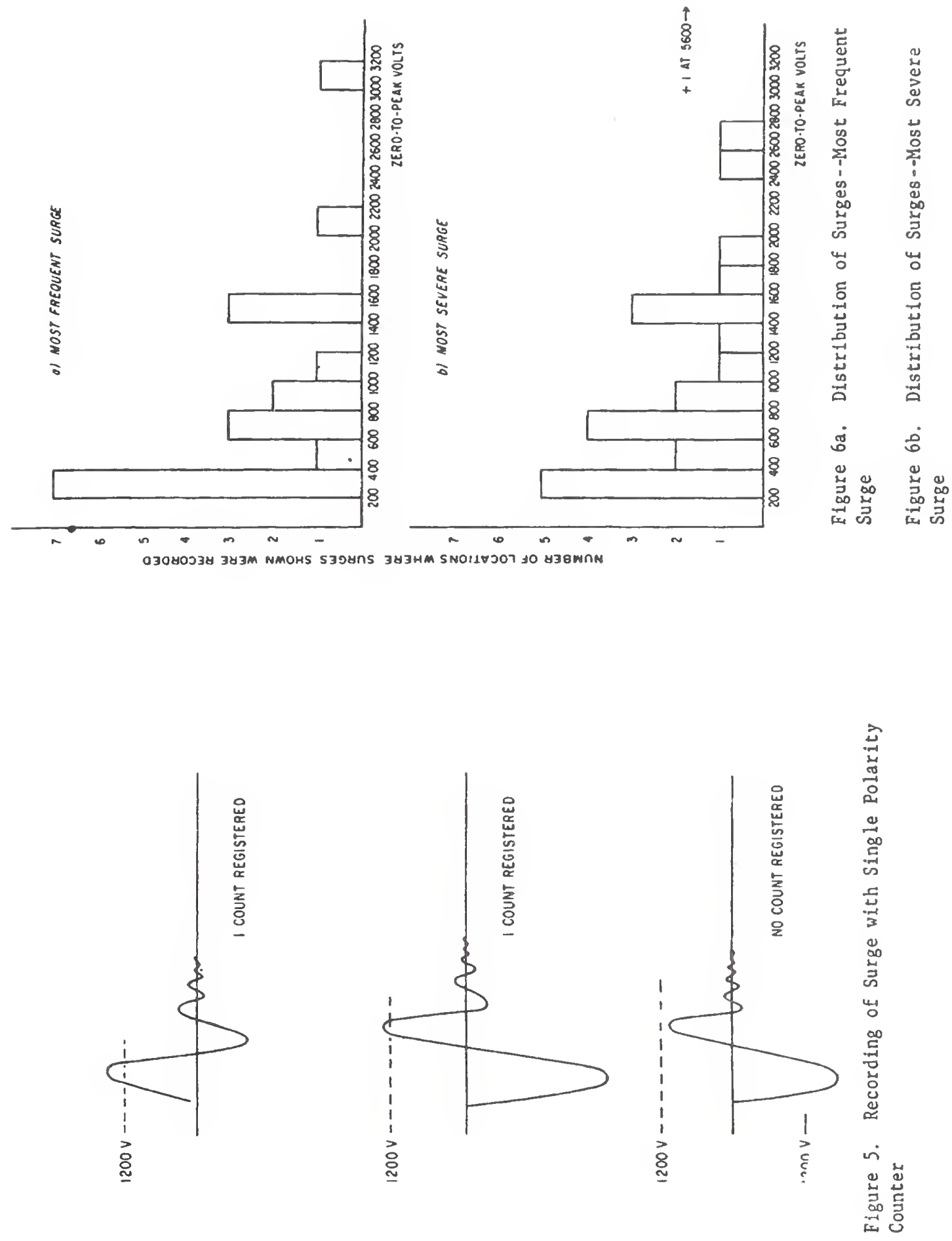

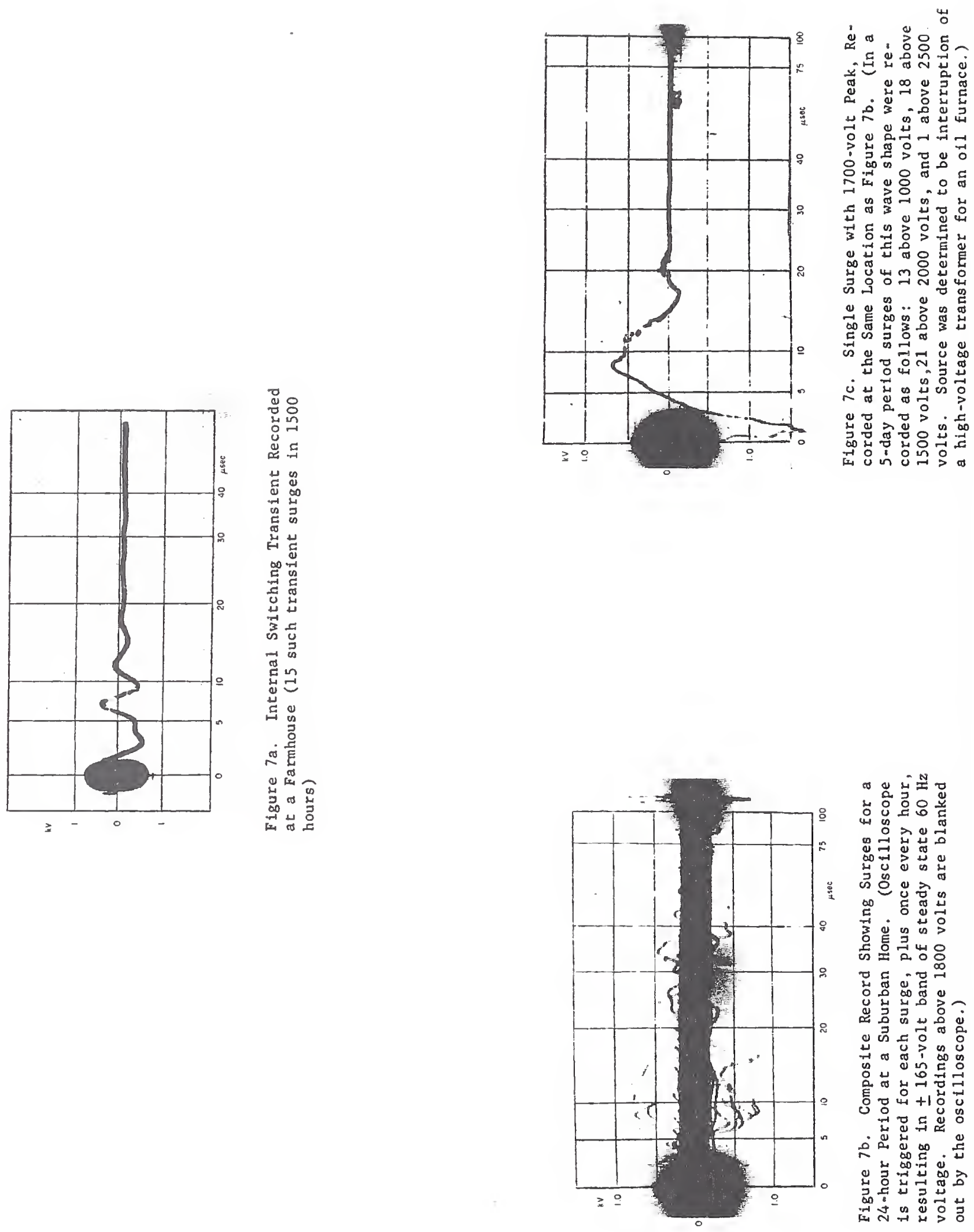


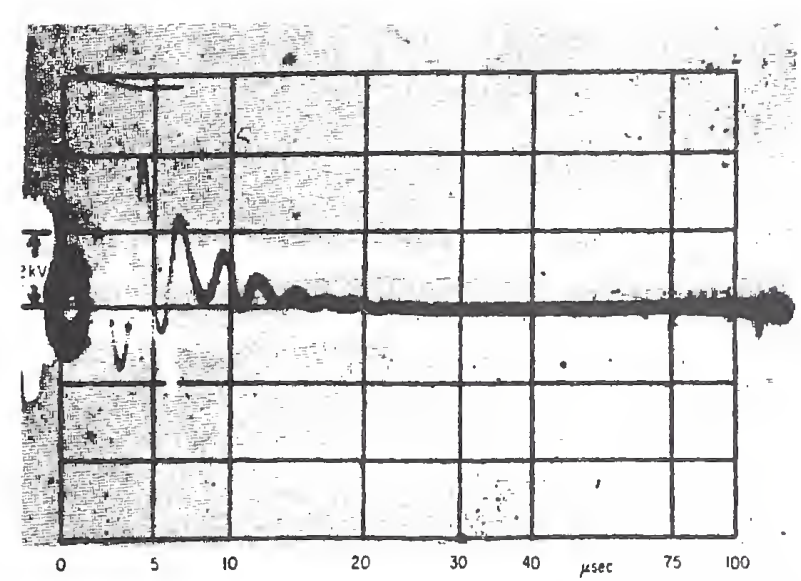

Figure 8a. Transient Surges Recorded on Overhead Distribution Systems in Charleston, South Carolina (3800-volt crest, $300 \mathrm{kHz}$ oscillation.)

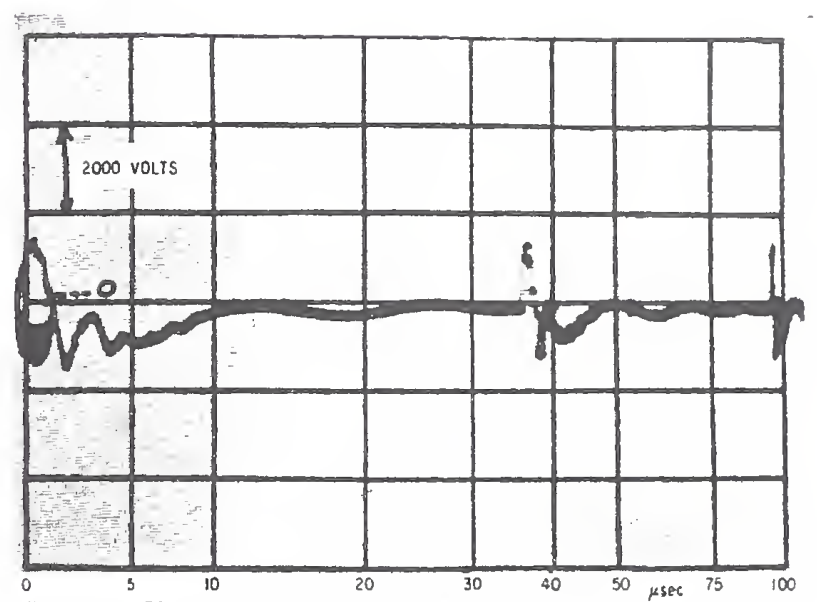

Figure 8b. Transient Surge Recorded at the Service Entrance of a Home in Florida 


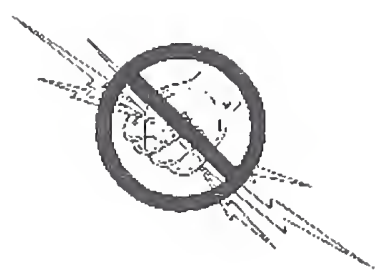




\section{Surge Voltages in Residential and Industrial Power Circuits}

\author{
François Martzloff \\ General Electric Company \\ Schenectady NY \\ f.martzloff@ieee.org
}

\author{
G.J. Hahn \\ General Electric Company \\ Schenectady NY
}

Copyright 1970 by IEEE

Reprinted, with permission, from

IEEE Transactions on Power Apparatus and Systems, Vol. PAS-89, No.6, July/August 1970

\section{Significance: \\ Part 3 Recorded occurrences}

At the invitation of the Surge Protective Devices Committee, the 1967 Conference Paper was resubmitted for consideration as a Transactions paper, with additional information presented on industrial case histories acquired since publication of the conference paper.

Both waveform information and frequency of occurrence marked the beginning of the IEEE effort toward characterizing surge voltages in low-voltage ac power circuits, a departure from the traditional unidirectional and separate $1.2 / 50$ and $8 / 20$ waveforms in use for high-voltage equipment testing. One of the outcomes of that effort was IEEE Std 587, which eventually evolved into IEEE Std C62.41 and its successive 1980, 1991 , and 2002 versions.

Note that the title still refers only to surge voltages, not surge currents. In the mid-sixties, when these recordings took place, there were very few, if any, surge-protective devices (SPDs) installed in residential power circuits and the threat was indeed one of surge voltages. After the emergence of ubiquitous consumer-type SPDs, the results of subsequent monitoring campaigns were drastically changed (See "Galore" in Part 2) but the information is still valid for the frequency of occurrences to the extent that the origins of surges have not changed, only the observed levels are now considerably reduced by the proliferation of SPDs (for which the available surge current becomes a matter of interest). 


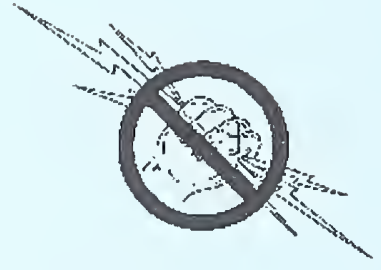




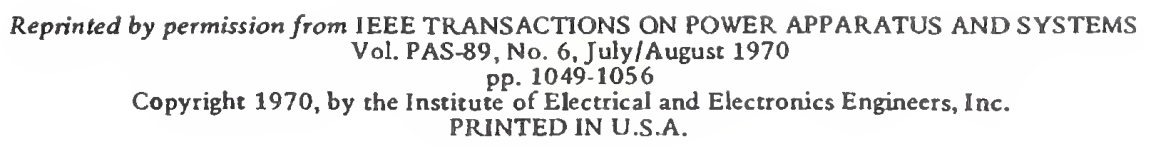

\title{
Surge Voltages in Residential and Industrial Power Circuits
}

\author{
FRANÇOIS D. MARTZLOFF, MEMBER, IEEe, AND GERALD J. HAHN
}

\begin{abstract}
Special instrumentation was developed for monitoring the magritude and frequency of occurrence of surge voltages in residential and industrial circuits. Over a period of 2 years, more than $\mathbf{4 0 0}$ locations in 20 cities were surveyed. Monitoring was accomplished by automatic recording cathode-ray oscilloscopes and simple surge counters. In residential circuits, two significant sources of surge voltages were identified: load switching within the house, and erternal surges, most likely associated with lightning, coming through the service drop. In industrial circuits, the levels of surges are lower than in residential circuits. However, switching surges on the load side of the switch can be severe. Internally generated surges as high as $\mathbf{2 5 0 0}$ volts were recorded during this test program, and surges due to lightning reaching 5600 volts have been recorded on a 120-volt overhead distribution lipe.
\end{abstract}

Paper 69 TP 618-PWR, recommended and approved by the Surge Protective Devices Committee of the IEEE Power Group for presentation at the IEEE Summer Power Meeting, Dallas, Tex., June 22-27, 1969. Manuscript submitted February 17, 1969; made available for printing April $7,1969$.

The authors are with the lResearch and Development Center, General Electric Company, Schenectady, N. Y. 12305.

\section{INTRODUCTION}

$T$ HE successful operation of semiconductors and new insulation systems in appliances and consumer electronic devices may be adversely affected by transient overvoltages occurring on the 120-volt power supply. Detection and measurement of these transient surges permits a designer to provide suitable built-in tolerance, or at least to recognize that there is a need for appropriate suppression or protection.

Special instrumentation has been developed for detection and measurement of surge voltages. In the first phase of testing, automatic recording cathode-ray oscilloscopes (CRO) provided complete information on waveshape, and on magnitude and frequency of occurrence at a small number of arbitrarily chosen locations. These data, although statistically restricted, were adequate to demonstrate the existence of the problem, define some sources, and indicate typical waveshapes. It also became clear that there was a need for a larger sample that would be more statistically valid. In the second phase of testing, 100 surge 
counters, simple in design and easy to install, were developed especially for this program. These counters were installed in several hundred homes in various cities located in the East and Midwest of the United States.

The purpose of this paper is to discuss recordings obtained during the two phases of this program and the statistical aspects of the results. It is hoped that publication of this paper will encourage other investigators to publish their findings. This would provide a broader statistical base for verification of the frequency and magnitude of surge voltages.

In regard to industrial circuits, less data have been accumulated, but a number of significant case histories are presented to illustrate the problems likely to be encountered in that field.

\section{INSTRUMENTATION}

Recording surge voltages in the ficld poses special problems. For example, the instruments camnot be continually attended, and the signals to be recorded are unpredictable in magnitude, polarity, and frequency of occurrence.

In cooperation with Tektronix, Inc., a type 515 CRO was modified to record transients on film, with automatic advance of the film after a recording.

The modifications involved a change in the trigger and sweep circuits, as well as removal of all knobs (an important detail for an instrument to be left in all types of locations).

Most oscilloscope trigger circuits arc polarized. This often causes a loss of recording when the polarity of the initial signal is not known. For surge recording, the trigger circuit was modified by feeding to the time base trigger through two or logic diodes the push-pull signal that is applied to the input of the oscilloscope delay line. With this modification, the sweep is started for either polarity, while the signal is delayed before reaching the defiection plate of the cathode-ray tube (CRT). In andition, the conventional blanking circuit holds the beam in low intensity before the sweep starts.

A second modification changed the sweep from a constant spreed to a logarithmic speed, fast at the start and slow toward the end. This allow's the recording of an impulse front with good resolution, while providing sufficient duration of the swcep to record a long tail.

Finally, a relay was added with its coil energized whenever the beam sweep is triggered. Through a set of contacts on this relay, the film advance sequence in the camera is activated.

The camera, attached to the scope bezel is a Beattie-Coleman system, acconmodating 100 fect of $35-\mathrm{mm}$ film, with no shutter, and recording on a $24-$ by $36-\mathrm{mm}$ frame the trace displayed on the CRT. Following the sweep, the contact mentioned above closes the motor circuit, advancing the film to the next frame in a few seconds. This film transport duration is matched in the oscilloscope trigger circuit by a hold off so that no sweep will occur during film advance.

In order to prevent the film from being fogged by extended exposure to the faint glow on the phosphor (caused by imperfect blanking of the beam, cathode glow, or light leaks) a built-in timer in the oscilloscope advances the film by one frame every hour. This provides an approximate method for timing the occurrence of surges. Since the surge-voltage survey was conducted, an automatic time recording feature has been added to give a more precise recording of time at each event.

Fig. 1 shows this oscilloscope canera system. The relatively high cost of this system, its conspicuous presence (e.g., size, camera noise, etc.) in a home, and the amount of film to be

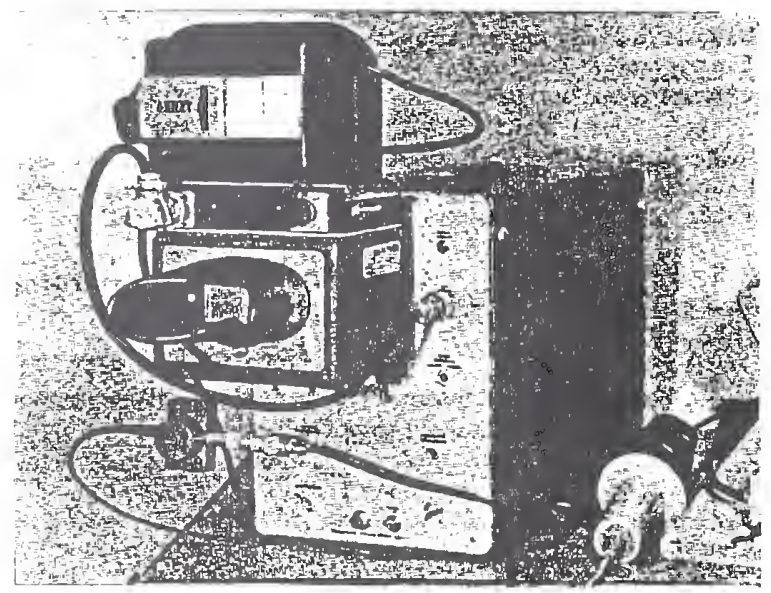

Fig. 1. Oscilloscope and camera.
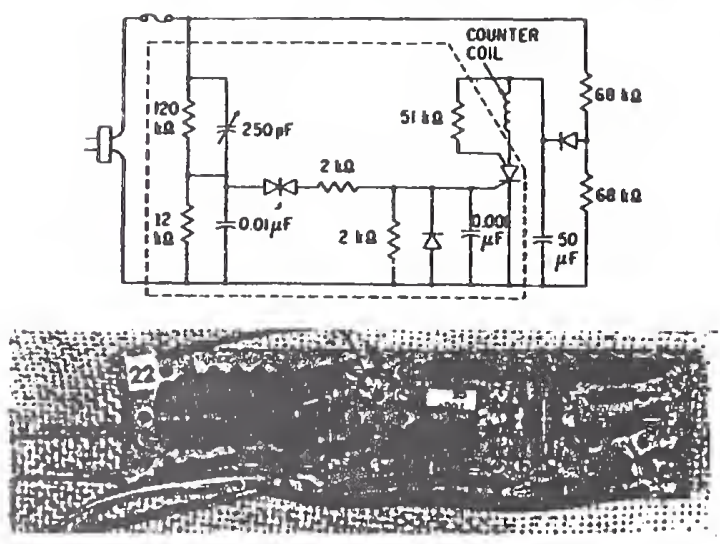

Fig. 2. Surge-counter circuit.

scrutinized frane by frame limit the number of locations at which recordings can be made. However, for conclusions to rest on a sound statistical basis, it is necessary to investigate a large number of locations. To be acceptable to coopera tive home owners, a transient detector should therefore lend itself to inconspicuous installation and simple data handling. Thus a device which can merely be plugged into a wall receptacle, and that has a digital counter indicating the number of surges occurring above a specified threshold is satisfactory for widespread recording.

The circuit shown in Fig. 2 was developed for this purpose. This devicc is connected to a wall receptacle by a conventional appliance cord, not a special probe. This connection is simple, establishes a typical final path for a surge impinging upon any appliance connected to this particular wall receptacle, and provides power for the high-impedance rectifier circuit and a signal input to the trigger-sensor circuit.

A crudely compensated divider attenuates the incoming surge before application to the silicon symmetrical switch (SSS). This device has the characteristic of turning on abruptly whenever the voltage across it reaches a threshold, such as 250 volts. This threshold remains constant for durations as short as 0.1 $\mu \mathrm{s}$. When the SSS turns on, the attenuated surge is applied to the gate of the very-sensitive fast-switching silicon controlled switch 


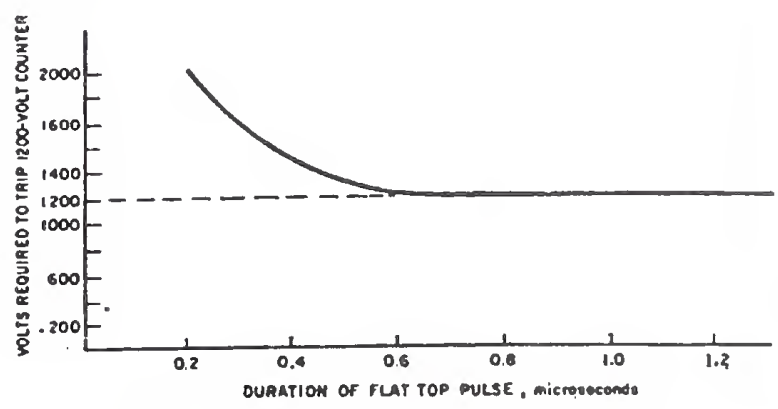

Fig. 3. Response characteristic of counter.

(SCS). If the polarity of this surgc is positive, the SCS turns on, allowing the $50-\mu \mathrm{F}$ capacitor to discharge through the coil of the solenoid-actuated counter. A high-impedance divider and half-wave rectifier provide a trickle charge 15-volt supply for the $50-\mu \mathrm{F}$ capacitor. The resistance of this divider represents a negligible load for the house wiring system, yet is sufficiently low to allow some leakage in the elcctrolytic capacitor. The long charging time (several seconds) of the capacitor is not objectionable since the transients to be detected do not have a high repetition rate.

Calibration of the circuit is obtained by adjusting the value of the divider elements. In these tests, the threshold level was set at 1200 volts for one group of counters and at 2000 volts for another group. A bench circuit was set up, whereby a surge with adjustable level and duration could be superimposed on a $60-\mathrm{Hz} 120$-volt power supply. Some consideration was given to the need to segregate, or filter out, the surge from the $60-\mathrm{Hz}$ power voltage; in this case, however, with the minimum level at 1200 volts, the base 170 -volt crest represented a small contribution and was included in the signal detected by the circuit. Surges with approximately flat top and durations from several to $0.2 \mu \mathrm{s}$ were applied to determine the variation of the threshold voltage as a function of surge duration. A typical response curve is shown in Fig. 3. The response of this crest-indicating counter can be considcred satisfactory since the oscilloscope recordings in homes, as will be discussed later, have indicated that the shortest half-period of oscillatory surges is in the order of $2 \mu \mathrm{s}$.

\section{Recording Procedure}

In the first phase, oscilloscopes were installed at the basement service entrance of homes in the Schenectady, N. Y., area. These locations do not represent a statistician's ideal sampling, but during the initial phase of the program, the nature of transients, rather than statistical accuracy, was the major subject of interest. Later in the program, the range of locations was broadened to include homes in other urban and rural arcas, particularly in Florida and South Carolina.

In the second phase, surge counters were installed at unspecified outlets in the homes of engineers in 20 cities in the Northeast and Midwest. Two distinct recording periods were scheduled: winter, because there is usually a minimum of lightning activity at that time of year; and summer, which ordinarily includes a maximum of lightning activity.

Since the oscilloscope input circuit operates at a levcl of a few volts, it is somewhat sensitive to direct radiation of electromagnetic noise in the preamplifier, even if there is no signal from the probe. In order to discriminate against this type of spurious

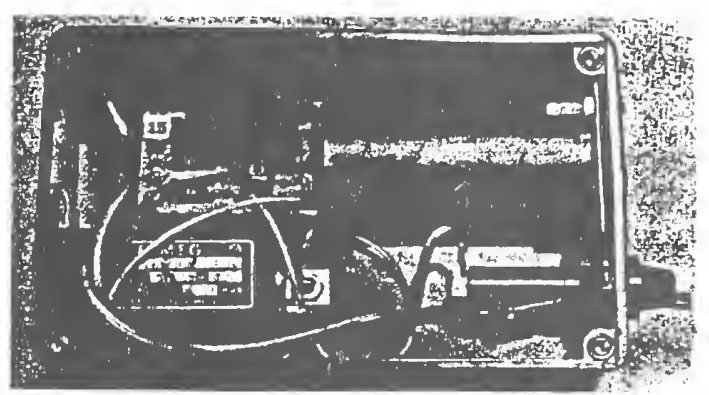

Fig. 4. Surge-counter package.
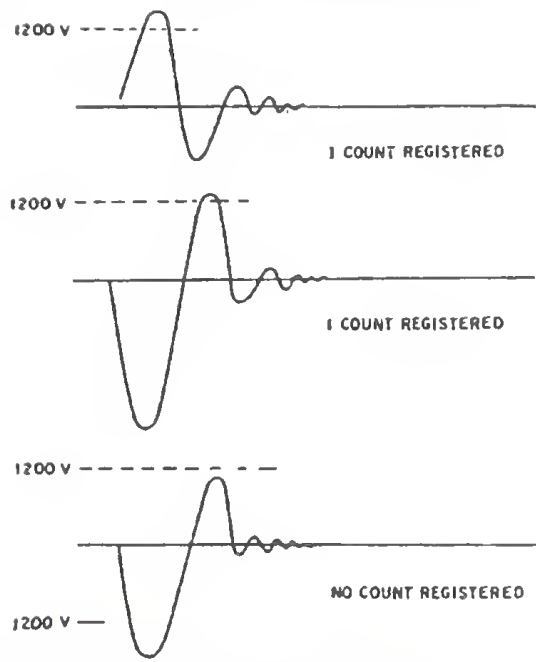

Fig. 5. Recording with single-polarity conntcr.

indication, the recording procedure included a period during which the oscilloscope probe was shorted with the ground terminal remaining connected so that spurious signals due to ground loops would be detected. In this manner, any noise entering the system could be recorded and later recognized for what it was in the analysis of the recordings made with the short circuit removed from the probe.

The surge counters record only one polarity; in order to minimize record keeping by the homeowner, the connection of the cord was not polarized. In the event of an oscillatory surge (which is always quickly damped in these systems), two cases of counting can occur. For instance, the high side of the divider can be connected to the "hot" terminal of the receptacle (Fig. 5). If the first half-cycle is positive and exceeds 1200 volts, a count is registered. If the first half-cycle is negative, and the second, positive half is highly damped, no count is registered. If the first half-cycle is well above 1200 volts causing the second half, in spite of some damping, to exceed 1200 volts, a count is registered. For the reverse connection, the same would occur for reverse polarity. Thus the actual number of surge occurrences of both polarities in excess of 1200 volts is between 1 and 2 times the number indicated by the counter. The objective of the recording in this test series was only to determine whether or not surges occurred rather than their exact number. Consequently, the value of the multiplying factor is not very significant. 
TABLE I

Detailed Analysis of Recorded Surges

\begin{tabular}{|c|c|c|c|c|c|c|c|c|}
\hline \multirow[b]{2}{*}{ House } & \multicolumn{3}{|c|}{$\begin{array}{c}\text { Most } \\
\text { Severe Surge }\end{array}$} & \multicolumn{4}{|c|}{$\begin{array}{l}\text { Most } \\
\text { Frequent Surge }\end{array}$} & \multirow[b]{2}{*}{ Remarks } \\
\hline & Type* & $\begin{array}{c}\text { Crest } \\
\text { (volts) }\end{array}$ & $\begin{array}{c}\text { Duration } \\
\text { ( } \mu \text { s or } \\
\text { cycles) }\end{array}$ & Type* & $\begin{array}{c}\text { Crest } \\
\text { (volts) }\end{array}$ & $\begin{array}{c}\text { Duration } \\
\text { ( } \mu \text { s or } \\
\text { cycles) }\end{array}$ & $\begin{array}{c}\text { Average } \\
\text { Surges } \\
\text { per Hour }\end{array}$ & \\
\hline \multirow{20}{*}{$\begin{array}{c}1 \\
2 \\
3 \\
4 \\
5 \\
6 \\
7 \\
8 \\
9 \\
10 \\
11 \\
12 \\
13 \\
14 \\
15 \\
16 \\
\text { Street pole } \\
\text { Hospital } \\
\text { Hospital } \\
\text { Department } \\
\text { store } \\
\text { Street pole }\end{array}$} & $A-1.5$ & 700 & $10 \mu \mathrm{S}$ & $A-1.5$ & 300 & $10 \mu \mathrm{S}$ & 0.07 & \multirow{5}{*}{$\begin{array}{l}\text { fluorescent light switch- } \\
\text { ing }\end{array}$} \\
\hline & $A=2.0$ & 750 & $20 \mu \mathrm{s}$ & $A-2.0$ & 500 & $20 \mu \mathrm{s}$ & 0.14 & \\
\hline & $B-0.5$ & 600 & 1 cycle & $B-0.5$ & 300 & 1 cycle & 0.05 & \\
\hline & $B-0.5$ & 400 & 2 cycles & $B-0.5$ & 300 & 2 cycles & 0.2 & \\
\hline & $c$ & 640 & $5 \mu \mathrm{S}$ & \multicolumn{4}{|c|}{ too few to show typical 10 total } & \\
\hline & $B-0.3$ & 400 & 1 cycle & $B-0.3$ & 250 & 1 cycle & 0.01 & \multirow{3}{*}{ lightning storm } \\
\hline & $B-1$ & 1800 & 1 cycle & $B-1.0$ & 800 & 1 cycle & 0.03 & \\
\hline & $C$ & 1200 & $10 \mu \mathrm{s}$ & $B-0.5$ & 300 & 4 cycles & 0.1 & \\
\hline & $B-0.25$ & 1500 & 1 cycle & \multirow{2}{*}{\multicolumn{3}{|c|}{ 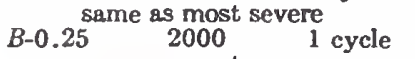 }} & 0.2 & \multirow{10}{*}{$\begin{array}{l}\text { oil burner } \\
\text { oil burner } \\
\text { water pump } \\
\text { oil burner } \\
\text { house next to } 12 \\
\text { lightning } \\
\text { rural area } \\
\text { surges } \\
\text { lightning stroke nearby } \\
\text { lightning storm }\end{array}$} \\
\hline & $B-0.25$ & 2500 & 1 cycle & & & & 0.4 & \\
\hline & $B-0.2$ & 1500 & 1 cycle & \multirow{2}{*}{\multicolumn{3}{|c|}{$\begin{array}{c}\text { same as most severe } \\
B-0.2 \quad 1400^{\circ} \text { cycle } \\
\text { too few to show typical }\end{array}$}} & 0.15 & \\
\hline & $\begin{array}{l}B-0.2 \\
B=0.1\end{array}$ & $\begin{array}{r}1700 \\
350\end{array}$ & $\begin{array}{l}1 \text { cycle } \\
1 \text { cycle }\end{array}$ & & & & $\begin{array}{l}0.06 \\
4 \text { total }\end{array}$ & \\
\hline & & 800 & $15 \mu \mathrm{s}$ & - & & - & 1 total & \\
\hline & $B-0.25$ & 800 & 3 cycles & $B-0.25$ & 600 & 3 cycles & 0.05 & \\
\hline & $B-0.15$ & 400 & $15 \mu \mathrm{s}$ & $B-0.13$ & 200 & $30 \mu \mathrm{s}$ & 0.4 & \\
\hline & $B-0.5$ & 5600 & 4 cycies & $B-0.3$ & 1000 & 1 cycle & & \\
\hline & $\underset{B=0}{C}$ & 2700 & $9 \mu \mathrm{s}$ & $C$ & 900 & $5 \mu \mathrm{s}$ & 0.1 & \\
\hline & 0.3 & 1100 & 1 cycle & & $\mathrm{shop}$ & ical & 4 total & \\
\hline & $B-0.5$ & 300 & 1 cycle & $B-0.5$ & 300 & 1 cycle & 0.5 & \\
\hline & $B-0.2$ & 1400 & 4 cycles & $B-0.2$ & 600 & 4 cycles & 0.07 & lightning storm \\
\hline
\end{tabular}

- $A$-long oscillation; $B$-damped osciliation; $C$-unidirectional. Number shows frequency in megahertz.

Results of the Recordings

\section{Oscilloscopes}

The first recording analysis revealed that some homes were subject to frequent surge voltages, some experienced only a few isolated surges, and others did not experience any surges in excess of the trigger level (300 to 400 volts). Furthermore, among those installations where surge voltages frequently occurred, the surges at some houses were relatively low (rarely in excess of 800 volts), while other houses had surges in the range of 1200 to 2500 volts. Rates of surge occurrence ranged from 0 (no surge in 1 to 2 weeks) to 0.5 per hour, with peak values from 300 volts (trigger threshold) to 5600 volts.

At the conclusion of the recording program, a total of 30 locations, including two overhead distribution poles had been monitored for a total of about 10000 hours. Table I shows a detailed analysis of the recordings at 21 locations. Three homes and six industrial locations did not produce any triggering with the threshold as low as 400 volts.

Further analysis of some recordings was made by deliberate switching of loads in the houses where frequent surges had been observed. In sorne cases, the operation of a specific device (e.g., oil burner, fluorescent lamp, pump motor, refrigerator, food mixer, etc.) was found to be the cause of the surges. In other cases, no amount of deliberate load switching could reproduce surges such as those recorded during unattended monitoring. The home owner was occasionally able to correlate surge recordings with lightning or power system disturbances.

A pattern emerged from all this information, showing two definite causes of surge voltages in the homes: load switching within the house and lightning storms.

Load Swilching: Load switching in the house occasionally produced transient surges; these affected only that particular house. For any particular house, these transient surges had a waveshape which was consistently repeated with variations in amplitude along the entire film recording. This probably resulted from a combination of the switch characteristics and the impedance of the house wiring system; the variations in amplitude were probably caused by variations of the switching angle and/or connected loads. In an industrial circuit, the same repetition of a particular pattern was also noted [1]. Typical waveshapes of the recorded surges are shown in Figs. 6-8.

. In one case, it was possible to install an oscilloscope in a house adjacent to that where repetitive surges up to 1700 volts were being recorded. The service drops were connected to the same pole, yet no surges occurring simultaneously were recorded in the second house.

Lightning: Surge voltages not associated with load switching within the house were associated with lightning storms. In some cases, the home owner was able to correlate the film advance counts with the storm. Although recorded during lightning storms at two different locations, the surges shown in Figs. 9 and 10 present the interesting characteristic of being oscillatory at a frequericy in the range of $300 \mathrm{kHz}$. The surge- shown in Fig. 9 was reconded at the overhend distribution line (oscilloscope mounted on the pole), while the surge of Fig. 10 was recorded at the service entrance in a home. The first exhibits far less damping than the second; this might be explained by the lower damping due to lower resistance of the system at the pole than at the end of a service drop. Both of these surges, as well as most of the other sunges recorded during lightning storms, exhibit this oscillatory characteristic at a frequency which is nearly constant for a particular locality. This constancy suggests that the oscillation of the system followed an excitation caused by the lightning stroke. A number of surges in the range of 800 to 1200 volts were observed during several storms. The maximum 


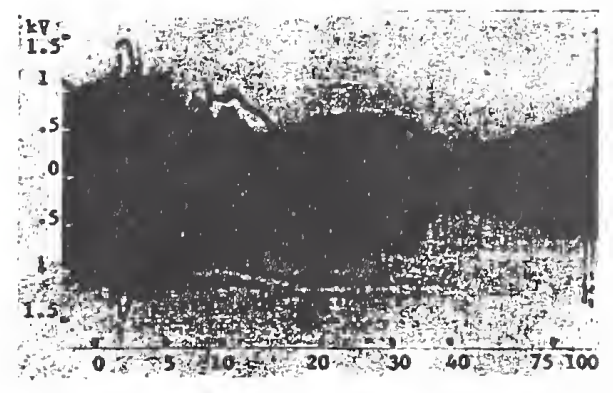

Fig. 6. Residential surges, 24-hour composite. Black band is \pm 170 -volt sweeps at hourly intervals.

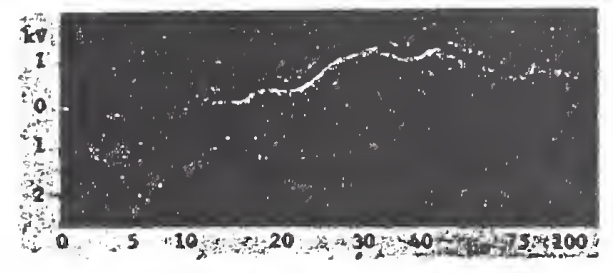

Fig. 7. Residential surge, oil burner ignition.

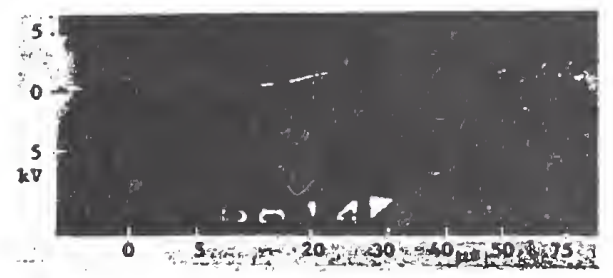

Fig. 8. Industrial circuit. Surge due to equipment maintenance; note digital timer record.

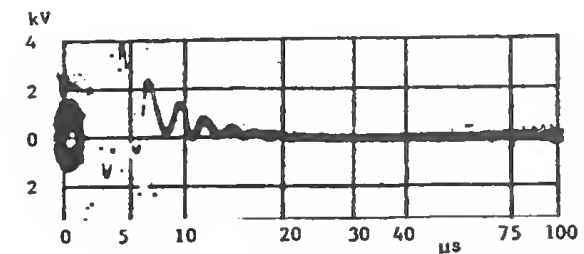

Fig. 9. Surge recorded on street pole in Charleston, N. C.

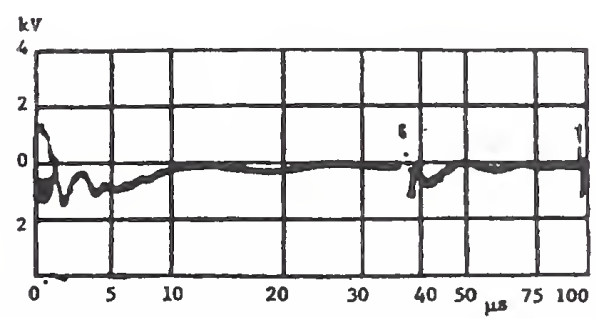

Fig. 10. Surge recorded at service entrance of Florida home.
TABLE II

Number of Houses with Repetitive

SURGE ACTVTTY ABOVE 1200 Volts

\begin{tabular}{lccc}
\hline \multicolumn{1}{c}{ Location } & $\begin{array}{c}\text { Number } \\
\text { of } \\
\text { Homes } \\
\text { Surveyed }\end{array}$ & $\begin{array}{c}\text { Recording } \\
\text { Period } \\
\text { (weeks) }\end{array}$ & $\begin{array}{c}\text { Houses } \\
\text { with } \\
\text { Repetitive } \\
\text { Surges }\end{array}$ \\
\hline Providence, R. I. & 4 & $2-6$ & none \\
Cleveland, Ohio & 28 & $2-4$ & none \\
Auburn, N. Y. & 12 & $2-3$ & none \\
Lynchburg, Va. & 3 & $2-3$ & none \\
Syracuse, N. Y. & 8 & $1-2$ & 1 \\
Chicago, Ill. & 23 & $1-6$ & none \\
Ashland, Mass. & 24 & $1-2$ & 1 \\
Holland, Mich. & 6 & $2-10$ & none \\
Louisvile, Ky. & 10 & $2-6$ & none \\
Somersworth, N. H. & 50 & $1-2$ & none \\
Plainville, Conn. & 5 & 10 & none \\
Asheboro, N. C. & 24 & $1-2$ & 3 \\
Fort Wayne, Ind. & 38 & $1-4$ & none \\
DeKalb, Ill. & 14 & $3-12$ & \\
\hline
\end{tabular}

TABLE III

Surge Counter Recordings Agove 1200 Volts (String, Summer, and Fald)

\begin{tabular}{lccc}
\hline \multicolumn{1}{c}{ Location } & $\begin{array}{c}\text { Number } \\
\text { of } \\
\text { Homes }\end{array}$ & $\begin{array}{c}\text { Total } \\
\text { Homes } \\
\times \text { Weeks }\end{array}$ & $\begin{array}{c}\text { Number } \\
\text { of } \\
\text { Surges }\end{array}$ \\
\hline Providence, $\mathbb{R}$. I. & 6 & 60 & 1 \\
Ashboro, N. C. & 13 & 85 & none \\
DeKalb, Ill. & 11 & 60 & 2 \\
Somersworth, N. H. & 3 & 48 & 1 \\
Chicagn, Ill. & 12 & 58 & none \\
Cleveland, Ohio & 8 & 106 & 1 \\
Decatur, Ill. & 12 & 72 & 2 \\
Holland, Mich. & 7 & 56 & none \\
Auburn, N. Y. & 3 & 70 & none \\
Springfield, Pa. & 1 & 24 & none \\
Ashland, Mass. & 6 & 72 & 1 \\
Pittsfield, Mass. & 3 & 60 & none \\
Plainville, Conn. & 3 & 60 & none \\
Lynchburg, Va. & 3 & 15 & 8 in \\
Total & 91 & 846 & \\
\hline
\end{tabular}

surge voltage recorded was 5600 volts; several other surges recorded during the same period were in excess of 4000 volts $x-3$

\section{Counters}

With the two causes of transients identified by the oscilloscope measurements, the surge counters were applied in two separate programs. First, during the winter months, the counters were installed in a large number of houses for periods of 1 or 2 weeks; the objective was to determine how many houses sustained repetitive surges. Second, during spring, summer, and fall, each counter was left at one or two locations for periods of 9 to 48 weeks; it was known from the first test that these homes were not subject to load switching surges. The objective was to determine the frequency and characteristics of externally generated surges, presumably caused by lightning.

The first period produced the data shown in Table II, and the results obtained during the second period are shown in Table III. 
Statistical Axalysis of the Rrcondivgs

Internally Generated Surges

The data in Tablc II show that 6 houses, or 2.4 percent, were subject to repetitive surges from among a total of 250 homes sampled. The true pcrcentage doubtless differs somewhat from 2.4 percent due to statistical variations.

However, one may be 90 -percent confident that the true percentage is between 1.0 and 4.7 percent." This band could be narrowed by taking additional samples. However, it should be noted that the precision is proportional to the square root of the sample size. Thus four times the number sampled, or 1000 homes, would be necessary to cut the size of the statistical error band by approximately one half. Since the preceding results refer to statistical variations only, they do not take into account possible biases due to such factors as restrictions in selecting members of the sample (principally engineers in a number of designated locations) or the time of year (winter months).

The probability of internally generated surges undoubtedly varies among economic groupings (i.e., the devices in use in homes probably vary with the economic status of the resident); however, devices found to generate surges (i.e., furnaces, refrigerators, etc.) exist in most homes.

\section{Externally Generated surges}

Results from the second testing period that was concerned with externally generated surges are shown in Tsble III. From 39 counters installed in a total of 91 homes in 14 localities, a total of 8 occurrences in 6 separate localities were observed during an equivalent exposure time of 846 weeks. A ninth occurrence was disregarded in this analysis because it occurred in the same home during the same storm. Of the two pairs of occurrences which took place in the same location, one pair occurred during the same storm and the second involved two occurrences at differcnt times.

Analyses could be conducted based on the following alternative assumptions.

1) Voltage surges above 1200 volts occur only during the period of the year that the counters were installed in the homes. Thus although the counters were in homes for only part of the year, the time involved (i.e., the summer months) was so chosen that no further surges would have been noted even if each counter had been run for 52 consecutive weeks. The average number of surges per year would then be estimated as $8 / 39$, or 0.205 , with a 90-percent confidence band of 0.102 to 0.370 .

2) Voltage surges occur randomly at a constant rate throughout the year. Thus a counter which was in use 9 weeks, on the average, would be subject to a third as many surges as a counter in use for a period of 27 weeks. Under this assumption, a total of 8 surges observed in a total time equivalent to 16 ycars (846 weeks) yield an estimated average of 0.5 surges per year, with a 90-percent confidence band of 0.25 to 0.90 .

Using these two extreme assumptions, a range could be established for the estimated number of surges per year. The preceding calculations refer only to single-polarity surges. If all surges are being considered, the given value must be multiplied by a value corresponding to the additional proportion of opposite

1 This result is obtained by the well-known method of setting confidence intervals for a percentage from a sample. Further detaila may be found in statistical texis $[3]-15]$. polarity surges above 1200 volts which do not also result in positive surges above 1200 volts. This multiplying factor is probably about 1.6 .

Lightning-induced surges are likely to affect more than one house when they occur. Local geographical and meteorological conditions are critical influences on these surges; however, these factors could not be considered in this preliminary investigation.

To relate the preceding data to risk of appliance failure, the given values must be modified by the probability that a surge above 1200 volts would cause failure of operating appliances. Failure effects would vary sith different appliances.

\section{Possible Further Analysis}

A more refined analysis to estimate the probability of voltage surges per lightning storm is possible if the geographical location of the homes, the occurrence rate of lightning storms during the testing period, and exact dates at which voltage surges occur is considered. The resulting values can then be used in conjunction with information given in [8], [9] to calculate the probability of a voltage surge in any specified geographic area and season. Such an analysis would remove the need for making one of the two alternative assumptions stated previously and lead to a single set of estimates. However, this would require more detailed data than could be collected in this program.

Finally, it is noted that if one has knowledge of the actual voltage surges, rather than merely the information concerning whether or not a surge above 1200 volts occurred, a more sensitive analysis is possible. In this case, for example, probability plotting and other techuiques based upon the statistical theory of extreme values [5], [7] night well be applicable.

\section{Efficts of Surgl: Voltages on Connheted Elictrical Di:vichs}

The surges which have been recorded in this program occurred during normal opreration of the household, with no knowledge of the connected load situation at the time of occurrence.

The question of energy involved in the surge is related to the impedance of the system since these recordings provide voltage data only. Surge impedance measurcnents of a house wiring cable indicate a valuc of 100 to 300 ohms for a typical branch circuit so that the surge impedancc at the service entrance could be in the order of 5 to $10 \mathrm{ohms}$. However, this low value exists only for the travel time (i.e., a fraction of a microsecond). Connected loads will have a lower impedance than that of the branch circuit. This value will be dependent upon frequency whenever inductive components are present. These loads will absorb part of the energy of the surges and thus lower their peak.

Devices such as motors and transformers have solid insulation and such a long history of successful application that their performance is not in question. Perhaps unusual failures can be explained by extreme values of surges as indicated by the data.

Defective wiring practices (e.g., pinched insulation, reduced air clearances in wall boxes, etc.) will cause air flashover with or without $60-\mathrm{Hz}$. power follow. In fact, one house was brought to our attention because of complaints of sparking in a light fixture. With the switch in the ground wire and the frame attached to a grounded pipe, flashover at 1700 volts was observed in correlation with the start of an oil burner in the house. This defective light fixture was acting as a voltage limiting gap for the house. 
Appliances containing semiconductors and directly exposed to the line transients may be more vulnerable. Actually, the $1200-$ volt threshold level was selected as the result of this consideration. It is interesting to note that, although a number of surges above 2000 volts were recorded by the oscilloscopes, the few surge counters calibrated for 2000 rather than 1200 volts did not produce any recording above 2000 volts.

An independent study of clock motor failures produced information on failure rates versus withstand levels. This study was very pertinent to the surge counter program since thousands of clocks are connected at all times to the power system. Over a period of 3 years, failure rates were correlated with the insulation level of the coils. A very significant 100 to 1 drop in failure rate resulted from an increase in withstand voltage from approximately 2000 to approximately 6000 volts. This shows that, even though no surges over 2000 volts were recorded by the 2000 -volt counters, surges in excess of 2000 volts do indeed occur.

\section{Indostral Circuit Case Histories}

The authors have been associated with a number of investigations where surges were suspected to be the cause of equipment problems. In the industrial environment, isolated cases tend to attract more attention than in residential circuits. The few case histories briefly summarized in this paper illustrate the types of problems likely to be encountered, where of ten surges are not in fact the cause of the problem, but where the presence of the test crew at the site precipitates a more thorough evaluation of the problem and sometimes reveals an unsuspected new fact.

On the occasion of these investigations, the surge counters were installed at the same time on the system and left for several weeks or months at the site whenever possible. So far, in over 15 locations, no surge over 1200 volts has been recorded on 240 or 480-volt buses ("mains"). On the other hand, severe surges have sometimes been recorded on the load.side of the switch. However, these load side surges are associated with the subsystem operation and can be controlled (if recognized) by the subsystem designer or operator, in contrast with the surges on the mains that affect all users in the house, building, or plant, and on which they have little control.

\section{Problem}

Occasional fashover in a 480 -volt distribution system at a steel welding shop.

Suspect: Switching surges associated with arc welding.

Inoestigation: Install surge recording oscilloscopes on the bus.

Result: No surges recorded.

Second Investigation: Power factor capacitors had been installed on the bus, but this fact had not been revealed by the initial discussions; their presence on the bus practically eliminated the passibility of surges on the bus. (Switching the whole bus system was tested and produced no surges in this case.) Final conclusion was contamination of the insulation in the polluted atmosphere.

\section{Problem}

Failures of a 480-volt saturable reactor in a motor control system.

Suspect: Switching surges associated with contactor operation.
Investigation: Record surges on site during delibcrate, controlled switching of the contactor.

Result: Contactor bouncing and restrike produce a number of steep front $(0.1 \mu \mathrm{s})$ surges on the winding, causing exccssive turn-to-turn stress.

\section{Problem}

Failures of rotor windings in 440 -volt induction motors in a crane system.

Suspect: Switching surges associated with contactor operation.

Investigation: Record surges with monitoring oscilloscope during deliberate, controlled switching of the contactor.

Resull: No excessive surges found; however the test crew notices during the on-site test that the overspeed protection of the motor control had been bypassed by the user.

\section{Problem}

Frequent blowing of fuses in a power factor correction capacitor bank.

Suspect: Switching surges.

Investigation: Record current in the fuse and system voltage during switching operation.

Result: Contactor bouncing produces a number of inrush current surges exceeding the rms capability of the fuse.

\section{Problem}

Failures of lamp ballasts in an industrial plant.

Suspect: Switching surges.

Investigation: Install monitoring oscilloscopes.

Results: No surges found in several weeks of monitoring, no further problem.

Conclusion: The best surge suppressor is a surge monitor.

\section{Conclusions}

1) Residential powèr circuits are subjected to surge voltages due to two distinct causes: load switching within the house, and externally generated surges that are most likely associated with lightning.

2) Internally generated surges caused by load switching are likely to be repetitive. They can generally be associated with a specific device, probably operating erratically or exciting some natural frequency of the wiring system. They are not related to lightning or disturbances from the utility. Peaks as high as 2500 volts have been observed. The best single statistical estimate is that 2.4 percent of households of the type sampled experience these internally generated repetitive surges in excess of 1200 volts. However, because of the statistical variability in the sample, this value may be as low as 1 percent or as high as 4.7 percent. Surges may be repeated several times a day.

3) The frequency of surges caused by lightning is not affected by household electrical devices but rather by local geographical and meteorological conditions. The limited data in this program reveal several lightning-caused surge occurrences above 3000 volts with one reaching 5600 volts.

4) Independent evidence shows that a significant number of surges above 2000 volts do occur periodically in residential power lines.

5) Industrial power circuits appear less likely to be subjected to surges on the mains. However, switching surges in subsystems can originate at the switch and affect the loads. 


\section{ACKNOWLEDGMENT}

The authors wish to thank the hundreds of individuals involved in the data collection and J. E. Lenz and-D. W. Spencer for the data on overhead distribution lines and industrial circuits.

\section{REFERENCES}

(1) D. W. Spencer, "Power line disturbances in a semiconductor component life test area," M.S. thesis, Cornell University, thaca, N. Y., 1968.

[2] J. E. Lenz, "Basic impulse insulation levels of mercury pp. 133-140, February 1964.
[3] W. J. Dixon and F. J. Massey, Jr., Introduction to Statistical Analysis. New York: McGraw-Huli, 1957

(4) A. H. Bowker and G. J. Liberman, Engineering Statistics. Englewood Cliffs, N. J.: Prentice-Hall, 1959. (5) G. J. Hahn and S. S. Shapiro, Slatistical Models in Engineering.

[6] K. A. Brownlee, Slatistical Theory and Method-Methodology in Science and Engineering. New York: Wiley, 1965

[7] E. J. Gumbel, Slatistics of Extremes. New York: Columbia University Press, 1958.

[8] IEEE Committee Report, "Bibliography on surge voltages in ac power circuits rated 600 volts and less," this issue, pp. 1056-1061.

[9] "Frequency of thundergtorms" in Electrical Transmission and Distribution Reference Book. Pittsburgh, Pa.: - Westinghouse Corp., 1942, chs. 12-18. 


\title{
Transient Overvoltages in Secondary Systems
}

\author{
François Martzloff \\ General Electric Company \\ Schenectady NY \\ f.martzloff@ieee.org
}

Reprint of unclassified General Electric Technical Information Series Report 81CRD121

\section{Significance:}

\section{Part 3 Recorded occurrences}

This unclassified (available to anyone) report was prepared to provide more details - until then contained in classified intemal reports or summarized in the two IEEE papers reprinted in this Part 3 - on the measurements made in the 1963-1967 period.

Only brief remarks are made in this report on possible suppression methods. Papers included in Part 6 (Tutorials), Part 7 (Mitigation techniques) and Part 8 (Coordination of cascades SPDs) provide information on protection techniques prior to and after the emergence and widespread use of metal-oxide varistors. 
Q 


\section{GENERAL (96) ELECTRIC}

\section{TECHNICAL INFORMATION SERIES}

General Electric Company

Corporate Research and Development Schenectady, New York

\begin{tabular}{|c|c|c|c|}
\hline \multirow{2}{*}{\multicolumn{2}{|c|}{ Martzloff, FD }} & \multirow{2}{*}{$\begin{array}{l}\text { SUвлEст } \\
\text { transient overvoltages }\end{array}$} & No. $81 \mathrm{CRD} 121$ \\
\hline & & & OATE May 1981 \\
\hline \multirow[t]{2}{*}{ TITLE } & \multirow{2}{*}{\multicolumn{2}{|c|}{$\begin{array}{l}\text { Transient Overvoltages } \\
\text { in Secondary Systems }\end{array}$}} & $\begin{array}{ll}\text { GE CLASS } & 1 \\
& 1\end{array}$ \\
\hline & & & 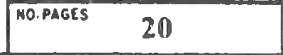 \\
\hline \multicolumn{3}{|c|}{ Automation and Control Laboratory } & $\begin{array}{l}\text { CORPORATE } \\
\text { RESEARCH ANO OEELOPMENT } \\
\text { SCHENECYAOY, N.Y. }\end{array}$ \\
\hline \multicolumn{4}{|c|}{$\begin{array}{l}\text { Transient overvoltages have been recorded in s } \\
\text { a period of four years, using recording oscilloscope } \\
\text { Conclusive evidence has been accumulated } \\
\text { surges at potentially damaging levels on } 120 \text { volt } \\
\text { Less frequent and less severe surges were found } \\
\text { industrial circuits. } \\
\text { This report is a summary of measurements m } \\
\text { and has been adapted from a } 1967 \text { internal re } \\
\text { bibliography is included. }\end{array}$} \\
\hline \multicolumn{4}{|l|}{ KEY WORDS } \\
\hline
\end{tabular}

INFORMATION PREPARED FOR

Additional Hard or Microfiche Copies Available From
Technical Information Exchange

Bldg. 81 Room A133, Schenectady, N.Y., 12345 
I. INTRODUCTION ............................. 1

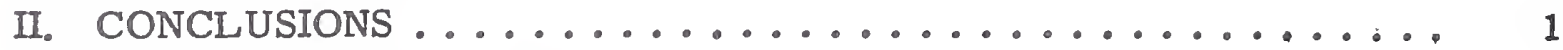

III. TRANSIENT MEASUREMENTS. ...................... 2

1. Oscilloscope Measurements .................. 2

2. Recordings with Surge Counters................ 3

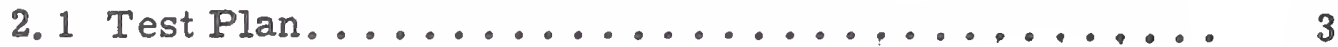

2. 2 Internally Generated Surges Investigation........ 4

2. 3 Externally Generated Surges ............... 5

2.3.1 Test Procedure ................... 5

2.3.2 Analysis of Voltage Surge Data and Some

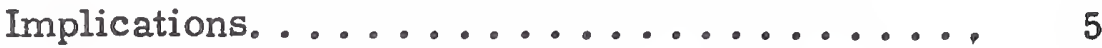

2. 4 Surge Suppression Experiment............. 7

IV. DISCUSSION OF THE TRANSIENT MEASUREMENTS . . . . . . 8

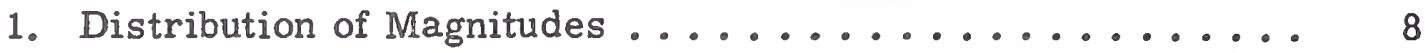

2. Distribution of Surge Generating Appliances. .......... 8

V. EFFECTS OF TRANSIENT OVERVOLTAGES ON

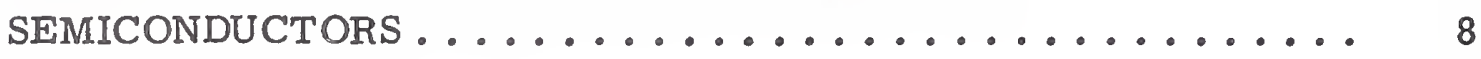

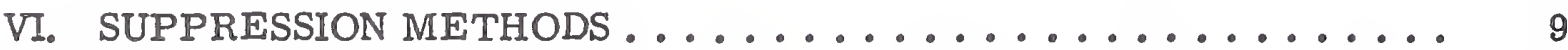

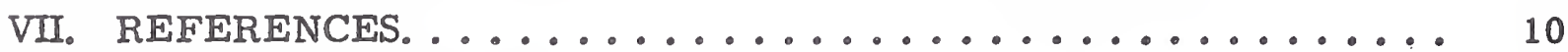

VIII. ACKNOWLEDGMENTS ......................... 10

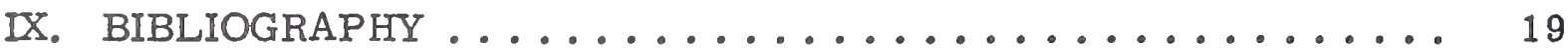




\title{
TRANSIENT OVERVOLTAGES IN SECONDARY SYSTEMS
}

\author{
F.D. Martzloff
}

\section{INTRODUCTION}

The increasing use of semiconductors in consumer and commercial applications has increased the risk of component failures due to transient overvoltages. This situation was recognized by the General Electric Company in the early sixties, and a program was initiated in 1962 for the purpose, among others, of recording transient overvoltages in low voltage systems in order to obtain factual information for an estimate of this risk.

Transients were recorded with oscilloscopes at a number of locations, in order to obtain data on representative waveshapes. These data were supplemented by a second project in which a large number of locations were monitored, using a fixed threshold surge counter especially developed for this program.

This report combines a presentation of the new results with a review of earlier data, in order to summarize present knowledge on the occurrence of transient overvoltages in secondary systems, with references to related areas of effects on semiconductors and transient suppression.

The cause of transients, the recording and the results are discussed, and conclusions based on statistical considerations are presented.

\section{CONCLUSIONS}

1. (a) Two major causes of transient overvoltages exist in residential secondary circuits: surges generated within the house by some device such as relays, contactors, mercury switches, etc., and surges fed in from the power service entrance, primarily lightning-induced.

(b) Commercial or industrial secondary systems are not subjected to the internally generated surges found in residential circuits, as they are "stiffer" than the latter.

2. Internally generated surges above 1200 volts are likely to occur at frequent intervals (one or more per day) in about 2. 5\% of all U.S. households.

3. Lightning-induced surges may occur at a rate of 0.1 to 0.9 per household and per year. Statistical evidence in this case is not as firm as in the case of the internally generated surges.

4. These surges can definitely cause failures in unprotected appliances, especially those containing semiconductors directly exposed to the line voltage.

5. A number of commercially available devices offer various amounts of protection at various costs. The need for built-in protection versus no protection, or protection external to the appliance at the owner's expense is a subject of 
discussion rather than a hard fact, since it involves variable parameters such as nuisance costs, prestige, duration of warranties, etc., in addition to the simple probability of failure considerations.

6. In spite of the impossibility of making definitive and all-encompassing conclusions, the author hopes that this report will increase the awareness of the occurrence of potentially damaging surge voltages on residential secondary circuits and promote a better anticipation of associated problems, which should ultimately increase the reliability of electronic products.

\section{TRANSIENT MEASUREMENTS IN SECONDARY CIRCUITS}

The measurement of transients was conducted over a period of three years; in 1962 and 1963 with oscilloscopes and in 1965 with surge counters designed and built in 1964. The objective of the oscilloscope measurements was to explore the characteristics (waveshape, magnitude) of surges, while the objective of the surge counter measurements was to establish a broad base for the statistical treatment of the results.

\section{Oscilloscope Measurements}

Table I shows an analysis of the surges recorded in terms of most severe, most frequent, and average number per hour at each of 23 locations.

Briefly, the oscilloscopes are modified Tektronix 515 oscilloscopes where a nonpolarized sweep trigger is provided by the transient overvoltage occurring in the circuit being monitored. A $35 \mathrm{~mm}$ camera, with no shutter, continuously monitors the blanked-out screen until a surge triggers the logarithmic sweep, at which time the transient is displayed on the screen and recorded on the film, and the motor-driven camera advances one frame.

This equipment, not without electronic and mechanical incidents, provided the means to monitor the voltage in homes and commercial buildings for a period of several days and thus establish patterns for transients recurring within this time period.

Typical waveshapes (corresponding to severe cases for amplitude but typical as far as shape is concerned) are shown in the oscillograms of Figs. 1, 2, and 3.

These oscilloscope measurements indicated that potentially damaging surges can occur very frequently in some households, while other households were relatively free from frequent disturbances. In some cases, the occurrence of frequent surges was correlated with the operation of an appliance such as a furnace, refrigerator, etc.

Measurements in larger secondary systems, i. e., commercial or industrial buildings, did not record frequent, internally generated surges similar to those found in households. Lower amplitude, less frequent occurrences were found, believed to be associated with switching surges or lightning-induced surges involving the complete local power grid. 


\section{Recordings with Surge Counters}

The oscilloscope measurements clearly established the dual source of surges in households, internal or external. In order to evaluate the possible effect of these on a national scale, a program of designing and building about 100 surge counters for installation in as many households as possible was initiated in 1964. These were installed late in 1964, and the readings monitored and analysed in 1965.

\section{1 Test Plan}

The recording of household surges was divided into two separate periods, each with distinct objectives. A first recording period held in winter and early spring covered short periods at each of a large number of residences, in order to investigate the proportion of households subjected to frequent internally generated surges.

A second recording period held in late spring and summer was organized at a reduced number of locations with longer periods, in order to investigate the frequency of lightning-induced surges at a number of specific locations.

A related program was also carried on at two locations whe re frequent internally generated surges were occurring, to demonstrate the effectiveness of the suppression obtainable from a small Thyrector stackconnected at the outlets.

The surge counter design has been described in a previously published paper. ${ }^{(1)}$ It provides cumulative counting of surges in excess of $1200 \mathrm{~V}$ or $2000 \mathrm{~V}$ for durations above $0.2 \mu \mathrm{s}$ when plugged into the $120 \mathrm{~V}$ outlet. *

Briefly, these recorders consist of a solenoid driven counter, with a storage capacitor discharged into the solenoid when triggered by a surge in excess of a set threshold, of one polarity. The threshold level of the counter was set at 1200 volts for three quarters and at 2000 volts for one quarter of the counters. The storage capacitor was held charged by a high resistance rectifier power supply drawing power from the line being monitored.

The choice of the 1200 volts and 2000 volts threshold levels was the result of data on the performance of semiconductors, especially diodes and SCR's under transient inverse voltage. It seems that appliance circuits containing diodes or $\mathrm{SCR}^{\prime} \mathrm{s}$ connected either directly or by low impedance components to the incoming 120 volt line may fail when the surges on this line exceed 1200 volts. On the other hand, a device with some degree of filtering, such as an input transformer, may require in the order of 2000 volts on the incoming line to pass on 1200 volts to the semiconductor(s) in the circuit.

*These recorders were designed specifically for installation in $120 \mathrm{~V}$ outlets and have a relatively low input impedance. Therefore, they may load down a circuit if, for instance, installed on the load side of a switch. 


\section{2 Internally Generated Surges Investigation}

This investigation was carried on with the cooperation of individual engineers at 18 departments, who installed the counters in their homes and returned the records to the author for compilation.

The recording period lasted from December 1964 to March 1965, corresponding to an expected minimum of lightning activity, and involved about 250 homes. Complete results are shown in Table II.

The results are summarized as follows:

1. Six homes in a total of 250 homes are subjected to repetitive surges in the 1200 to 2000 volt range, which are most likely limited to each of the six, i. e. not affecting adjacent houses. This represents a percentage of $2.4 \%$ of the houses surveyed where potentially damaging repetitive surges can occur. The statistical validity of this percentage is discussed below.

2. Three isolated random surges were recorded, associated with no known or suspected system disturbances.

The recording results were analyzed by G.J. Hahn, who prepared the following discussion.

Statistical Aspects of the Recording Results

The data indicated 6 voltage surge situations in a total of 250 homes sampled. This indicates a rate of $2.4 \%$ in the sample. One would expect that the true voltage surge rate in the population from which the random sample was taken would differ from the sample rate due to statistical variations. However, one may be $99 \%$ confident that the voltage surge rate in the population is between $0.6 \%$ and $6.3 \%$ and $95 \%$ confident that the true proportion is between $0.9 \%$ and 5. $3 \%$.

Assuming now that more homes had been surveyed, one can wonder how much narrower the band would be. In response to this question, if we had observed 12 voltage surges in 500 homes, the $99 \%$ confidence interval would have been $1.0 \%$ to $4.8 \%$ and the $95 \%$ interval would have been $1.2 \%$ to $4.2 \%$. Similarly, with 24 voltage surges in a sample of 1000 the $99 \%$ confidence interval would have been $1.3 \%$ to $4.0 \%$ and the $95 \%$ confidence interval would have been $1.5 \%$ to $3.6 \%$.

The above results refer to statistical variations only, and thus represent limits on the proportion of voltage surges in the population from which the sample was selected. Thus, they do not take into account any possible biases that might have been introduced by such factors as restrictions in selecting members of the sample (principally GE engineers in a number or designated locations) or the time of year (winter months).

The statistical calculations are based on the well-known method of establishing confidence intervals for the binomial parameter using the Poisson approximation. Further details may be found in statistical tests. $(2,3,4)$ 
Discussion of the Results

Within the limitation that the homes surveyed are assumed to be typical of all residential buildings where new solid state appliances are likely to be found, the $1 \%$ to $5 \%$ probability of repetitive surges is not negligible. That is, electronic appliances with a surge damage threshold below 1200 volts are likely to suffer in-warranty failures at a rate of $1 \%$ to $5 \%$ of sales.

While the small number (6) of locations detected in this survey may appear to be small and thus intuitively unconvincing, there is a $99 \%$ level of confidence that the actual rate is 0.6 to $6 \%$.*

Continuing the data accumulation by increasing the number of homes surveyed will of course increase the validity of the conclusions, but not by a very large amount; for instance, if the same percentage $(2.4 \%)$ had been obtained from a sample of 1000 homes (an effort 4 times as large as the one reported here) the range of probability for a $99 \%$ confidence level would be reduced to 1.3 to $4 \%$ compared to the present 0.6 to $6 \%$. This offers some incentive for increasing the number of homes surveyed, especially at locations where only a few homes were surveyed, but again, the return of better data are disproportionate to the effort that could be applied in one year.

\section{3 Externally Generated Surges}

\subsubsection{Test Procedure}

At the conclusion of the repetitive surge detection program the surge counters were installed for an extended period at a few homes for the duration of the summer, or at least for several weeks. Presumably, these homes were not subjected to repetitive internally generated surges (as confirmed by the recordings), so that only externally generated surges would be recorded. Except when a correlation was established with a lightning storm, there is no available information on the cause of the surge, so that lightning as well as system switching surges are included in this statistic.

Table III summarized the recording data. A complete discussion of the results by $G$. J. Hahn follows.

\subsubsection{Analysis of Voltage Surge Data and Some Implications}

A. Introduction

Data have been obtained on single polarity voltage surges above 1200 volts on 39 counters installed in a total of 91 homes in 15 localities for a total exposure time of 841 weeks. A total of 8 occurrences were observed during this

*The fact that the counters record only one polarity is immaterial in this case: the point was to detect those houses which had repetitive surges, not the number of surges at each location. (With random polarity in the surges, and some damping in oscillating surges, there is a factor of more than one and less than two to be applied to the number of surges indicated in order to obtain the total number of surges of both polarities.) 
period. From this information, it is desired to draw some conclusions concerning the expected number of such surges per home per year. The total time per counter ranged from 9 weeks to 48 weeks, with the average time per device being 22 weeks. The program was so planned that all devices would be in homes during the summer months, that is, the period during which lightning storms, and thus voltage surges, are most likely to occur.

\section{B. Results of Analysis}

Analyses were conducted based on the following two alternate assumptions:

1. Voltage surges above 1200 volts occur only during the period of year that the counters were installed in the homes. Thus, although the counters were in homes only for parts of the year, the time involved was so chosen (namely. the summer months) that no further surges would have been noted even if eaih counter had been run for 52 consecutive weeks.

2. Voltage surges occur completely randomly throughout the year. Thus a counter that was in use only 9 weeks would on the average have only a third as many observed surges as a counter in use for a period of 27 weeks.

The above two assumptions clearly represent extremes. Thus, although neither is very realistic, results based on such assumptions permit one io obtain bounds within which one can reasonably expect the true expected number of surges to lie. The results are as follows:

Under assumption 1: A total of 8 surges occurred on 39 counters, thus the best estimate of the expected number of surges per home per year is $8 / 39$ or 0.205 . This estimate is subject to statistical error, since only a limited number of counters were involved. However, from the appropriate statistical calculations $(3,4)$ we can state with $90 \%$ confidence that the average number of surges is between 0.102 per year and 0.370 per year.

Under assumption 2: A total of 8 surges were observed in a total of 16.173 years of testing. Thus the expected number of surges per year is $8 / 16.173$ or 0.495 . The $90 \%$ confidence interval on this estimate is 0.246 surges per year to 0.892 surges per year.

The above calculations refer only to single polarity surges. If one is irterested in all surges, the given values need be multiplied by a value corresponding to the additional proportion of opposite polarity surges above 1200 volts, which do not also result in positive surges above 1200 volts. This multiplying factor is probably in the order of 1.6, accounting for the damping between the first and second $1 / 2$ cycle of an oscillating surge.

Some additional assumptions are also involved in the analysis. Although these assumptions are not strictly met, they are probably not sufficiently incorrect to critically affect the validity of the analysis. These assumptions are:

1. The homes were selected strictly at random.

2. The voltage surge rate is the same from one home to the next.

3. All voltage surges of one polarity during the period of installation were recorded. 
If it is desired to relate the above data to probability of appliance failure, one must clearly multiply the given values by the probability that a surge above 1200 volts would lead to appliance failure assuming the appliance is in use during the time of the lightning storm. (This would clearly be different for a toaster from what it would be for a radio.) If one is interested only in failures during the warranty period an additional adjustment would be required.

C. Possible Further Analysis

A more refined analysis is possible by taking into account the geographical location of the homes, the occurrence rate of the lightning storms during the period under examination in these homes, and the exact dates at which the voltage surges occurred in order to obtain a measure of the probability of a voltage surge per lightning storm. The resulting values can then be used in conjunction with the information given in Ref. 4 to calculate a probability of voltage surge in any specified geographic area during a particular part of the year. Such an analysis would remove the need for making one of the two alternate assumptions stated above and lead to a single set of estimates. How ever, this would require more detailed data than could be collected in this program.

\section{4 Surge Suppression Experiment}

At two of the locations where repetitive surges were found, a prototype surge suppressor was installed at the receptacle into which the counter was plugged. This suppressor consists of a Thyrector packaged for plug-in installation at receptacles, and is currently under evaluation by the Semiconductor Products Department for the home market. The counters were installed in alternating periods with and without suppressors, and the recording rates compared. A counter was especially modified to record surges over $60 \mathrm{a}$ volts in order to roughly evaluate the effectiveness of the suppressor in reducing the surges of 1200 volts or more occurring without suppression.

Location No. 1 - (Home in Ft. Wayne, Ind., refrigerator identified as source)

Dates

$\underline{(1965)}$

$3 / 11$ to $8 / 10$

$8 / 10$ to $9 / 16$

$9 / 16$ to $11 / 12$

$10 / 29$ to $11 / 12$ No Suppressor

$11 / 12$ to $11 / 26$ Suppressor

(1966)

$1 / 24$ to $1 / 31$

No Suppressor

$1 / 31$ to $2 / 8$

No Suppressor
No. of Surges Above Days 1200 Volts Recorded

7 252

107

Unknown

0

Unknown 3

No. of Surges Above 600 Volts Recorded

Unknown

Unknown

Unknown

11

0

Unknown 12 
Location No. 2 - (Home in Newton, Mass., oil burner identified as source)

\begin{tabular}{|c|c|c|c|}
\hline $\begin{array}{l}\text { Dates } \\
(1966) \\
\end{array}$ & Conditions & Days & $\begin{array}{c}\text { No. of Surges Above } \\
600 \text { Volts Recorded } \\
\end{array}$ \\
\hline $5 / 10$ to $5 / 17$ & No Suppressor & 7 & 8 \\
\hline $5 / 17$ to $5 / 24$ & Suppressor in & 7 & 0 \\
\hline $5 / 24$ to $5 / 31$ & No Suppressor & 7 & 0 \\
\hline
\end{tabular}

There were eight recordings which occurred in the first seven days without the use of the suppressor. On or about May 18, the warm weather really set in, and it is doubtful that the burner went on after that, which explains the absence of surges in the second period without the suppressor.

The results of the experiment at both locations are quite conclusive for the effectiveness of the Thyrector in suppressing the internally generated surges from a potentially damaging value in excess of 1200 volts to an innocuous value of less than 600 volts.

\section{DISCUSSION OF THE TRANSIENT MEASUREMENTS}

1. Distribution of Magnitudes

The histogram, Fig. 4, shows the distribution as recorded by the oscilloscopes; the low frequency shown below 500 volts is due to a deliberate cutoff in the sensitivity of the oscilloscopes (in order to limit the number of oscilloscope triggers). This is to be compared with the distribution reported in Ref. 5 and reproduced on Fig. 5, where the frequency increased by three decades with a threshold lowered from 400 to 50 volts.

The highest internally generated surge was about 2800 volts, with the majority of the surges in the 1000 to 1500 volts range at locations where these were occurring frequently.

Lightning surges were found as high as $5.6 \mathrm{kV}$; however, the small total number of surges recorded makes it difficult to present definitive conclusions.

\section{Distribution of Surge Generating Appliances}

The 2. 4\% estimate derived from the surge counter survey has already been discussed from the statistical point of view in Section III. The real problem, however, is that of trading off minimum manufacturing cost (and, therefore, a calculated risk of failure) against complaint expenses. This is certainly the prerogative and responsibility of individual departments, and not that of the

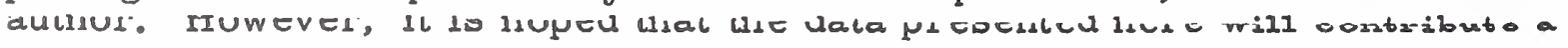
factual input to this trade-off. 


\section{EFFECTS OF TRANSIENT OVERVOLTAGES ON SEMICONDUCTORS}

Previous investigations have indicated some significant factors to be considered when semiconductors are exposed to transient voltages in the reverse direction (forward direction generally results at worst in one-half cycle forward conduction into the load, which is not catastrophic with the AC power sources):

1. Failure modes, nonavalanche rectifiers

a. The nonavalanche (or at least the non-"controlled avalanche") rectifiers fail by breakdown of the insulation surface at the edges of the wafer. This breakdown is a characteristic of the semiconductor geometry and materials, and has no direct relation to the PRV rating of the device.

b. Application of a reverse voltage transient during forward conduction produces failure at levels substantially lower than when the transient is applied during blocking.

c. No significant difference was found between the failure level for single vs multiple (several thousands) application of overvoltages.

d. For steep pulse fronts (shorter than $1 \mathrm{MS}$ ), the failure level increases with rate of rise.

e. Aging of semiconductors by storage at high temperature does not affect the failure levels.

f. Energy level of the transient, i.e., duration for a specified voltage appearing across a specified impedance, does not affect the fail ure level.

2. Failure Modes--Controlled Avalanche Rectifiers

The energy dissipating characteristic of the device can hold the transient voltage level below surface breakdown level, however, long pulses may heat the material so much as to produce:

bulk failures by hot spot

an increase in the voltage across the device such that surface breakdown voltage is reached

Therefore, care and not indiscriminate selection is required in applying avalanche characteristics for circuits exposed to "long" transients.

\section{SUPPRESSION METHODS}

Transient suppression can be accomplished either at the source or at the sensitive load. System designers may be able to specify the suppression at the source, but the majority of users will have to protect their appliances at the load, or at some location of their system. For instance, in a home, the suppressor may be installed at the service entrance or at an outlet. The service entrance location is optimum for protection against incoming surges, while the 
outlet location is optimum for protection of a single appliance at that outlet. Nevertheless, a substantial protection is obtained throughout the house if a suppressor is installed at one outlet only.

While protective devices are fairly well known, their application can lead to some pitfalls. (6) For large and expensive equipment, it seems more acceptable to provide some investment in surge protection, which can then be specified by technical performance rather than cost. On the other hand, mass market devices are subject to economic criteria which make the selection of a surge protector a more delicate trade-off.

\section{REFERENCES}

1. Martzloff, F.D. and Hahn, G. J., "Surge Voltage in Residential and and Industrial Power Circuits, "IEEE Transactions on Power Apparatus and Systems, Vol. PAS-89, July/August 1970, pp. 1049-1056.

2. Dixon, W.J. and Massey, F.J., Jr., Introduction to Statistical Analysis, McGraw-Hill Book Company, Inc., New York, 1957.

3. Bowker, A.H. and Lieberman, G.J., Engineering Statistics, PrenticeHall, Inc., Englewood Cliffs, New Jersey, 1959.

4. Brownlee, K. A., Statistical Theory and Methodology in Science and Engineering, John Wiley \& Sons, Inc., New York, N. Y.

5. Bull, J.H. and Nethercot, W., "The Frequency of Occurrence and the Magnitude of Short Duration Transients in Low Voltage Mains, "The Radio and Electronic Engineer, September 1964.

6. Martzloff, F.D., "Coordination of Surge Protectors in Low-Voltage AC Power Circuits, "IEEE Transactions on Power Apparatus and Systems, Vol. PAS-99, January/February 1980, pp. 129-133.

\section{ACKNOWLEDGMENTS}

The author wishes to acknowledge the support received from the departments involved in the pooled program, involving financial support from the departmente as well as the cooperation from the hundreds of individuals who took the surge counters home and returned the records to the author.

The contribution of G.J.Hahn, Statistician, Research and Development Center, in interpreting and discussing the statistical aspects of the results is acknowledged. 
TABLE I

DETAILED ANALYSIS OE RECORDED SURGES

\begin{tabular}{|c|c|c|c|c|c|c|c|c|c|c|c|}
\hline \multirow[b]{2}{*}{ LOCATION } & \multicolumn{4}{|c|}{ MOST SEVERE SURGE } & \multicolumn{4}{|c|}{ MOST FREQUENT SURGE } & \multirow{2}{*}{$\begin{array}{l}\text { AVERAGE } \\
\text { NUMBER } \\
\text { OF SURGES } \\
\text { PER HOOR }\end{array}$} & \multirow[b]{2}{*}{$\begin{array}{l}\text { DURATION OF } \\
\text { OBSERVATION } \\
\text { HOURS }\end{array}$} & \multirow[b]{2}{*}{ REMARKS } \\
\hline & *TYPE & $\begin{array}{l}\text { CREST } \\
\text { VOLTS } \\
\end{array}$ & $\begin{array}{c}\text { PK-TO-PK } \\
\text { VOLTS }\end{array}$ & $\begin{array}{l}\text { DURATION } \\
\text { IIS OR } \\
\text { CYCLES } \\
\end{array}$ & *TYPE & $\begin{array}{l}\text { CREST } \\
\text { VOLTS }\end{array}$ & $\begin{array}{l}\text { PK-TO-PK } \\
\text { VOLTS }\end{array}$ & $\begin{array}{l}\text { PURATION } \\
\text { CYCLES } \\
\text { CYCLE }\end{array}$ & & & \\
\hline D.P. Shattuck & A-1.5 & 700 & 1400 & $10 \mu \mathrm{s}$ & $A-1.5$ & 300 & 600 & $10 \mu \mathrm{s}$ & 0.07 & 450 & \\
\hline K.N. Mathes & $A-2.0$ & 750 & 1440 & $20 \mu \mathrm{s}$ & $A-2.0$ & 500 & 1000 & $20 \mu \mathrm{s}$ & 0.14 & 250 & $\begin{array}{c}\text { Fluorescent } \\
\text { light } \\
\text { switchtng } \\
\end{array}$ \\
\hline P. Chowdhuri & $B-0.5$ & 600 & 1000 & 1 cycle & $B-0.5$ & 300 & 500 & 1 cycle & 0.05 & 500 & \\
\hline P.H. Bosworth & $B-0.5$ & 400 & 750 & 2 cycles & $B-0.5$ & 300 & 500 & 2 cycles & 0.2 & 300 & \\
\hline R.L. Maul & c & 640 & - & $5 \mu s$ & \multicolumn{4}{|c|}{$\begin{array}{l}\text { Two few surges to show } \\
\text { cypical value. }\end{array}$} & $\left|\begin{array}{c}10 \text { surges } \\
\operatorname{cotal} 1\end{array}\right|$ & 500 & \\
\hline R.G. Hoft & $B-0.3$ & 400 & 600 & I cycle & $B-0.3$ & 250 & 400 & 1 cycle & 0.01 & 300 & \\
\hline P.A. Fessler & $B-1$ & 1800 & 3400 & 1 cycle & $B-1.0$ & 800 & 1400 & 1 cycle & 0.03 & 1000 & $\begin{array}{l}\text { Probably all } \\
\text { during } 11 \text { ght- } \\
\text { ning gtorm. }\end{array}$ \\
\hline $\begin{array}{l}\text { Ellis } \\
\text { Hospital }\end{array}$ & c & 1200 & - & $10 \mu \mathrm{s}$ & B- 0.5 & 300 & 600 & 4 cycles & 0.1 & 900 & \\
\hline $\begin{array}{l}\text { St. Clare's } \\
\text { Hosptital }\end{array}$ & c & 2700 & - & $9 \mu s$ & C & 900 & - & $5 \mu \mathrm{s}$ & 0.1 & 1000 & $\begin{array}{l}\text { All during } \\
\text { lightning } \\
\text { storw. }\end{array}$ \\
\hline $\begin{array}{l}\text { Barney's } \\
\text { Dept. Store }\end{array}$ & $B-0.3$ & 1100 & 1400 & I cycle & \multicolumn{4}{|c|}{$\begin{array}{c}\text { Two few surges to show } \\
\text { typical value. }\end{array}$} & $\begin{array}{c}4 \text { surges } \\
\text { tots } 1\end{array}$ & 700 & \\
\hline L \& M Motel & $B-0.5$ & 300 & 500 & 1 cycle & $B-0.5$ & 300 & 500 & 1 cycle & 0.5 & 600 & \\
\hline H.R. Sellers & $B-0.25$ & 1500 & 2000 & $\mid \begin{array}{r}4 \mu 8 \\
1 \text { cycle }\end{array}$ & \multicolumn{4}{|c|}{ same as most severe } & 0.2 & 100 & $\begin{array}{l}\text { Probably } \\
\text { oll burner. }\end{array}$ \\
\hline พ.ห. Bellamy & B- 0.25 & 2500 & 3500 & $\mid \begin{array}{l}\quad \begin{array}{l}4 \mu 8 \\
\text { cycle }\end{array} \\
1 \text { cy }\end{array}$ & $B-0.25$ & 2000 & 3000 & $1 \begin{array}{r}4 \mu s \\
\text { cycle }\end{array}$ & 0.4 & 125 & oll burner \\
\hline W.J. Stoiley & $B-0.2$ & 1500 & 2000 & $\begin{array}{r}5 \mu s \\
1 \text { cycle }\end{array}$ & \multicolumn{4}{|c|}{ same as most severe } & 0.15 & 150 & $\begin{array}{l}\text { Probably } \\
\text { water pump }\end{array}$ \\
\hline J.R. Ross & B- 0.2 & 1700 & 2000 & $\begin{array}{r}5 \mu s \\
1 \text { cycle }\end{array}$ & $B-0.2$ & 1400 & 1700 & $\begin{array}{r}5 \mu s \\
1 \text { cycle }\end{array}$ & 0.06 & 500 & oll burner \\
\hline F.D. Martzloff & $B=0.1$ & 350 & 400 & $\begin{array}{r}5 \mu s \\
1 \text { cycle }\end{array}$ & \multicolumn{4}{|c|}{ too few to show typical } & $\mid \begin{array}{l}4 \text { surges } \\
\text { total }\end{array}$ & 150 & $\begin{array}{l}\text { Houre adjacent } \\
\text { to J.R. Ross }\end{array}$ \\
\hline P.A. AbetcI & c & 800 & - & $15 \mu s$ & - & - & - & - & $\begin{array}{rr}1 & \text { surge } \\
& \text { total }\end{array}$ & 200 & $\begin{array}{l}\text { Probably } \\
\text { 11ghtning }\end{array}$ \\
\hline D.G. Gruber & $8-0.25$ & 800 & 1000 & $\begin{array}{l}12 \mu s \\
3 \text { cycles }\end{array}$ & $B-0.25$ & 600 & 800 & \begin{tabular}{c|}
$12 \mu s$ \\
3 cycles
\end{tabular} & 0.05 & 1500 & Rural area \\
\hline X.H. Hof fmann & $B-0.15$ & 400 & 600 & $15 \mu$ & $B-0.13$ & 200 & 350 & $30 \mu \mathrm{s}$ & 0.4 & 130 & $\begin{array}{l}\text { includes low } \\
\text { anplites low } \\
\text { surges }\end{array}$ \\
\hline Deer Park & B. 0.5 & 5600 & 10000 & $4 \begin{array}{c}2 \mu s \\
\text { cycles }\end{array}$ & B- 0.3 & 1000 & 1500 & 1 cycle & 0.1 & 400 & $\begin{array}{l}\text { Lightning } \\
\text { stroke within } \\
\text { loo0 feet. }\end{array}$ \\
\hline Palmetco & $B-0.2$ & 1400 & 200 & 4 cycles & B- 0.2 & 600 & 1000 & $\mid \begin{array}{c}10 \mu \mathrm{us} \\
4 \text { cycles }\end{array}$ & 0.07 & 100 & Lightning \\
\hline \#2 MG System & c & 600 & - & $50 \mu \mathrm{s}$ & c & 300 & - & $50 \mu s$ & 0.15 & 150 & $\begin{array}{l}\text { 1solated } \\
\text { system }\end{array}$ \\
\hline $\begin{array}{l}480 \text { volt } \\
\text { feed system }\end{array}$ & B- 1.2 & 300 & 400 & $\begin{array}{l}.4 \mu \mathrm{us} \\
\frac{1}{2} \text { cycle }\end{array}$ & \multicolumn{4}{|c|}{ too few to show typical } & 0.1 & 100 & \\
\hline
\end{tabular}

No surges above 300 volts were recorded at the 7 following locations: GE Bldg. 37, roof-top house, alr conditioning bus, 440 volts bus, 550 volts bus; Hotel Van Curler; MG system 1; B. Murphy.

\#TYP: A - Long Oscillation; B - Damped Oscillation; C - Unidirectional - NUMBER SHOWS FREQUENCY IN MEGACYCLES 
TABLE II

SUMMARY OF SURGE COUNTER RECORDINGS IN HOMES - DECEMBER 1964 TO MARCH 1965

\begin{tabular}{|c|c|c|c|c|}
\hline $\begin{array}{l}\text { Location } \\
\text { (Approximate) }\end{array}$ & $\begin{array}{l}\text { Number } \\
\text { of homes } \\
\text { surveyed }\end{array}$ & $\begin{array}{l}\text { Recording } \\
\text { Period } \\
\text { (weeks) }\end{array}$ & $\begin{array}{l}\text { Number of } \\
\text { Houses with } \\
\text { Surge Activity }\end{array}$ & Detalled Information \\
\hline Providence, R.I. & 4 & $2-6$ & None & \\
\hline \multicolumn{5}{|l|}{ cleveland, Ohio } \\
\hline Lg. Lamp data & 14 & $2-4$ & 1 & $\begin{array}{l}1 \text { surge over } 1200 \text { - community-wide power } \\
\text { failure. }\end{array}$ \\
\hline M1n. Lamp data & 14 & $2-4$ & None & \\
\hline Auburn, $N_{0} Y$. & 12 & $2-3$ & None & \\
\hline Lynchburg, Va. & 3 & $2-3$ & None & \\
\hline Syracuse, N.Y. & 8 & $1-2$ & 1 & $\begin{array}{l}1200 \text { to } 2000 \text { surge, } 1 \text { polarity only, } 64 \text { counts } \\
\text { in } 10 \text { days, probably refrigerator. }\end{array}$ \\
\hline Chicago, Ill. & 23 & $1-6$ & None & \\
\hline Ashland, Mass. & 24 & $1-2$ & 2 & $\begin{array}{l}1 \text { surge over } 1200 \mathrm{v} \text { in a } 20 \text { day period, no } \\
\text { known system disturbance. } \\
6 \text { surges over } 1200 \text { in a } 12 \text { day period, no } \\
\text { known system disturbance. }\end{array}$ \\
\hline Holland, Mich. & 6 & $2-10$ & None & \\
\hline Louisville, Ky. & 10 & $2-6$ & 1 & $\begin{array}{l}1 \text { surge over } 1200 \mathrm{~V}-1 \text { lghtning stroke which } \\
\text { burned out TV set and UHF converter in the } \\
\text { home. }\end{array}$ \\
\hline $\begin{array}{l}\text { Somersworth, N.H. } \\
\text { (and nearby N.H. } \\
\text { Malne locations) }\end{array}$ & 50 & $1-2$ & 1 & $\begin{array}{l}\text { Surges between } 1200 \text { and } 2000 \text { volts, some } \\
\text { probably close to } 1200 \text { as two counters at } \\
\text { same location had difference in count. } \\
\text { Councer gimultaneously installed in adjacent } \\
\text { houge did not record any surges. Most } \\
\text { frequent count at night in cold weacher; } \\
\text { probable cause } 18 \text { oil burner. }\end{array}$ \\
\hline Pla Inville, Conn. & 5 & 10 & None & DAD \& CPDD data. \\
\hline Asheboro, N.C. & 24 & $1-2$ & None & \\
\hline $\begin{array}{l}\text { Ft. Wayne, Ind. } \\
\text { Spey. Transf. data } \\
\text { Laboratory data }\end{array}$ & $\begin{array}{l}23 \\
15\end{array}$ & $\begin{array}{l}1-2 \\
2-4\end{array}$ & $\begin{array}{c}\text { None } \\
3\end{array}$ & 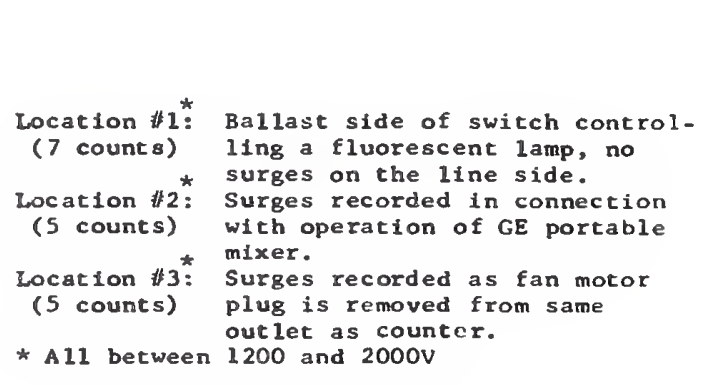 \\
\hline Deka 1b, Ill. & $\begin{array}{r}10 \\
4 \\
\end{array}$ & $\begin{array}{r}3 \\
12 \\
\end{array}$ & None & \\
\hline Pitcsfield & 26 & $1-2$ & 1 & One surge with no known system disturbance \\
\hline
\end{tabular}


TABLE III

Summary of Surge Counter Recordings in Homes April - December 1965

\begin{tabular}{|c|c|c|c|c|}
\hline Location & $\begin{array}{l}\text { No. of } \\
\text { Homes }\end{array}$ & $\begin{array}{c}\text { Total } \\
\text { Home } x \text { Week }\end{array}$ & $\begin{array}{l}\text { No. Surges } \\
\text { Over } 1200 \mathrm{~V}\end{array}$ & Remarks \\
\hline Providence, R.I. & 6 & 60 & 1 In 1 Home & $\begin{array}{l}\text { Frequent power interruption } \\
\text { at home where surge was } \\
\text { recorded. }\end{array}$ \\
\hline Ashboro, N.C. & 13 & 85 & 0 & Several storms in area. \\
\hline De Kalb, Ill. & 11 & 60 & $\begin{array}{l}1 \text { in Home 非1 } \\
1 \text { in Home 非 }\end{array}$ & $\begin{array}{l}\text { Violent storm. } \\
\text { No known disturbance. }\end{array}$ \\
\hline Somersworth, N.H. & 3 & 48 & 1 in 1 Home & $\begin{array}{l}\text { Owner installed arrester } \\
\text { after the first count. }\end{array}$ \\
\hline Chicago, Ill. & 12 & 58 & 0 & \\
\hline Cleveland, Ohio & 5 & 66 & 1 In 1 Home & During power outage. \\
\hline Decatur, Ill. & 12 & 72 & $\begin{array}{l}1 \text { in Home 非 } 1 \\
2 \text { in Home 非 } 3\end{array}$ & $\begin{array}{l}\text { During storm. } \\
\text { During same storm. }\end{array}$ \\
\hline Cleveland, Ohio & 3 & 40 & 0 & \\
\hline Holland, Mich. & 7 & 56 & 0 & \\
\hline Auburn, N.Y. & 3 & 70 & 0 & \\
\hline Springfield, $\mathrm{Pa}$. & 1 & 24 & 0 & \\
\hline Ashland, Mass. & 6 & 72 & 0 & \\
\hline Pittsfield, Mass & 3 & 60 & 1 in 1 Home & $\begin{array}{l}2000 \text { volt counter at same } \\
\text { outlet did not register } \\
\text { (during storm). }\end{array}$ \\
\hline Plainsville, Conn. & 3 & 60 & 0 & \\
\hline Lynchburg, Va. & 3 & 15 & 0 & \\
\hline Total & 91 & 846 & 9 in 8 Homes & \\
\hline
\end{tabular}




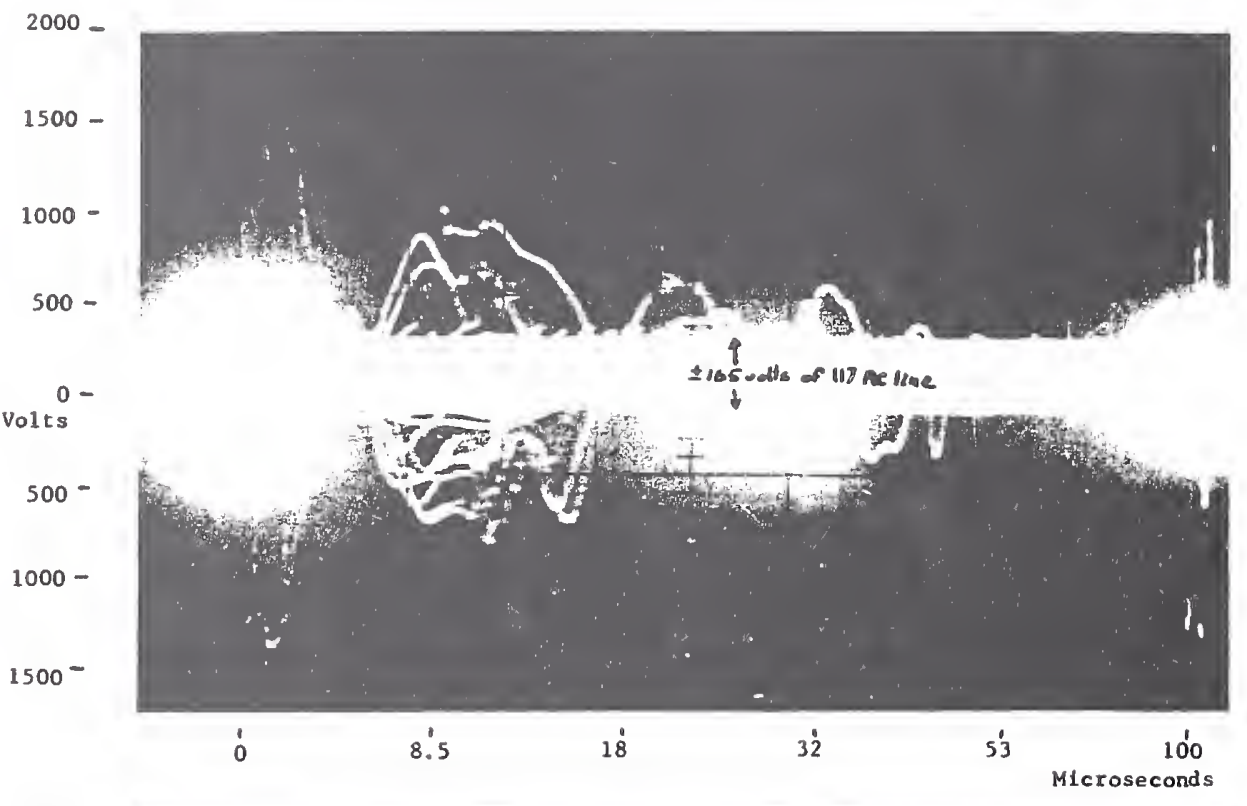

Composite record showing surges for a 24-hour period.

Oscilloscope is triggered for each surge, plus once every hour, resulting in \pm 165 volt band of steadystate $60 \mathrm{cps}$ voltage.

Recordings above $1800 \mathrm{~V}$ are blanked out by oscilloscope.
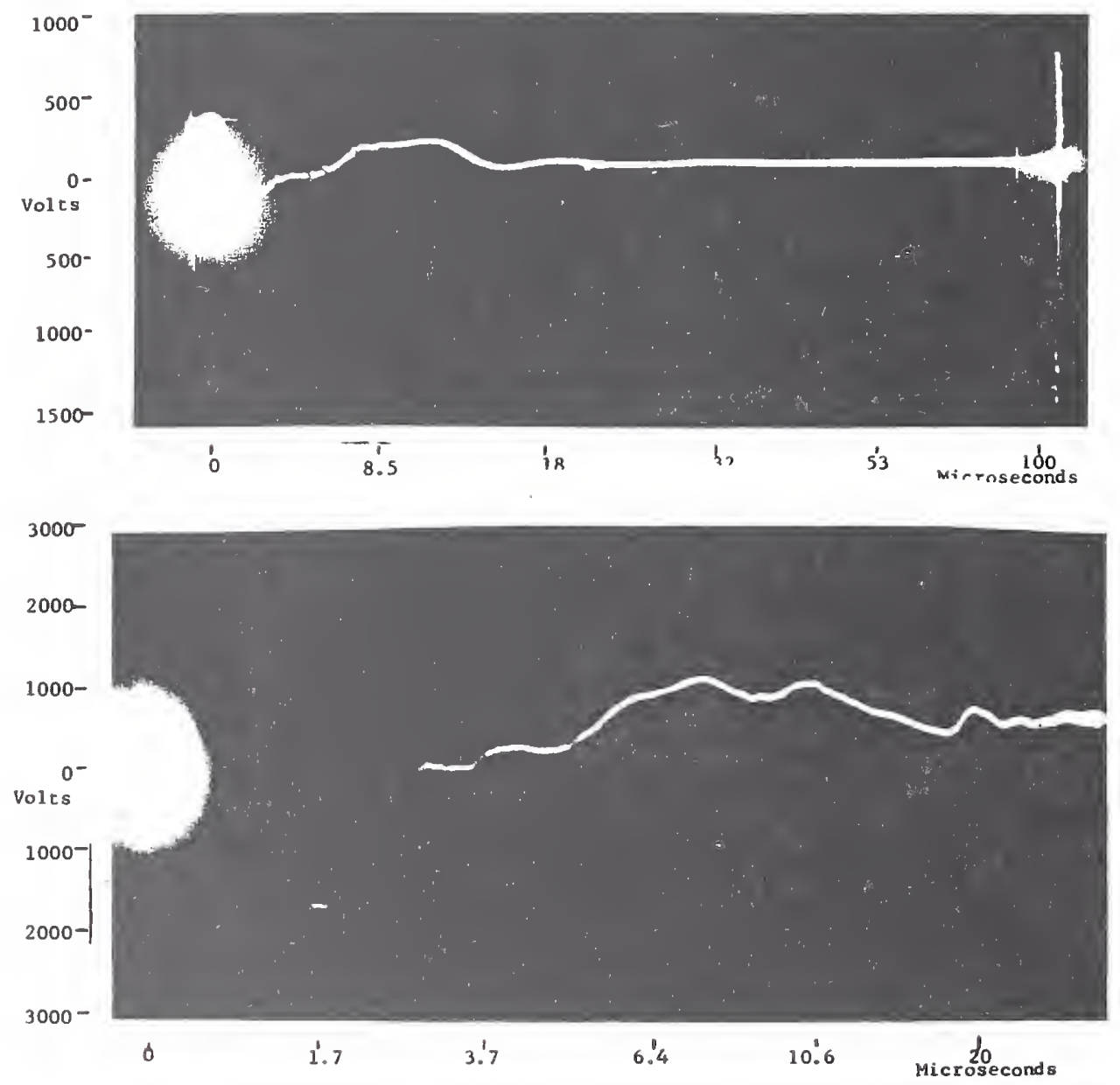

Maximum recorded surge, at 2600 volts.

In a 5-day period surges of chis wave shape were recorded as follows :

Number Voltage Range of surges

$\begin{gathered}1 \\ 1\end{gathered} 2500=3000$

$\begin{array}{ll}1 & 2000=2500 \\ 18 & 1500-2000 \\ 13 & 1000=1500\end{array}$

Cause: H.V. transformer for oll furnace interrupted

Fig. 1. Typical Surges Recorded at Stewart Manor, L. I., N. Y., February 16-21, 1963. 


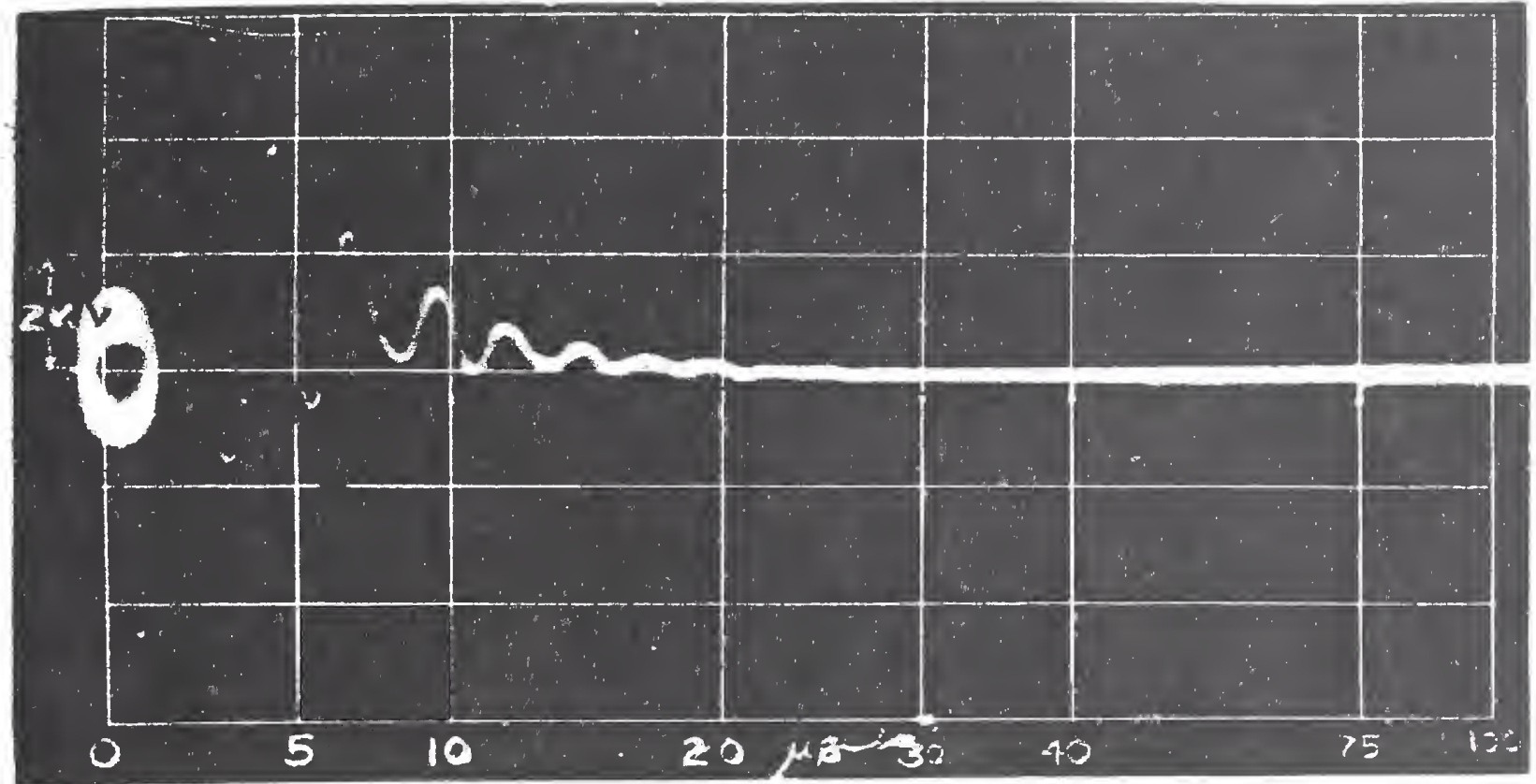
Lightning surge at Deer Park
$3.8 \mathrm{KV}$ crest, lus rise time
$330 \mathrm{KC}$ osciliation

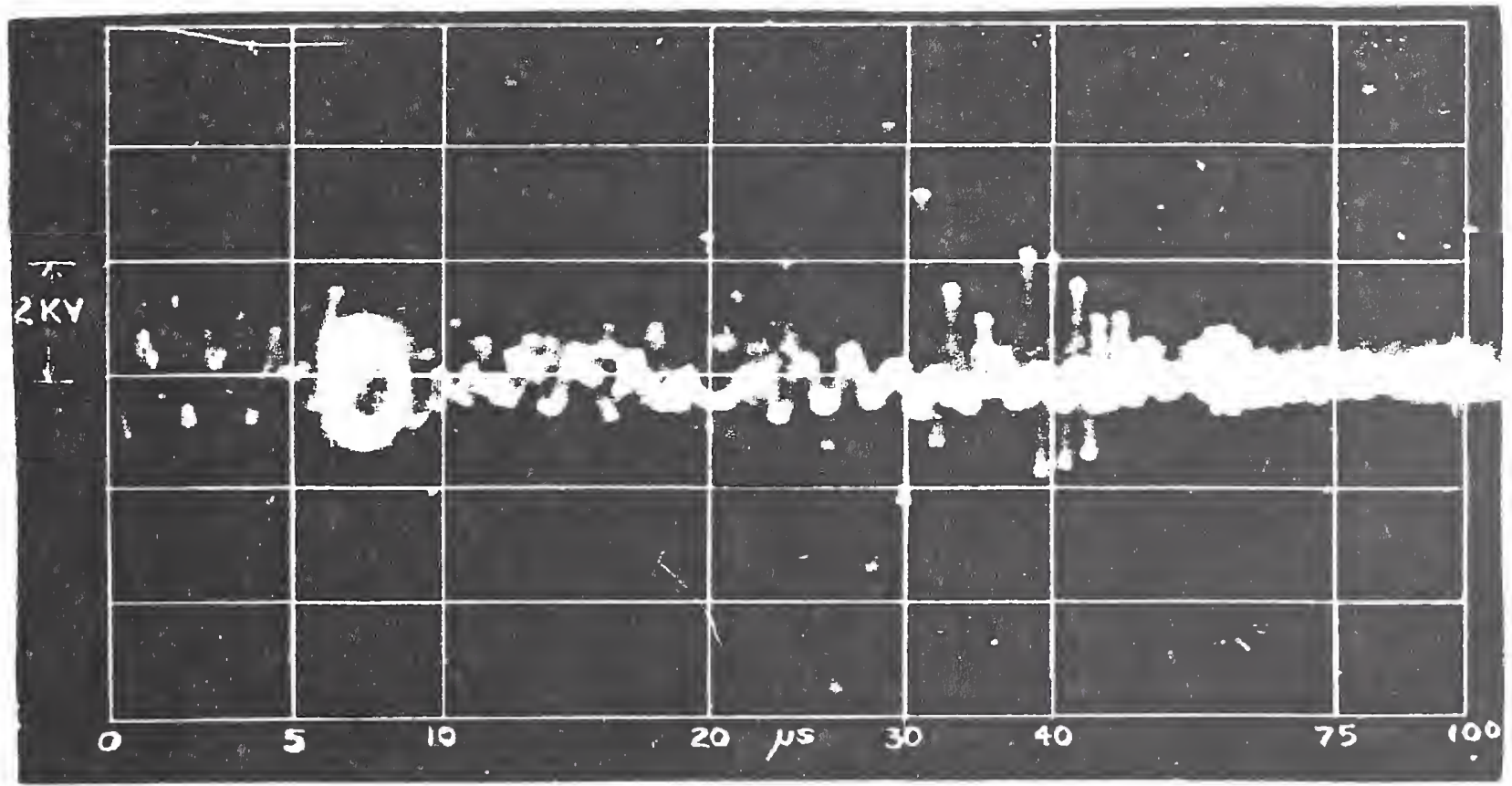

Lightning surge at Deer Park

$5.6 \mathrm{KV}$ crest, rise time $<1 \mathrm{us}$ $500 \mathrm{KC}$ oscillation

Fig. 2. Transients Recorded on Overhead Distribution Systems in Charleston, S. C. , July 1963. 

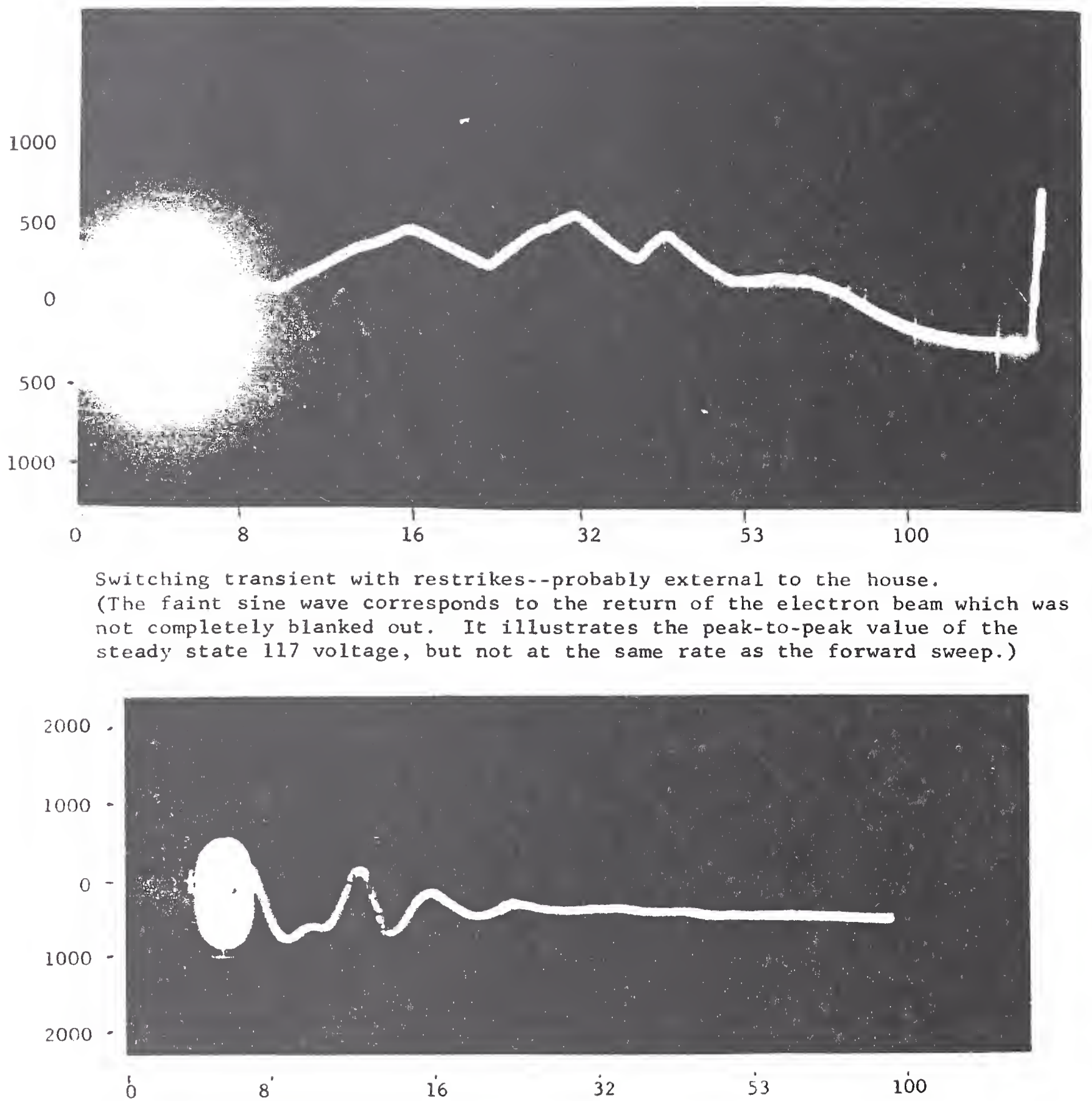

Internal switching transient

(15 such transients in 1500 hours)

Fig. 3. Transients Recorded at a Farmhouse, August 1963. 


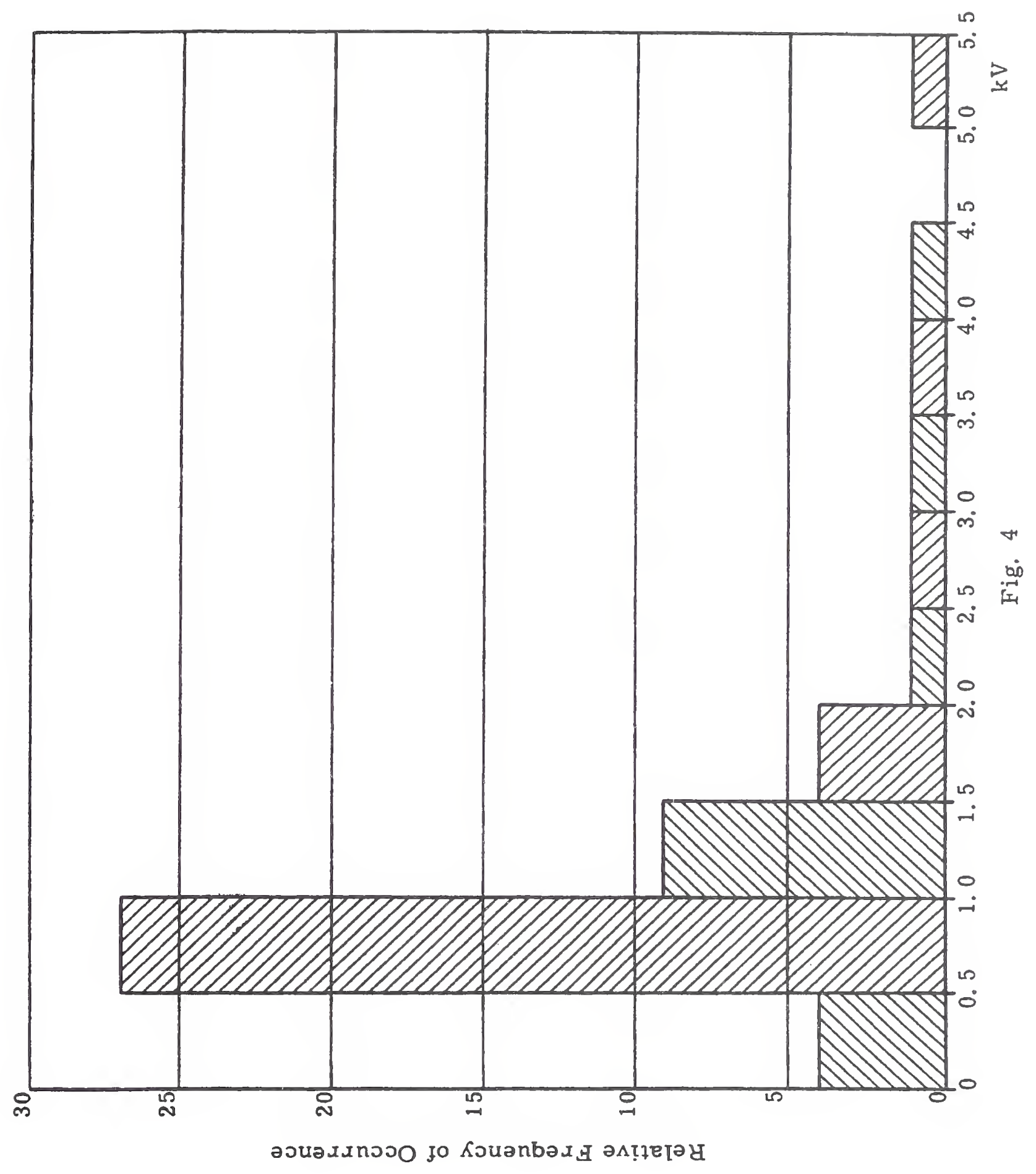




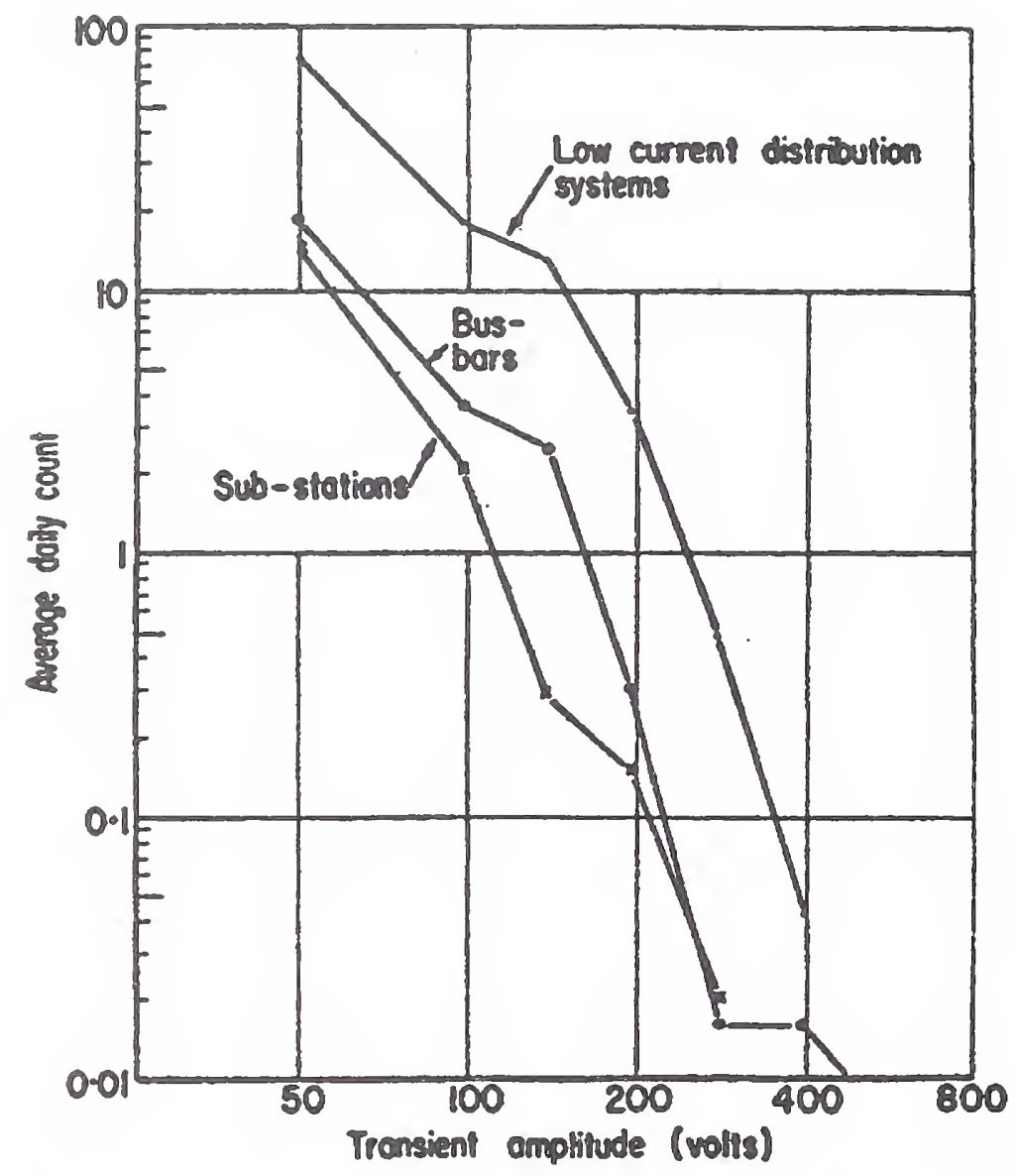

Pre. 5. Variation of frequency of occurrence with amplitude for short duration transients.

Fig. 5. Excerpt from Bull and Nethercot Paper. 


\section{BIBLIOGRAPHY}

This bibliography was prepared by the author for IEEE Standard 587 - 1980 , "IEEE Guide for Surge Voltages in Low-Voltage AC Power Circuits". It is reprinted with permission of The Institute of Electrical and Electronics Engineers, Inc., 345 East 47th Street, New York, New York 10017.

D1. Publications Describing the Environment

[DI] AIEE COMMITTEE REPORT. Switching Surges Due to De-Energization of Capacitive Circuits, AIEE Transactions, Aug 1957, pp 562-564.

[D2] ALLEN, G. W., and SEGALL, D. Mon. itoring Computer Installations for Power Line Disturbances, presented at the IEEE Power Engineering Society Winter Meeting, New York, NY, Jan 1974, Paper C74-199-6.

[D3] BODLE, D. W., GHAZI, A. J., SYED, M., and WOODSIDE, R. L. Characterization of the Electrical Environment, Toronto and Buffalo, NY: University of Toronto Press, 1976.

[D4] BULL, J. H. Impedance of the Supply Mains at Radio Frequencies, Proceedings of the First Symposium on EMC, Montreux, May 1975, 75CH1012-4 Mont.

[D5] CHOWDHURI, P. Transient-Voltage Characteristics of Silicon Power Rectifiers, IEEE Transactions on Industry Applications, vol IA-9, Sept/Oct 1973, p 582.

[U6] LlaNUS, N., ana FHELL, E. 1. A Ground-Lightning Environment for Engineering Usage, Stanford Research Institute, Menlo Park, CA 94205, Aug 1972.

[D7] Golde, R. H., Ed. Lightning. vols 1 and 2, New York: Academic Press, 1977.

[D8] HASLER, R., and LAGADEC, R. Digital Measurement of Fast Transients on Power Supply Lines, proceedings of the Third Sym. posium on EMC, Rotterdam, May 1979.

[D9] JOHNSON, I. B. IEEE Tutorial Course: Surge Protection in Power Systems, IEEE Power Engineering Society, 79EH0144-6.PWR, 1978.

[D10] LENZ, J. E. Basic Impulse Insulation Levels of Mercury Lamp Ballast for Outdoor Applications, Illuminating Engineering, Feb 1964, pp 133-140.

[D11] LERSTRUP, K. Atmospheric Overvoltages on Low-Voltage Installations, International Electrotechnical Commission, Doc IEC-28A/ WG1, Feb 1976.
[D12] MARTZLOFF, F. D. Coordination of Surge Protectors in Low.Voltage AC Power Cir. cuits, presented at the IEEE Power Engineering Society Summer Meeting, 1979, Paper F 79 635-4.

[D13] MARTZLOFF, F. D. Protection contre les surtensions: Importance des nouvelles techniques. Proceedings, 1980 IEEE Canadian Conference on Communications and Power, 80CH1583, pp 267-270.

[D14] MARTZLOFF, F. D., and CROUCH, K. E. Coordination de la protection contre les surtensions dans les réseaux basse tension résidentiels, Proceedings 1978 IEEE Canadian Conference on Communications and Power, 78CH1373-0, pp 451-454.

[D15] MARTZLOFF, F. D., and Hahn, G. J. Surge Voltage in Residential and Industrial Power Circuits, IEEE Transactions on Power Apparatus and Systems, vol PAS-89, July/ Aug 1970, pp 1049-1056.

[D16] PLUMER, J. A., and CROUCH, K. E. Lightning Protection for Traffic Control Sys-

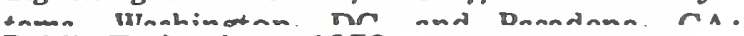
Public Technology, 1978.

\section{D2. Publications Describing Test Methods}

[D17] CROUCH, K. E., FISHER, F. A., and MARTZLOFF, F. D. Transient Control Levels: A Better Way to Voltage Ratings in Power Converter Applications, Conference Record, IEEE Industry Applications Society, 11th Annual Meeting, Chicago, IL, Oct 11-14, 1976, pp 940-944.

[D18] FISHER, F. A. and MARTZLOFF, F.D. Transient Control Levels, a Proposal for Insulation Coordination in Low-Voltage Systems, IEEE Transactions on Power Apparatus and Systems, vol PAS-95, Jan/Feb 1976, pp 120129.

[D19] LUTZ, M. Testing with Impulse Voltages and Impulse Currents in the Range of 0.5 to 75 $\mathrm{kV}$ and $1 \mathrm{~A}$ to $30 \mathrm{kA}$, Haefely Application Note, 1979. (Available from American HV Test Systems, Central Garrett Industrial Park, Accident, MD 21520.) 
[D20] MARTZLOFF, F. D. Transient Control Level Test Generators, Corporate Research and Development, General Electric Company, Schenectady, NY, 1977, Rep 77CRD241.

[D21] MARTZLOFF, F. D. and FISHER, F.A. Transient Control Level Philosophy and Implementation: The Reasoning Behind the Philosophy, Proceedings 2nd Symposium on EMC, Montreux, June 1977, 77CH1224-5EMC.

[D22] MONDRUSAN, M. Long-Duration Impulse Current Generator for Arrester Tests According to IEC Recommendations, Bulletin SEV/VSE, vol 68, 1977, pp 1304-1309.

[D23] RICHMAN, P. Conductive Surge Testing of Circuits and Systems, presented at the FAANASA Symposium on Lightning Technology, Florida Institute of Technology, Apr 22-24, 1980.

[D24] RICHMAN, P. Diagnostic Surge Testing, pts I, II, Power Conversion, Oct/Nov, 1979.

[D25] TIMPERLEY, J. E. Construction and Application of a SWC Generator, presented at the IEEE Power Engineering Society Winter Meeting, New York, NY, Jan 1972, Paper C72-040-9.
D3. Standards and Related Documents

[D26] ANSI C62.2-1969, Guide for Application of Valve Type Lightning Arresters for Alternating Current Systems.

[D27] ANSI/IEEE C37.90a-1974, Guide for Surge Withstand Capability (SWC) Tests.

[D28] ANSI/IEEE Std 28.1974, Standard for Surge Arresters for AC Power Circuits.

[D29] Code of Federal Regulations, Longitudinal Voltage Surge Test \#3, sec 68.302(e), title 37, Telecommunications. Washington, DC: US Government Printing Office, 1977.

[D30] IEC No 664 (1980), Insulation Coordination within Low-Voltage Systems Including Clearances and Creepage Distances for Equipment.

[D31] IEEE Std 4-1978, Standard for HighVoltage Testing Techniques.

[D32] IEEE Std 465.1-1977, Test Specifications for Gas Tube Surge Protective Devices.

[D33] Rural Electrification Administration (REA) Specification PE-60, Trunk Carrier Multiplex Equipment. Washington, DC 20250, 1975.

[D34] UL943, Standard for Safety - Ground Fault Circuit Interrupters, May 1976. 


\title{
Varistor versus Environment: Winning the Rematch
}

\author{
François Martzloff, Life Fellow, IEEE
}

National Institute of Standards and Technology

Gaithersburg MD 20899 USA

f.martzloff@ieee.org

\section{(C) 1986 IEEE}

Reprinted, with permission, from IEEE Transactions on Power Systems, Vol.PWRD No.3, April 1986

\section{Significance:}

This paper is listed under four categories of the Annotated Bibliography as it bears on the corresponding topics. The multiple listing reflects the sections in which this paper is cited as supporting material for IEEE Std C62.41.1 and 662.41 .2 . Therefore, it can be found in the following four parts of the Anthology:

Part 2 Development of standard - Reality checks

Provides an example of the need to recognize capacitor switching transients when characterizing the surge environment

Part 3 Recorded occurrences, surveys and staged tests

Provides an example of monitoring and staged tests motivated by field failure, leading to a better understanding of the environment in which SPDs were expected to perform.

Part 4 Propagation and coupling of surges

Provides an example of how far (3000 meters) the low-frequency transients generated by capacitor switching can propagate, unabated, in a path involving two step-down transformers.

Part 7 Mitigation techniques

Provides an example of improved mitigation design based on field experience 
$\varnothing$ 
Reprinted by permission of the Institute of Electrical and Electronics Engineers from:

\title{
VARISTOR VERSUS ENVIRONMENT: WINNING THE REMATCH
}

\author{
Françols D. Martzlofi, Fellow IEEE \\ Corporate Research and Development \\ General Electric Company \\ Schenectady, New York 12345
}

\begin{abstract}
An unusual case of difficult application of surge protective devices was solved by field measurements with retrofit of protective devices suitable for the particular environment. Onsite measurements indicated that capacitor switching transients were causing excessive current surges in the varistors and fuses protecting the input to a thyristor motor drive. Knowledge of the environment gained by the measurements allowed understanding of the problem and specification of matching surge protective devices.
\end{abstract}

\section{SUMMARY}

During the initial startup of a solid-state motor drive in a chemical processing plant, difficulties arose with the varistor and its protective fuse at the input of the thyristor circuits. Frequent blowing of the fuse was observed, with occasional failure of the varistor. On-site measurements of the voltages and currents at the input to the drive indicated that switching transients associated with the operation of a remote substation capacitor bank and the relatively low clamping level of the varistor were producing current above the fuse and varistor ratings; hence the short lives of these two components. When the actual conditions at that site were determined by measurements, it became possible to specify surge protective devices capable of withstanding that environment. Immediate relief was secured by the installation of a larger varistor at the same point of the circuit; long-term protection was obtained by the addition of a gapless metal-oxide varistor arrester on the primary side of the step-down transformer feeding the drive. The situation has been changed from failures occurring every few days to no further problems in the 3 years since the larger varistor was installed.

\section{INTRODUCTION}

This paper presents a case history illustrating how surge protective devices that are successfully applied for the majority of cases can occasionally suffer failure when exposed to exceptionally severe surge environments. This paper also shows how little attenuation occurs, at the frequencies produced by switching surges, between the distribution level $(23 \mathrm{kV})$ and the utilization level $(460 \mathrm{~V})$, even though a long line and two step-down transformers exist between the source of the transient and the point of measurement.

85 SM 365-2

A paper recommended and approved by the IEEE Surge Protective Devices Committee of the IEEE Power Engineering Soclety for presentation at the IEEE/PES 1985 Summer Meeting, Vancouver, B.C., Canada, July $14-19,1985$. Manuscript submitted February 1, 1985; made avallable for printing Apri1 22, 1985.
The problem involved a $460 \mathrm{~V}$ power supply to a thyristor drive circuit in a chemical processing plant extending over several square miles. During the initial startup, difficulties arose with the varistor and its protective fuse at the in put of the thyristor circuits. Frequent blowing of the fuse was ohserved, with occasional failure of the varistor. The plant substation, fed at $23 \mathrm{kV}$ from the local utility, included a large capacitor bank with one-third of the bank switched on and of to provide power factor and system voltage regulation. These frequent switching operations were suspected of generating high-energy transients that might be the cause of the failure of the fuses and varistors, because literally thousands of similar drive systems have been installed in other locations without this difficulty. On-site measurements performed after repeated blowing of fuses and occasional failure of varistors connected at the input to the thyristor drive indicated that indeed the devices were not matched to their environment. From this point on, specifying larger sizes, sizes appropriate to the environment [1], solved the problem.

\section{POWER SYSTEM AND SWITCHING TRANSIENTS}

Figure 1 is a simplified one-line diagram of the significant elements of the power system causing the varistor failures. The incoming $115 \mathrm{kV}$ power is stepped down to $23 \mathrm{kV}$. Three banks of $5400 \mathrm{kVAR}$ capacitors are connected to the $23 \mathrm{kV}$ bus. Typical operating conditions involve two banks connected at all times, with the third bank switched on or off automatically to provide yoltage regulation. Power distribution throughout the site is done at the $23 \mathrm{kV}$ level.

The various drive systems which experienced the difficulty are supplied at $460 \mathrm{~V}$ by a $2300 / 460 \mathrm{~V}$ transformer in their control house. A substation close to the control house supplies the $2300 \mathrm{~V}$ power from the $23 \mathrm{kV}$ distribution system.

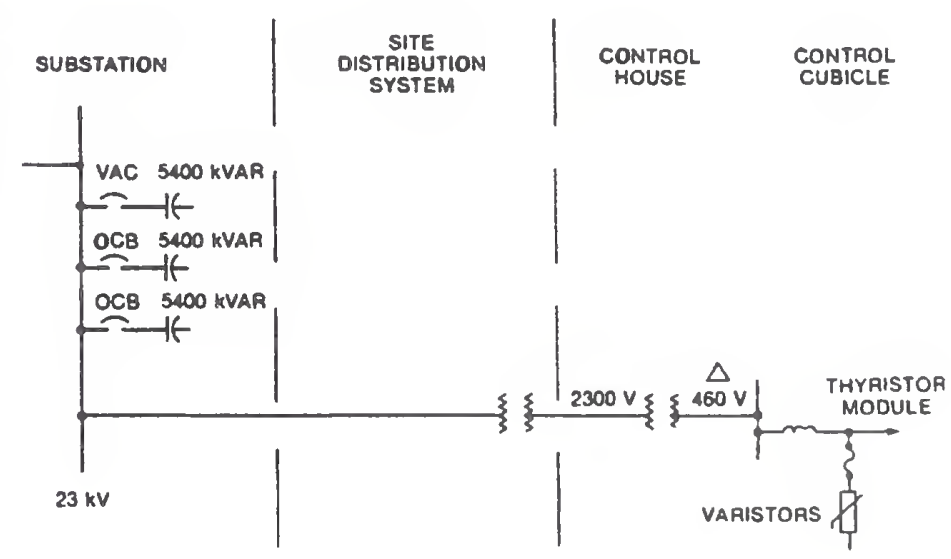


Figure 2 is a simplified three-phase schematic of the power input. In the original circuit, the thyristor modules were protected by varistors at the power input of the $1250 \mathrm{hp}$ drive, where the measurements were made. A $6 \mu \mathrm{H}$ line inductance, $\mathrm{L} 1$, was inserted between the bus and the thyristor modules; $20 \mathrm{~mm}$ varistors rated $510 \mathrm{~V}$ were connected in a delta configuration, in series with a current-limiting fuse in each line. The varistor connection was about $80 \mathrm{~cm}$ long, introducing an estimated $1 \mu \mathrm{H}$ inductance into each lead.

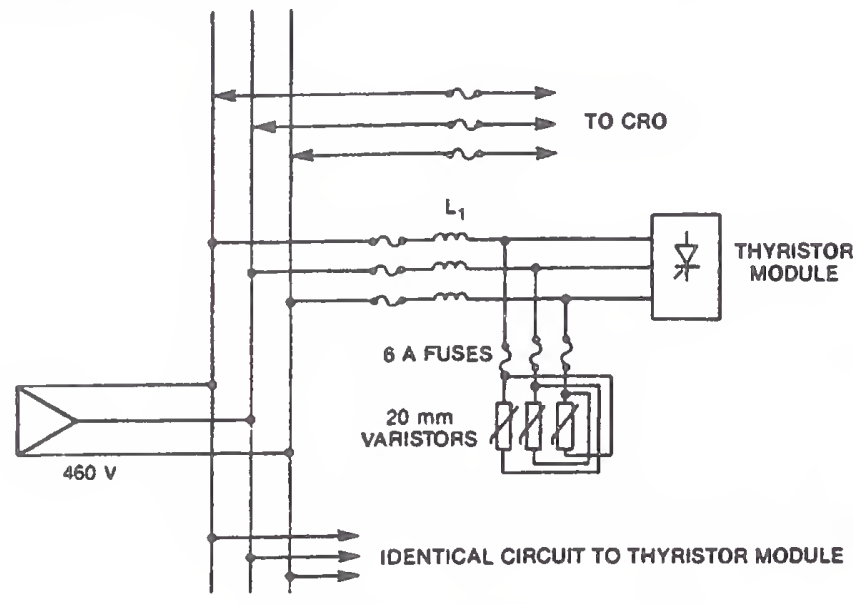

Figure 2. Simplified three-phase schematic

\section{Instrumentation and Measurements}

Oscilloscopes were used to measure voltage across one varistor and its connection and currents through all varistors. Voltage measurements were made phase-to-phase on the floating delta $460 \mathrm{~V}$ bus bars with Tektronix P6015 1000:1 probes, connected to a Tektronix 7633 storage oscilloscope in differential mode. Curreni measurements were made with a Tektronix CT5 20:1 current transformer coupled with a $\mathrm{P} 6021$ current probe and connected to a second Tektronix 7633 storage oscilloscope.

The trigger modes used during a two-hour monitoring period included positive or negative slopes for both slow ac and highfrequency modes. For the various modes, the level was adjusted to produce a trigger for a voltage exceeding the normal line voltage crest by about $20 \%$, or a varistor current in excess of $2 \mathrm{~A}$. No trigger occurred during the monitoring period. A low-frequency voltage recorder installed by plant personnel produced a recording characterized as representative of an unusually quiet day in the power system operations.

Manual off-on switching of the $5400 \mathrm{kVAR}$ capacitor bank at the $23 \mathrm{kV}$ utility substation was the next step in the measurement procedures because the switching of a capacitor bank is always a prime suspect for producing transients. Measurements were performed with one oscilloscope monitoring the line voltage upstream of the line inductors (Figure 2) and another oscilloscope monitoring the sum of the currents in the three varistors (Figure 3 ).

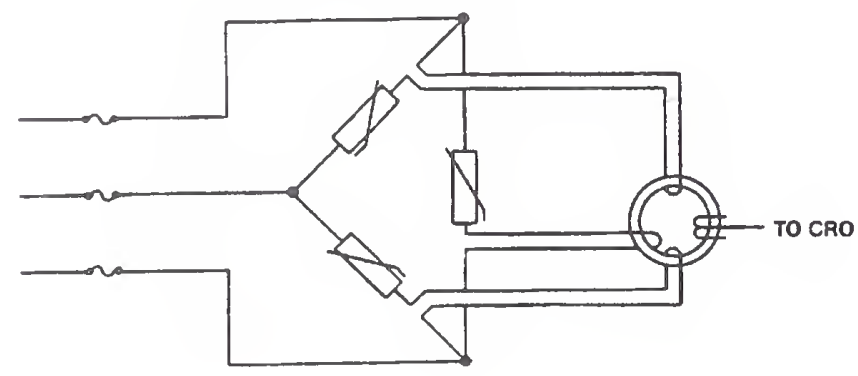

Figure 3. CT connection for recording all three varlstor currents

\section{Results}

The oscillogirms of Figure 4 show typical voltage recordings made during this sequence. The voltages are not open-circuit transient voltages. They are instances of the voltage appearing at the bus entrance point. This voltage is the sum of the varistor clamping voltage, the voltage drop in the varistor connections, and the voltage across two $\mathrm{Ll}$ inductances.

A typical total event recorded on one of the phases during a capacitor bank closing is shown in Figure 4A. A low-frequency oscillation with a period of $3 \mathrm{~ms}(330 \mathrm{~Hz})$ and initial peak-to-peak amplitude of $450 \mathrm{~V}$ decayed in about $10 \mathrm{~ms}$. The high-frequency oscillations are resolved in the recording of Figure $4 \mathrm{~B}$ (recorded during a similar switching sequence). This high frequency has an initial peak-to-peak amplitude of $2000 \mathrm{~V}$, decaying in about $5 \mathrm{~ms}$. The period is $180 \mu \mathrm{s}(5.5 \mathrm{kHz})$. A similar, third event is shown in Figure 4C. For scaling the amplitudes, the steady-state voltage is shown in Figure 4D.

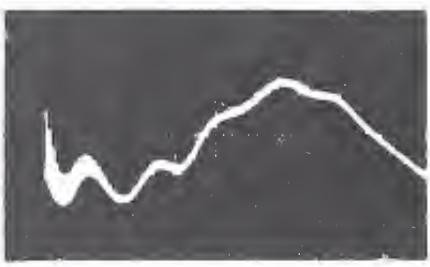

A Sweep: $2 \mathrm{ma} / \mathrm{div}$ Vertleal: $500 \mathrm{~V} / \mathrm{dl}$

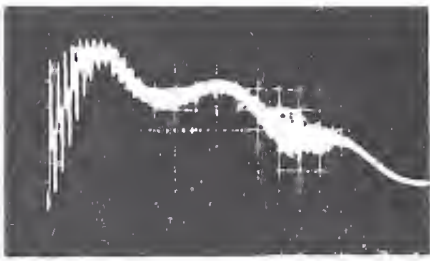

C Sweep: $1 \mathrm{~ms} / \mathrm{dtv}$ Ventical: $\mathbf{s 0 0} \mathrm{V} / \mathrm{dl}$

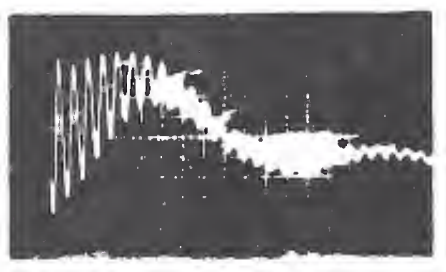

B Srerp: $0.5 \mathrm{~ms} / \mathrm{dlv}$ Vertleal: $300 \mathrm{~V} / \mathrm{dl}$

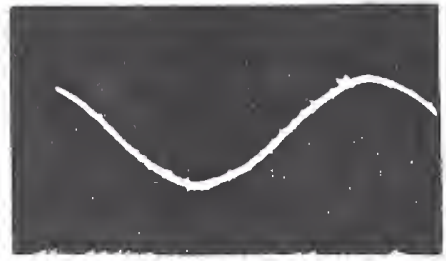

D Sreep: $2 \mathrm{~ms} / \mathrm{div}$ Vertieal: $500 \mathrm{~V} / \mathrm{dl}$
Figure 4. Capacitor switching transients and steady-state voitage

Observe that, depending on the time of closing with respect to the $60 \mathrm{~Hz}$ voltage, the $5.5 \mathrm{kHz}$ oscillation varies in amplitude; furthermore, the modulation by the $330 \mathrm{~Hz}$ oscillation pushes crests of the $5.5 \mathrm{kHz}$ oscillation above the $1000 \mathrm{~V}$ level some time after the beginning of the trace, at a time when the $5.5 \mathrm{kHz}$ amplitude is already lower, producing a burst of pulses above the $1000 \mathrm{~V}$ level.

The significance of this finding will be discussed next, with reference to Figure 5, which shows recordings of transient currents in all of the three varistors. The $510 \mathrm{~V}$ varistor has a nominal voltage at $1 \mathrm{~mA} \mathrm{[2]} \mathrm{in} \mathrm{the} \mathrm{range} \mathrm{of} 735 \mathrm{~V}$ to $970 \mathrm{~V}$. For a varistor with a nominal voltage in the middle of this range, a current in the order of tens to hundreds of amperes will flow if a voltage of $1000 \mathrm{~V}$ is applied to the varistor. Figure $5 \mathrm{~A}$ shows a train of current pulses in the range of 10 to $40 \mathrm{~A}$. In the burst of Figure $5 B$, the recorded current pulses range from $5 \mathrm{~A}$ to $200 \mathrm{~A}$. The current and voltage traces are not simultaneous events because each of the two oscilloscopes was triggered by its internal circuit. The nearly symmetrical appearance of this burst can be compared to the symmetry of the voltage peaks exceeding the $1000 \mathrm{~V}$ level in Figure 4, the one correlating with the other.

The oscillograms of Figures 4 and 5 were selecied as most severe from a series of 20 capacitor switching sequences. Some sequences could not even produce a current or voltage trigger; four sequences produced bursts with the central peak exceeding $120 \mathrm{~A}$, two of these reaching $200 \mathrm{~A}$ peaks. 


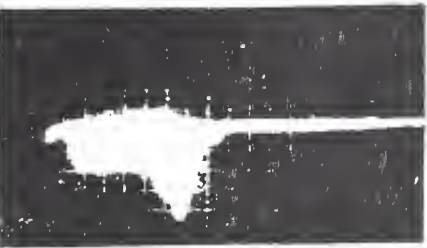

A Sweep: $0.2 \mathrm{~ms} / \mathrm{div}$ Vertlcal: $20 \mathrm{~A} / \mathrm{dl}$

Figure 5. Current surge bursts during capacitor switching

These recordings establish the nature of the current surges that are conducted by the varistors, with an estimate of $10 \%$ reaching $200 \mathrm{~A}$ maximum crests and another $10 \%$ reaching $120 \mathrm{~A}$ crests, for all capacitor bank switching.

In Figures 4 and 5 , we note that the characteristic appearance of the voltage and current usually observed during a switch restrike is absent [3], indicating a clean switching action of the vacuum interrupters used for switching the capacitor bank. Restrikes are most likely to occur during de-energizing. In all the offon switching sequences of this test series, no significant transient was observed during de-energizing; all occurred during energizing.

The oscillograms of Figures 4 and 5 establish and explain the pattern of current pulses. The voltages of Figure 4 are not the open-circuit voltages impinging the drive input but, rather, the voltages resulting from the clamping action of the varistors. To better evaluate the magnitude of the switching transients, opencircuit voltages were recorded in a next sequence, with all fuses to the drive open, thus disconnecting both the varistors and all sensitive loads. Figure 6 shows two typical recordings of open-circuit voltages and two of voltages resulting from varistor clamping, recorded during a series of 10 switching sequences for each condition. Table 1 shows the recorded crests of the five highest voltages in each condition; the difference between the two groups, with due allowance for the imperfect statistical basis of the observations, indicates that the $510 \mathrm{~V}$ varistors reduced the peaks from a typical high of $1450 \mathrm{~V}$ to a typical high of $1100 \mathrm{~V}$.
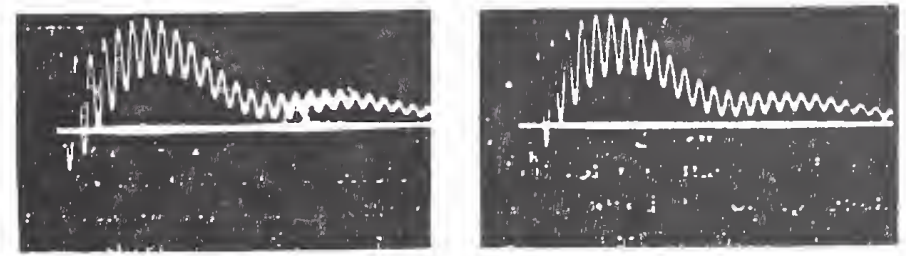

Open.Cireull Volleges
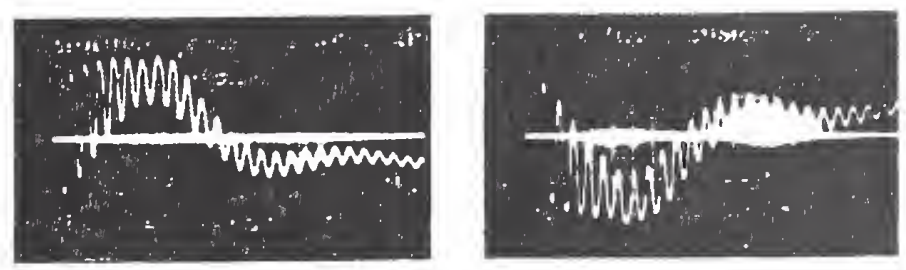

Whth $20 \mathrm{~mm}$ Varlstors

All Traces: Sweep: 0.5 mus/div Vertleal: $500 \mathrm{~V} / \mathrm{div}$
Table 1

FIVE HIGHEST TRANSIENTS IN SEQUENCE OF 10 SWITCHINGS

\begin{tabular}{c|c}
\hline Without Varistors & With Varistors \\
\hline 1450 & 1100 \\
1400 & 1100 \\
1300 & 1050 \\
1300 & 1050 \\
1300 & 1050 \\
\hline
\end{tabular}

\section{DISCUSSION}

\section{Nature of the Transients}

The absence of any transient (over $120 \%$ of normal crest) during the 2-hour monitoring period was somewhat surprising, in the context of earlier reports of high counts recorded with Dranetz disturbance analyzers. Frequent checks of threshold levels and variations of the possible trigger modes were made, maximizing the chance of catching an overvoltage, but indeed none occurred. This unusual quiet was also reflected in the chart recording made by the plant personnel, so that the absence of random transients for that period can be accepted at face value.

Therefore, conclusive evidence was obtained that substantial current pulses were absorbed by the varistors during capacitor switching. The magnitude and duration of these pulses were excessive for the capability of a $20 \mathrm{~mm}$ disc; many similar drives installed elsewhere do not experience the failures encountered at that particular location.

Another significant finding from these measurements is the fact that the switching transients, generated at the $23 \mathrm{kV}$ level, propagate down to the point of utilization at the $460 \mathrm{~V}$ level. Numerical discussion of this finding is given later in this paper.

\section{Effect of Transients on Varistors}

Published varistor specifications include the "pulse ratings," a family of curves that define, for each varistor type, the number of isolated pulses that a varistor can absorb until its "rating" is reached [4]. The curves show lines relating amplitude, duration, and total number of pulses. Figure 7 shows this family of curves for the original $20 \mathrm{~mm}$ varistor.

Figure 8 shows the same curves for a proposed $32 \mathrm{~mm}$ varistor. It should be noted that the pulse rating does not mean catastrophic failure of the varistor at the end of this rating, but only a $10 \%$ change in the varistor nominal voltage. Although some change is indicated, the varistor is quite capable of staying on line voltage and of clamping surges.

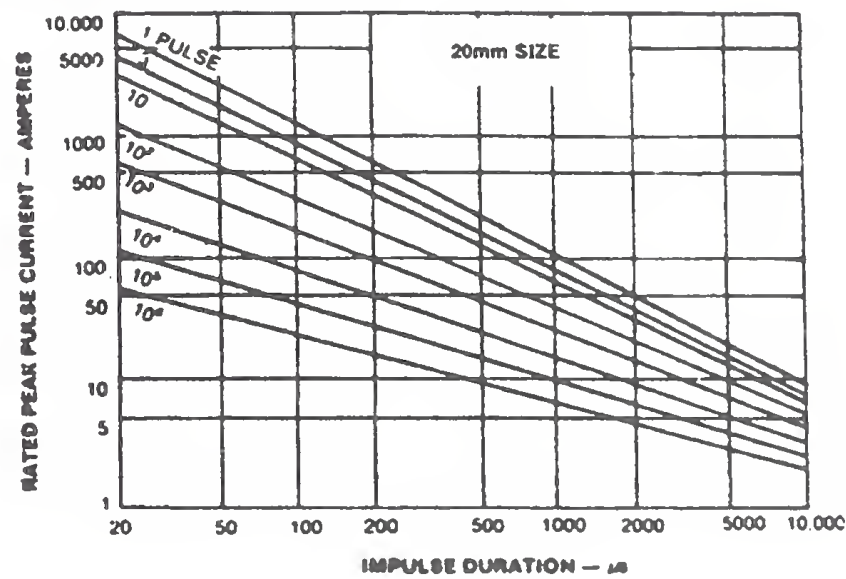

Figure 7. Pulse ratings of $20 \mathrm{~mm}$ varistor $|4|$ 


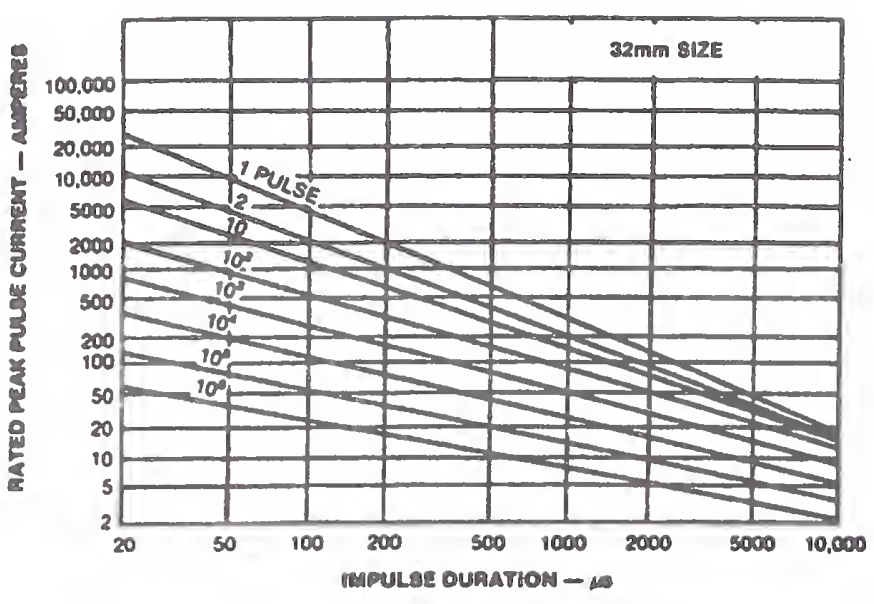

Figure 8. Pulse ratings of $32 \mathrm{~mm}$ varistor [5]

A careful examination of the pulse rating curves will show that the duration of the pulses has a strong influence on the number of permissible pulses. Furthermore, the relationship between the increased duration of the pulses and the decreased number of permissible pulses is not proportional. For instance, consider pulses of $100 \mathrm{~A}$ peak and $100 \mu \mathrm{s}$ duration (Figure 9A): the curves show 5000 pulses allowed. Now increase the duration of the pulses to $1000 \mu \mathrm{s}$ (a ten-fold increase), while keeping the amplitude at $100 \mathrm{~A}$ : the curves show the permissible number as one pulse only. Thus, the ten-fold increase in duration does not result in a ten-fold decrease in the number of permissible pulses; the reduction in that number is much greater than the inverse of the increase in duration. Conversely, taking a pulse duration of $1000 \mu \mathrm{s}$, and seeking the amplitude allowable for the same 5000 pulses, Figure $9 \mathrm{~B}$ shows that the current is $20 \mathrm{~A}$, which is five times less than the original $100 \mathrm{~A}$, not ten times less. Therefore, it would be incorrect to treat the multiple pulses of Figure 5 as five separate short pulses; rather, one equivalent long pulse has to be defined.

The five-pulse burst of Figure 5 has been redrawn in Figure 10 in order to plot an equivalent continuous pulse of approximately equal duration, with a crest such that the i $t$ integral of the burst and the it of the equivalent pulse are approximately the same. The use of $i \cdot t$ rather than the $\mathrm{i}^{2} \cdot 1$ integral typically used for fuses or other linear loads is justified by the fact that heat deposited in the varistors is the significant parameter because the nominal voltage change process is temperature related; this heat is the product of the variable $i$ and the nearly constant voltage across the nonlinear varistor during the burst.

The equivalent pulse of Figure 10 can then be used to evaluate, from the pulse ratings of Figure 7, the number of highamplitude switching transients that will consume $100 \%$ of the varistor pulse rating. Inspection of Figure 6 shows that for a $800 \mu \mathrm{s}$ duration and $100 \mathrm{~A}$ amplitude, the pulse rating of the $20 \mathrm{~mm}$ varistor (6 kA rating at $8 / 20 \mu \mathrm{s}$ ) is reached with two such events. With a probability of about $10 \%$ that this highest switching transient would occur during random timing of the switching (the effect decreases rapidly for transients other than the highest) and with 2 to 4 switching operations each day, the pulse rating of the varistors could be reached with 20 operations, failure perhaps starting at 40 to 50 operations, or after about 10 days of exposure to that power system environment. This estimate is unavoidably imprecise because the pulse rating curves represent a conservative minimum; actual failures will occur only for amplitudes or numbers of pulses exceeding the rating by a large but imprecise margin to allow for manufacturing variations. However, the order of magnitude of this estimated time to failure is in accord with the observations made at that installation.

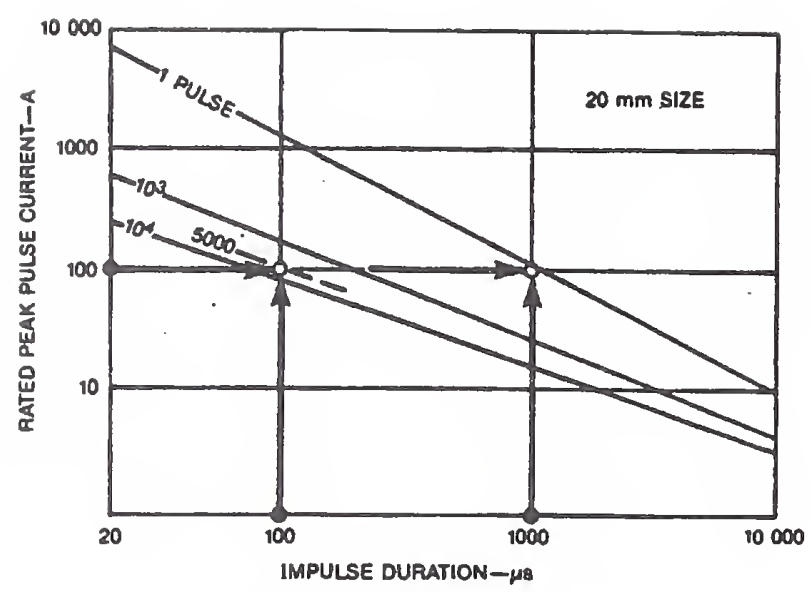

A. Same current, increasing duration

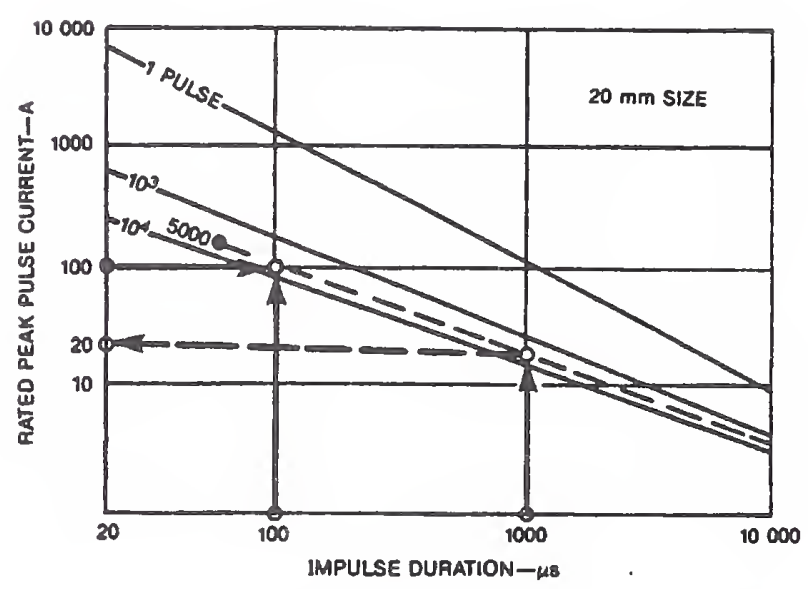

B. Same nmmber of pulses, increasing duration

Figure 9. Reading pulse ratings curves

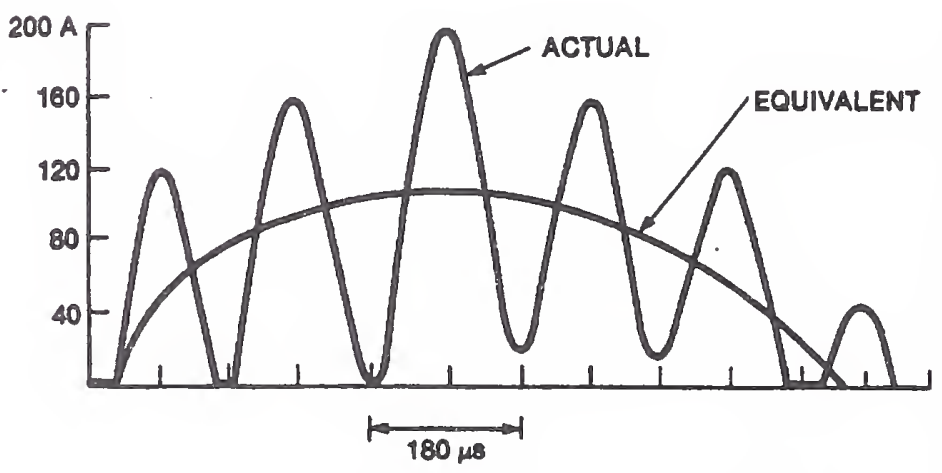

Figure 10. Single-puise equivaient puise for muitiple pulses

Note that two types of events occur. One is the premature blowing of the fuse, which is not caused by a varistor failure but by the $l^{2} \cdot t$ capacity of the fuse being exceeded by the environment [1]. The other is the fuse blowing caused by the varistor end-of. life ultimate failure. 


\section{Alternate Varistor Selection}

An obvious remedy would be to use a varistor with greater energy-handling capability. The $32 \mathrm{~mm}$ size offers such a possibility. Inspection of Figures 7 and 8 shows that the equivalent pulse of Figure $10(800 \mu \mathrm{s}$ and $100 \mathrm{~A})$ corresponds to a permissible occurrence of 100 pulses for the $32 \mathrm{~mm}$ varistor, in contrast to the two for the $20 \mathrm{~mm}$ varistor. The improvement in the number of pulses is 50 times more pulses until pulse rating is reached. The improvement in the number of pulses until varistor failure occurs, however, is not necessarily 50 times more pulses. Because of the imprecision mentioned previously in the margin between end of pulse rating and ultimate failure, that margin is not necessarily the same for the two sizes, $20 \mathrm{~mm}$ and $32 \mathrm{~mm}$, but it is reasonable to expect the same order of magnitude improvement in the ultimate failure as in the pulse rating. This expectation of a 50 times improvement would change the time between failures from the few days observed with the $20 \mathrm{~mm}$ size to perhaps one year with the $32 \mathrm{~mm}$ size, providing immediate relief and time to make further changes for the long term. Therefore, the change to a $32 \mathrm{~mm}$ size, connected at the same point of the circuit, was immediately implemented for that particular environment.

Further gains could be obtained in the length of time between varistor failures by increasing the clamping voltage of the varistors. This increase would result in lower current pulses for the same open-circuit transient voltage. A $510 \mathrm{~V}$ rating had been selected by the designer of the drive as the result of a trade-off between varistor clamping voltage and the withstand voltage of the thyristors protected by the varistors. If thyristors with higher voltage withstand were used, the solution would be easy.

Of course, the standard varistor product line has a certain tolerance band, reflecting normal production lot variations. In principle, a selection could be requested from the manufacturer that varistors with a narrower band be supplied for this application. The maximum clamping voltage allowed by the drive specifications would be retained, but those varistors in the lower half of the distribution, which draw larger current pulses for a given open-circuit transient voltage, would have been removed from the population of varistors. For instance, the range of nominal voltages for a $575 \mathrm{~V}, 32 \mathrm{~mm}$ varistor (the next higher voltage offered) is 805 to $1005 \mathrm{~V}$ for $1 \mathrm{~mA} \mathrm{dc}$, while the maximum nominal voltage of the same diameter but rated $510 \mathrm{~V}$ is $910 \mathrm{~V}$ for $1 \mathrm{~mA}$ dc. Thus, for a normal distribution of nominal voltages of the $575 \mathrm{~V}$ varistor, $50 \%$ of the devices could theoretically be used without exceeding the upper limit of the $510 \mathrm{~V}$ varistor that is consistent with the drive specifications. To achieve this end, it would be necessary for the supplier or user to make a careful determination of the nominal voltage on a population of $575 \mathrm{~V}$ varistors in order to retain only the lower half of the distribution (Figure 11).

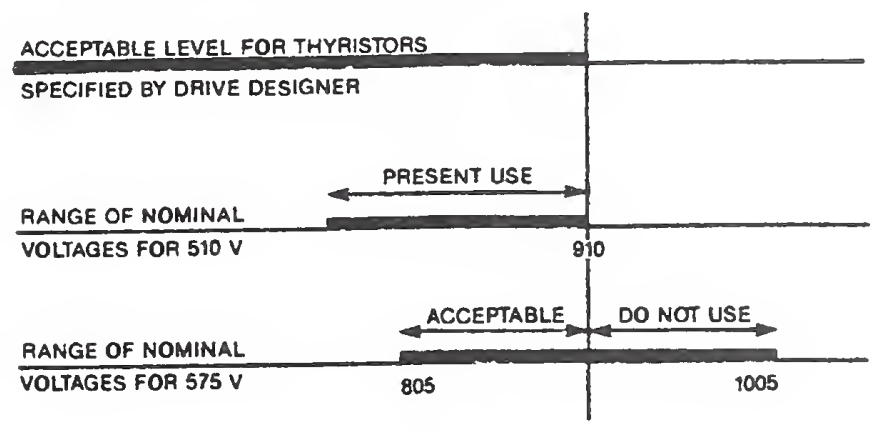

Figure 11. Tolerances bands of $510 \mathrm{~V}$ and $575 \mathrm{~V}$ varistors

\section{Other Remedles}

In addition to the proposed upgrading of protection at the $460 \mathrm{~V}$ level, three other remedies could be considered: installation of surge arresters at the $2300 \mathrm{~V}$ level, installation of surge arresters at the $23 \mathrm{kV}$ level, or a change in the circuits involved in the capacitor switching, designed to reduce the severity of the transients at their origin.

In general, the protection available from surge arresters tends to improve when the arresters are installed at higher circuit voltages. Thus, it is quite possible that arresters installed at the $2300 \mathrm{~V}$ primary of the $2300 / 460$ transformer could provide a more effective clamping (and at the same time relieve some of the energy stress) than the varistors at the $460 \mathrm{~V}$ level. (It is of course implied that these would be the zinc-oxide type, gapless arresters.) The full benefit of these arresters depends on the configuration of the $2300 \mathrm{~V}$ system and its grounding (solidly grounded neutral in a wye system, resistance-grounded wye, or floating delta) when the arrestors are connected in the conventional line-to-ground mode. In a second phase of the retront described here, $2300 \mathrm{~V}$ arresters were installed at the transformer primary. A discussion of their expected performance, validated by the success of the retrofit, is given later on.

Likewise, arresters on the $23 \mathrm{kV}$ side could be installed at the $23 \mathrm{kV}$ substation to mitigate the capacitor switching transients at their origin, or at the primary of the $23 \mathrm{kV} / 2300 \mathrm{~V}$ substation near the control house, where they would also serve as lightning protection for the overhead $23 \mathrm{kV}$ incoming power line. These arresters, again, must be of the gapless type to obtain the most effective protection.

The final remedy in the list of alternatives, but perhaps the first in effectiveness when the opportunity exists, would be to attempt reducing the severity of the capacitor switching transients at their origin. Series inductors or damping resistors may be considered, the effectiveness of which would be predictable if a simulation of the power system behavior were performed by computer modeling. While that remedy could not be applied to this particular location, it is a remedy that should be considered for a similar case of exceptionally severe environment.

\section{EXPECTED PERFORMANCE OF THE 2300 V ARRESTERS}

The measurements made first with open-circuit, then with the $20 \mathrm{~mm}, 510 \mathrm{~V}$ varistors on the $460 \mathrm{~V}$ side have shown a reduction of maximum voltage from $1450 \mathrm{~V}$ to $1100 \mathrm{~V}$ (Table 1) when a current of approximately $200 \mathrm{~A}$ is llowing in the line and varistors (Figure 5).

We can assume that the voltage drop in the line from the substation and two step-down transformers is mostly inductive at $5.5 \mathrm{kHz}$, and that the voltage in the varistors can be treated as the voltage across a resistor at the time of the crest of the current wave. The diagram of Figure 12 shows the relationship between the three voltages $V O C, V L$, and $V V$, respectively, the open-circuit voltage generated by the capacitor switching action, the voltage drop in the line and two transformers, and the varistor voltage at the current peak. Treating this highly nonlinear circuit as a linear circuit is an approximation that will provide at each point of the full range of voltage and current conditions a valid order of magnitude for the purposes of this discussion. Numerical methods are available for rigorous treatment at any instant over the full range of conditions [6]. With this simpifying assumption, we can determine the order of magnitude of the $5.5 \mathrm{kHz}$ current that would flow in an arrester installed at the primary terminals of the 2300 $\mathrm{V} / 460 \mathrm{~V}$ transformer as follows. 
1. From the actual measured vollages shown in Figure 12, we derive the voltage drop, VL, in the $23 \mathrm{kV}$ line and two stepdown transformers:

$$
\begin{aligned}
V_{L} & =\left(1450^{2}-1100^{2}\right)^{1 / 2} \\
& =940
\end{aligned}
$$

Thus, at $5.5 \mathrm{kHz}$, the impedance between the source and the varistor is

$$
\begin{aligned}
Z_{L} & =\frac{V_{L}}{I} \\
& =\frac{940 \mathrm{~V}}{200 \mathrm{~A}} \\
& =4.7 \Omega
\end{aligned}
$$

Note that this $4.7 \Omega$ impedance means that the $5.5 \mathrm{kHz}$ switching transient, generated at a distance of about $3000 \mathrm{~m}$ ( 2 miles) from the point of measurement, and at the $23 \mathrm{kV}$ level, can travel a long distance and pass through two step-down transformers with less attenuation than might be expected from the unsound but popular view that "surges cannot trevel that far without substantial attenuation."

2. We now arbitrarily assign equal values to the three elements of this impedance, $\mathrm{ZL}$ : (1) the $23 \mathrm{kV}$ line impedance; (2) the $23 \mathrm{kV} / 2300 \mathrm{~V}$ transformer; and (3) the $2300 / 460 \mathrm{~V}$ transformer. The impedance between the source and the primary of the $2300 / 460 \mathrm{~V}$ transformer is then two-thirds of the total impedance, $Z \mathbf{Z}$, or about $3 \Omega$ for the $460 \mathrm{~V}$ side of the transformer.

3. On the $2300 \mathrm{~V}$ side, the impedance of $3 \Omega$, calculated above, becomes $3 \Omega \times(2300 / 460)^{2}=75 \Omega$ and the open-circuit voltage of $1450 \mathrm{~V}$ which was measured on the $460 \mathrm{~V}$ side becomes $1450 \mathrm{~V} \times(2300 / 460)=7250 \mathrm{~V}$

4. Knowing the open-circuil voltage and the impedance between the source and the $2300 \mathrm{~V}$ arrester, we can compute the current in the arrester by iteration if we assume some current value and read the corresponding clamping voltage on the I-V characteristic of the arrester:

a) Assume a current crest of $50 \mathrm{~A}$, producing a drop of 50 $\times 75=3750 \mathrm{~V}$ in the line and $23,000 / 2300 \mathrm{~V}$ transformer. Adding this voltage to the varistor voltage, corresponding to $50 \mathrm{~A}$, which is read as about $5700 \mathrm{~V}$ on the arrester characteristic curve for minimum discharge voltage (Figure 13), we have $\left(3750^{2}+5700^{2}\right)^{1 / 2}=6780 \mathrm{~V}$, or somewhat below the expected $7250 \mathrm{~V}$ open-circuit voltage, which is to equal the quadratic sum of the two voltages $V L$ and $V V$.

b) Assume, for a new iteration, a crest of $60 \mathrm{~A}$, producing a drop of $60 \times 75=4500 \mathrm{~V}$, while the varistor voltage remains essentially the same, i.e., $5700 \mathrm{~V}$. The quadratic addition becomes $\left(4500^{2}+5700^{2}\right)^{1 / 2}=7210 \mathrm{~V}$, or a value close to the goal of 7250 .

5. Thus, we can expect that the $2300 \mathrm{~V}$ arrester will experience current pulses occurring in bursts not exceeding 60 to $70 \mathrm{~A}$, with durations similar to those found on the $460 \mathrm{~V}$ varistors, i.e. 5 10 7 pulses per train, or a total duration in the order of $1 \mathrm{~ms}$. Information on arrester duty available from the manufacturer indicates that, for a pulse train of that duration and a crest of less than $100 \mathrm{~A}$, no limitation of the number of pulses need be imposed on the arrester as long as enough time is allowed between pulses to permit cooling of the artester.

Furthermore, the $5700 \mathrm{~V}$ clamping level predicted for the $2300 \mathrm{~V}$ surge arresters at $60 \mathrm{~A}$ would be reflected as a crest of $5700 \mathrm{~V} \times 460 / 2300=1140 \mathrm{~V}$ on the $460 \mathrm{~V}$ side. The $510 \mathrm{~V}$, $32 \mathrm{~mm}$ varistors, connected in series with the impedance of the $2300 / 460 \mathrm{~V}$ iransformer, would then be exposed to this maximum

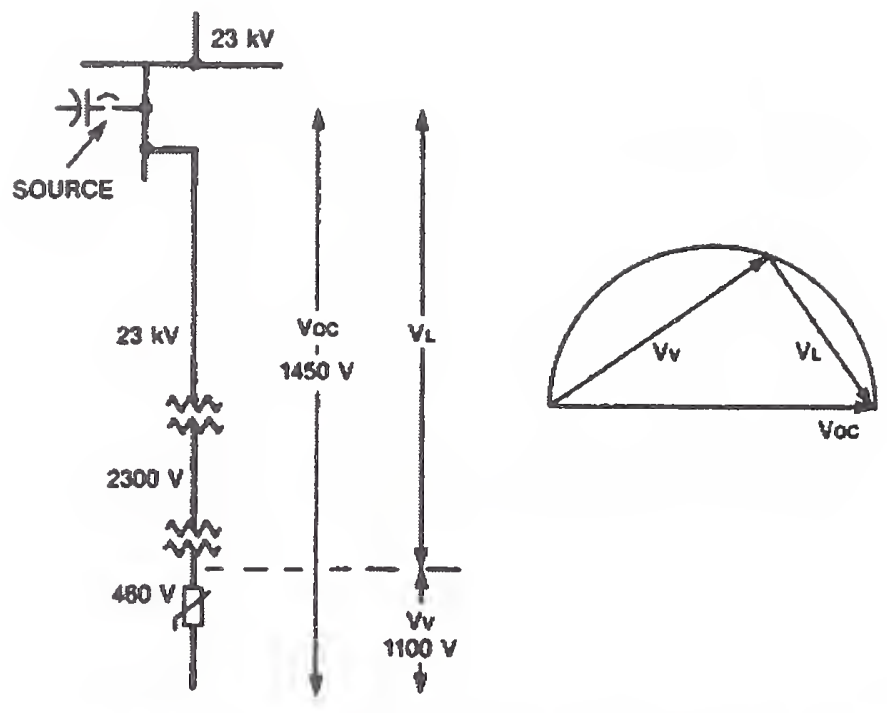

Figure 12. Opeal-circult voltage and voltage drops In the system

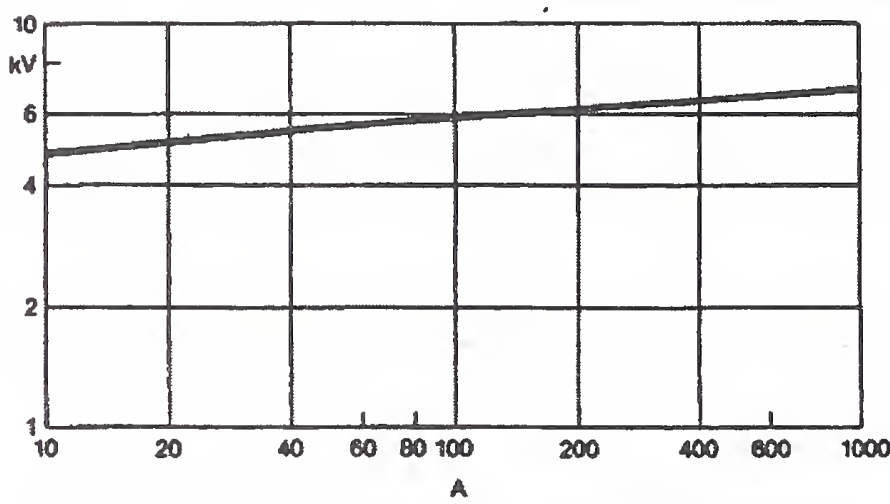

Figure 13. Minimum clampinge voltage characteristic for $2300 \mathrm{~V}$ arrester

open-circuit voltage of $1140 \mathrm{~V}$, a value much lower than the $1450 \mathrm{~V}$ open-circuit voltage that was applied to them in the absence of the $2300 \mathrm{~V}$ arresters. For that applied voltage, the current drawn by the varistor would be in the range of 10 to $20 \mathrm{~A}$, values much lower than the 200 A measured without the $2300 \mathrm{~V}$ arrester. Computing the equivalent pulse, as was done in Figure 10 for the $200 \mathrm{~A}$ crests, would yield an equivalent crest of about $10 \mathrm{~A}$, for which the pulse rating curves of the $32 \mathrm{~mm}$ series show more than 100,000 pulses before its rating is reached.

To place these large differences of performance and withstand capability into perspective, Table 2 shows the relative sizes and volumes of varistor material applied to the caming of the capacitor switching transieat. In other words, the environmeat bas now been matched by the cepablity of the varlstors.

Table 2

VARISTOR AND ARRESTER DIMENSIONS

\begin{tabular}{c|c|c|c}
\hline \multicolumn{1}{c|}{ Type } & Diameter & Thickness & Volume \\
\hline $20 \mathrm{~mm}$ & $1.8 \mathrm{~cm}$ & $0.35 \mathrm{~cm}$ & $0.9 \mathrm{~cm}^{3}$ \\
$32 \mathrm{~mm}$ & $3.0 \mathrm{~cm}$ & $0.35 \mathrm{~cm}$ & $2.5 \mathrm{~cm}^{3}$ \\
$2300 \mathrm{~V} \mathrm{Arr.}$ & $6.1 \mathrm{~cm}$ & $2.4 \mathrm{~cm}$ & $70 \mathrm{~cm}^{3}$ \\
\hline
\end{tabular}




\section{CONCLUSIONS}

Voltage and current measurements made on the $460 \mathrm{~V}$ input to a thyristor motor drive, during staged capacitor switching operations, showed current surges in the varistors originally used in the system that could consume the pulse rating life of these varistors in a few days of typical operation. Short-and long-term remedies were achieved.

For the short term, the change to a larger varistor connected on the $460 \mathrm{~V}$ side of the system was readily implemented to maintain the originally specified protective level, while the fuse-blowing nuisances were eliminated by use of a larger fuse. Available devices for this $460 \mathrm{~V}$ circuit may still have a relatively short life (a few hundred days) in the prevailing environment of the site, but they offered immediate relief and therefore allowed successful startup of the system.

For the long term, further protection was obtained by the installation of conventional station-class surge arresters, of the zinc-oxide, gapless type, at the $2300 \mathrm{~V}$ level. The system has now operated for 3 years without problems.

This case history also illustrates the low attenuation of the switching transient between the distant source at $23 \mathrm{kV}$ (about $3000 \mathrm{~m}$, or 2 miles) and the point of utilization at $460 \mathrm{~V}$.

\section{ACKNOWLEDGMENTS}

J.S. Kresge and B.I. Wolff provided information and guidance on the surge arrester and the varistor characteristics; C.L. Fisher contributed advice in clarifying and unifying the presentation of the concepts. Their contributions are gratefully acknowledged.

\section{REFERENCES}

[1] F.D. Martzloff, "Matching Surge Protective Devices to their Environment," Proc. IEEE/AS Meeting, Ociober 1983, pp. 387-392. (Also scheduled for IAS Transactions, Jan/Feb 1985.)
[2] ANSI/IEEE Std C62.33-1982. IEEE Slandard Test Specifications for Varistor Surge Protective Devices, The Institute of Electrical and Electronic Engineers, Inc., New York.

[3] A. Greenwood, Electrical Transients in Power Systems, Wiley Interscience, New York, 1971.

[4] Transient Voltage Suppression Manual, Fourth Edition, General Electric Company, Auburn, NY, 1983.

[5] Transient Voltage Suppression Manual, Third Edition, General Electric Company, Auburn, NY, 1983.

[6] H.W. Dommel, "Digital Computer Solution of Electromag. netic Transients in Single and MuItiphase Networks," IEEE Transactions on Power Apparatus and Systems, Vol. PAS-88, pp. 388-399, April 1969.

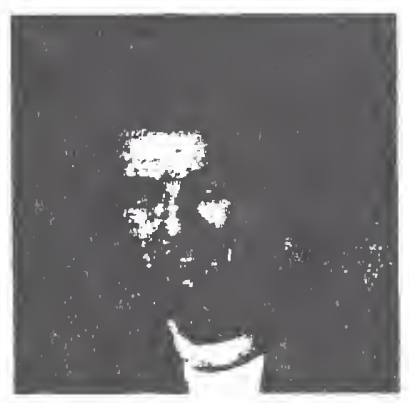

Françols D. Martzloff (M'56, F'83) was born in France, and received his undergraduate degree at the Ecole Spéciale de Mécanique et d’Electricité in 1951; he received the MS in Electrical Engineering degree from Georgia Tech in 1952 and the MS in Industrial Administration degree from Union College in 1971.

Since 1956 he has been with the General Electric Company, where he gained experience in the Transformer and Switchgear Division. Upon joining General Electric Corporate Research and Development in 1961, he became involved in power semiconductor circuits and overvoltage protection. He has participated in the introduction and application of metal oxide varistors since 1971 .

In IEEE, Mr. Martzloff is active on the Surge Protective Devices Committee. He is chairman of the Working Group on Surge Characterization in Low-Voltage Circuits. He is also a member of the Ad Hoc Advisory Subcommittee of the USA Advisory Committee on IEC S/C 28A, ANSI C.62 Subcommittee on Low-Voltage Surge Protective Devices, and Chairman of the NEMA Low-Voltage Arresters Technical Committee. He has been awarded 13 U.S. patents, primarily in the field of varistors and transient protection. 


\section{Discussion}

J. L. Roepringer (Duquesne Light Company, Pittsburgh, PA): The author has addressed one of many mechanisms for producing repetitive overvoltages on low-voltage circuits. In this particular instance, it was possible to obtain controlled conditions so that a measurement could be made of the voltage and currents resulting from the capacitor switching. It would be useful if there was an analytical method presented that correlated the generation of the $5.5-\mathrm{kHz}$ pulses with those measured. Did the author attempt to make such a correlation?

This paper points out the need to know the characteristic of the surge so that proper sizing of the protection can be achieved. Therefore it would be desirable to be able to have some analytical tool to permit calculation of the frequency of the surge due to remote capacitor switching.

Manuscript received July 24, 1985.

Fravcois D. Martzlof: The paper reported a case history from which useful information may be derived on retrofitting corrections of similar problems or, better, on avoiding the problem by foresight. The situations confronting the author was the need for immediate corrective action rather than complete investigation and mutual validation of analytical methods and field measurements.

The literature is fairly rich in both theoretical and practical papers on the problems associated with capacitor switching, both for energizing and for de-energizing, the latter involving the risk of restrikes. Because of this availability and the limited space available in the TRANSACTIONS on one hard, and because of the limitations in scope of the field retrofit mission on the other hand, no attempt was made to correlate the measurements with the power system parameters (which were not readily available to the author). In response to Mr. Koepfinger's suggestion, abstracts are cited below to provide references to both analytical tools and practical results published by other workers.

\section{Bibliography, 1970-1985 : REFERENCES}

(1) M. F. McGranaghar, W. E. Reid, S. W. Law, and D. W. Gresham, "Overvoltage Protection of Shunt-Capacitor Banks Using MOV Arresters," IEEE Trans. Power App. Syst., PAS-103, No. 8, Aug. 1984, pp. 2326-2333.

Protection requirements and surge arrester duties are analyzed for both digital and transient network analyzer (TNA) simulations. Sim. ple analytical expressions are developed for evaluating arrester duty as a function of capacitor bank size. Guidelines and limitations for applying arresters at grounded-and ungrounded-wye capacitor banks are developed based on overvoltage characteristics and arrester capabilities.

[2] J. H. Brunke and G. G. Schoeckelt "Synchronous Energization of Shunt Capacitors at $230 \mathrm{kV}$," IEEE PES (Power Eng. Soc.) Winter Meeting, New York, NY; Jan. 20-Feb. 3, 1978; Publ. by IEEE 1977, Paper A78-148-9, p. 4.

This paper reports on the application of synchronous switching to reduce inrush transients when switching a $230-\mathrm{kV}$ shunt capacitor bank. Computer studies determined the required switch performance.

[3] J. D. Cuffman, John Linders, M. A. Zucker, and S. Willima , "Power Factor Correction Capacitors and Their Side Effects," IIEEE Conf. Rec., 28th Ann. Conf. Electr. Ens. Probl. Rubber Plast. Ind., Akron, OH, April 5-6. 1976, pp. 37-49.

The major reason for applying capacitors to an electrical distribution system is to correct poor power factor. In the greater majority of installtions it is a routine procedure. In some instances capacitors may cause problems with other in-plant equipment and in other instances they may suffer undesirable side effects that originate in other equipment. Among these problems are switching surges, voltage unbalance due to fuses blowing, and harmonics generated by SCRcontrolled equipment.

[4] H. J. Yelland, and C. P. Yellna, "Vacuum Contactors: Latest Development in Their Design and Application," Certif. Ens. V 54, No. 1, Jan. 1981, pp. 824-841.

The paper includes the following topics: Design of vacuum bottles (glass and ceramic); design of the complete vacuum contactor and their panels; panels with on-load isolation, and panels with off- load isolation; vacuwm contactor applications (motor control), capacitor switching, arc and other (furnace-switching, transformer switching, mine-winder-reversers). Surge generation by vacuum contactors is considered under the following heads: basic energization and de-energization transients; transients generated when switching inductive loads; assessment of a vacuum contactor from a surge generation point of view; types of surge suppression devices; switching of capacitive loads. An extensive discussion of the paper is appended.

[5] Jack R. Harbaugh and John E. Harder, "Important Considerations for Capacitor Applications in the Petroleum and Chemical Process Industries," IEEE Pet. Chem. Ind. Conf., 27th Ann. Rec. of Conf. Pap., Houston, TX, Sept. 8-10, 1980; IEEE, \#80CH1549-5 IA), Piscataway, NJ, pp. 157-167.

The location of capacitors may have a significant effect of the (1" $2 \mathrm{R}$ losses within the plant transformers and conductors, which is wasted energy. Transients generated by capacitor switching may require attention in the selection of arresters, system insulation, or other equipment. The presence of capacitors amy require some special attention to large motors during system reclosing or load transfer. This study addresses each of these considerations, providing some guidelines for effective, reliable capacitor application. In addition, a checklist is provided for general industrial capacitor applications.

[6] J. F. Burser, R. J. Santoro, J. W. Stolle, R. E. Owen and C. R. Clinkenbeard, "Comparative Evaluation of Field Test Data and Computer Results on Capacitor Switching Transients," Meeting Minutes PA Electr. Assoc., Eng. Sect., Trans. and Distrb. Comm. West Middlesec, PA, May 15-16, 1979; PA Electr. Assoc. Eng. Sect., Harrisburg, PA 1979.

An arrester failure case was analyzed occurring at the time of substation capacitor bank switching with the use of a transient network analyzer (TNA) and digital computer techniques. The case involved a 12.5-kV ground-wye distribution sytem. Results of the TNA study, which were validated by field tests, showed the ef fects of system configuration magnitude of transient over voltages.

[7] Eldon J. Rosers, and Don A. Gilles, "Shunt Capacitor Switching EMI Voltages, Their Reduction in Bonneville Power Administration Substations," IEEE Trans. Power Appar. Syst. PAS-93, No. 6, Nov.-Dec. 1974, pp. 1849-1860.

Back-to-back switching of grounded wye shunt capacitors cause high frequency, high-magnitude current flow in overhead bus and ground mat conductors. Measurements of induced voltages on control cables and receptacles, transwerse voltages on fuse blown PT secondaries and personnel intercept voltages are reported. BPA methods of confining transients to capacitor areas and shielding techniques are reviewed.

18] Paul C. Krause and William C. Mauser, "On-Line Transient Control of Capacitor Switching to Improve System Stability," IEEE Trans. Power Appar. Syst. PAS-92, No. 1, Jan-Feb. 1973, pp. 321-329.

A simplified voltage-reactance equivalent of the one-machine infinite bus system was used. The material presented in this paper shows that this simplified model does not predict the performance of a onemachine infinite bus system with the accuracy necessary to determine the capacitor switching times so as to achieve the control objectives. However, it is shown that computation accuracy may be improved by including system losses. It appears that in order to apply optimal control techniques it will be necessary to develop more accurate models of the power system components. Also, faster than real time iterative, on-line computation techniques as simulated in this paper should be implemented and used to calculate the switching times. Until these obstacles are overcome, optimal control theory will have litule impact upon the power industry.

[9] D. O. Wiitanen, J. D. Morgan, and G. L. Gaibrois, "Station Capacitor Switching Transients, Analytical and Experimental Results," IEEE Trans. Power App. Syst. PAS-90, No. 4, July-Aug. 1971, pp. 1639-1645.

Station capacitor bank energization transients predicted by a circuit model are compared to field-test results. Selection of a suitable model is discussed. A computer solution of the model is presented.

Manuscript received September 19, 1985. 


\title{
ANNEX A \\ Statistics on Failure Rates of Clock Motors
}

\author{
Clock and Timer Department \\ General Electric Company
}

Excerpt of a 1964 declassified General Electric memorandum discussing failure of clock motors

\section{Significance:}

\section{Part 3 Recorded occurrences}

The memorandum from which this excerpt is drawn was provided to Martzloff in support of his contribution to gathering data on the occurrence of surges in low-voltage ac power systems, for a just-launched IEEE project on the emerging concerns about surge occurrences.

These statistics provide convincing evidence, based on a large number of reported failures, that a correlation exists between the rate of failures and the surge withstand capability of the motor windings.

A design change in this withstand level, from $2 \mathrm{kV}$ to $6 \mathrm{kV}$ produced a 100:1 drop in the failure rate. Interestingly, this 100:1 ratio, when plotted on a chart in which data from other sources were entered, produced a slope in good agreement with these other sources. Thus, the large number of clocks, operating 24/7/365 and unwittingly serving as sacrificial "surge counters" boosted confidence that the limited observations (in duration and in locations) being reported by other researchers were consistent.

Of course, the present-day significance of surge voltages is affected by the proliferation of surgeprotective devices, but these data are still useful as an indication of the occurrence of surges, only the levels have changed but presumably the mechanisms are still in action. 


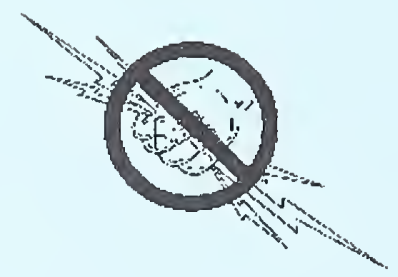


MEMORANDUL

January 9,1964

Sabject: Surge Information - Clock and

Timer Dept. Motor Cofl

Daring the sumer of 1953, an increase in defective coll returns to Service Stations became apparent. An investigation showed that the majority of failures were due to surge conditions. A study was made of the coll design at that time and it was found that impulse insulation levels dowa to $2000 \mathrm{~V}$ were obtained. In October of 1953 , a change was made in the coll design to improve the insulation level at the points of highest potential within the coll. This had an lamediate effect of Increasing the surge protection of t.3e coll from approximately $2000 \mathrm{~V}$ to approximately $6000 \mathrm{~V}$ minimum.

At the same time, a study was undertaken to collect all defective coll returns to the Ashland Service Station. These returns were examined to determine the causes for fallure. This study contiaued for a period of three years during which time 5,254 colls were collected and exaluined. Approximately $75 \%$ of these colls returned falled due to lightaing and/or other transient surge conditions. The attached chart shows the nuaber of colls receired for surge fallure in the fleld rersus their date of manufacture. The large numbers shom, particularly during 1951, can be explained by the fact that our collection of these colls was started in October of 1953. If the study whlch started in October had been started earlier, the portion of the curve prior to 1951 would have shown a corresponding lacrease in numbers. It was found in this study that it took approximately 18 months for a clock to find its way from our factory to use in the field.

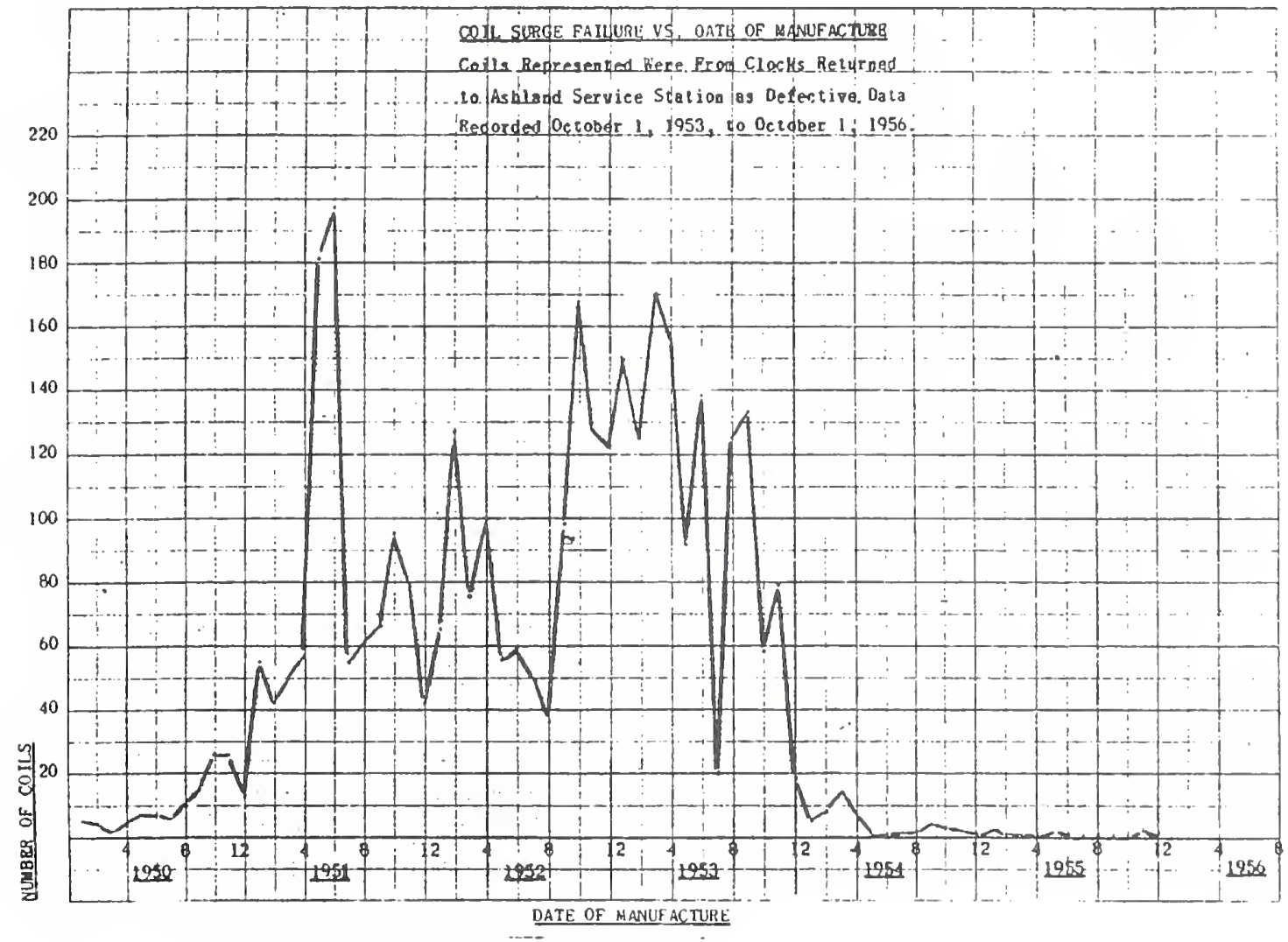




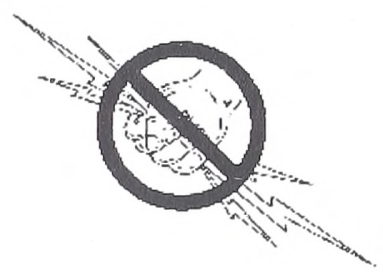


Annex B

Citations Part 3

Recorded surge occurrences, surveys, and staged tests 


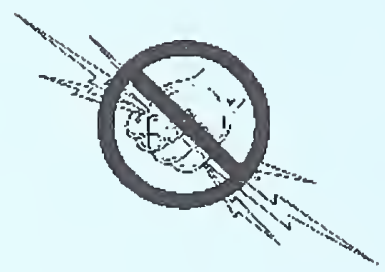




\section{Annex B}

Citations Part 3 - Recorded surge occurrences, surveys, and staged tests Alphabetical order by first author - See Part 1 for a listing of all the citations of the SPD Anthology, including Part 1 through Part 8.

ACKERMANN, G., HUDASCH, M., SCHWETZ, S., and STIMPER, K., "Überspannungen in Niedersparınungsanlagen" [Overvoltages in low-voltage installations], ETZ Bd. 114 (1993).

- Reports surge monitoring performed in Germany.

ACKERMANN, G., SCHEIBE, K., and STIMPER, K., "Isolationgefährdende Überspannungen im Niederspannungsbereich," [Overvoltages hazardous to insulation in low-voltage systems], ETZ, Bd 118 (1997).

- Reports surge measurements in Germany that include "energy content" in Ws (watts x seconds).

- 10 references

AIEE Committee Report "Switching Surges - I - Phase to Ground Switching Voltages," AlEE Transactions PAS-80, June 1961.

- Comprehensive report, 1961 vintage, of the subject.

- 84 references, 10 discussions

ALLEN, G.W. and SEGALL, D., “Monitoring of Computer Installation for Line Disturbances," presented at the IEEE Power Engineering Society Winter Meeting, New York, NY, Jan. 1974, Paper C74 (Conference preprint only.)

- Reports occurrence rates at computer sites, recorded with memory scopes.

- Possible artifact of insufficient writing speed discussed but not appended to conference preprint. See IEEE Std C62.41.1-2002 data base for that discussion.

- 7 references

ANDERSON, R.B. and ERIKSSON, A.J., "Lightning Parameters for Engineering Application," ELECTRA No.69, 1980.

- Probability of occurrence of lightning flashes.

- Peak current amplitude and waveshape parameters.

- 55 references.

ASPNES, J.D., EVANS, B.W., and MERRITT, R.P., "Rural Alaska Electric Power Quality," IEEE Transactions PAS-104, No.3, March 1985.

- Survey with digital-output disturbance monitors.

- Did not consider the effect of SPDs integrated in the instrument power supply that limited observed surges.

- 28 references, 2 discussions

BACHMAN, L., GULLBERG, M., STRICKLER, F., and SACHS, H., "An Assessment of Shipboard Power Line Transients.”Proceedings, International IEEE EMC Symposium, Aug. 1981.

- Surge recordings with storage oscilloscope and disturbance analyzers.

BARKER, P.P., MANCAO, R.T., KVALTINE, D.J., and PARRISH, D.E., "Characteristics of Lightning Surges Measured at Metal-Oxide Distribution Arresters," IEEE Transactions PWRD-8, January 1993.

- Recording of 1309 lightning surges at four sites of distribution systems.

- Uses a modified MOV arrester as transducer to bring signals down to low-voltage input of recorder.

- 23 references

BEJLERI, M., RAKOV, V.A., UMAN, M.A., RAMBO, K.J., MATA, C.T., and FERNANDEZ, M.I., "Triggered lightning testing of an airport runway lighting system," Proceedings, $25^{\text {th }}$ International Conference on Lightning Protection, Rhodes, September 2000.

- Injection of triggered lightning current into a runway lighting system at Camp Blanding.

- Measurements of the dispersion of lightning current among ground rods and counterpoise.

- 3 references 
BELHOMME, R., PLAMONDON, M., NAKRA, H., DESROSIERS, D., and GAGNON, C. "Case Study on the Integration of a Non-Utility Induction Generator to the Hydro-Québec Distribution Network," IEEE

Transactions PWRD-10, No.3, July 1995.

- Investigates the influence of load, capacitive compensation, machine parameters on resulting overvoltages.

- Presents results of simulation of a distribution network.

- 11 references

BERGER, K., ANDERSON, R.B., and KRÖNINGER, H., "Parameters of Lightning Flashes," ELECTRA No.41, 1975.

- The seminal paper on lightning parameters.

- Statistical distribution of 10 parameters, including peak current, charge, and waveshape parameters.

- 8 references

BODLE, D.W., GHAZI, A.J., SYED, M., and WOODSIDE, R.L., Characterization of the electrical environment, University of Toronto Press, 1976.

- Book initially written from the communications point of view but applicable to AC power circuits.

- 124 references, 320 pages

BOEHNE, E.W. and LOW, S.S., "Shunt Capacitor Energization with Vacuum Interrupters - A Possible Source of Overvoltage," IEEE Transactions, PAS-88, No. 9, Sept. 1969.

- Field tests and computer analysis for overvoltages on transformers and arresters, with proposed corrective measures.

- 15 references, 11 discussions

BULL, J.H. and NETHERCOT, M.A., "The frequency of occurrence and magnitude of short duration transients in low-voltage supply mains," Radio Electronic Engineer, September 1964.

- Peak-reading recordings at substations, bus-bars, and point-of use.

- 5 references

CANNOVA, S.F., "Short-Time Voltage Transients in Shipboard Electrical Systems,"”EEE Transactions IA-9, No.5, Sept/Oct 1973.

- Oscilloscope recordings and histograms.

- 18 references

CHOWDHURI, P., “Estimation of Flashover Rates of Overhead Power Distribution Lines by Lightning Strokes to Nearby Ground," IEEE Transactions PWRD-4, No.3, July 1989.

- Computation of flashover rates as a function of BIL.

- 18 references, 1 discussion

CIANOS, N. and PIERCE, E.T., “A Ground-Lightning Environment for Engineering Usage," Stanford Research Institute, Menlo Park, CA 94205, Aug 1972.

- Comprehensive statistics on the characteristics of lightning.

- 108 references, 136 pages

CUMMINS, K.L., MURPHY, M.J., BARDO, E.A., HISCOX, W.L., PYLE, R.B., and PIFER, A.E., “A Combined TOAMDF Technology Upgrade of the U.S. National Lightning Detection Network," Journal of Geophysical Research, Vol 103 No D8, Apriil 1998.

- Summarizes the development and upgrade of the U.S. National Lightning Detection Network.

- Provides examples of the cumulative distribution of peak current.

- 36 references

DARVENIZA, M. and UMAN, M.A., "Research Into Lightning Protection of Distribution Systems - Part II, Results from Florida Field Work 1978 and 1979," IEEE Transactions PAS-103, No. 4, 1984.

- Statistics on the occurrence of lightning.

- 14 references 
DORR, D.S., "Point of Utilization Power Quality Study Results," IEEE Transactions IA-31 No.4, July/August 1995.

- Presents results of four years of monitoring at 112 North American locations.

- Cites relatively low rate of occurrence of surges above 500 volts, suggesting that the proliferation of SPDs can be the cause of this low incidence.

- Other Power Quality statistics include sags, swells, and outages.

- 17 references

FERNANDEZ, M.I., RAMBO, K.J., STAPLETON, M.V., RAKOV, V.A., and UMAN, M.A., "Review of triggered lightning experiments performed on a power distribution system at Camp Blanding, Florida, during 1996 and 1997.Proceedings, 24 ${ }^{\text {th }}$ International Conference on Lightning Protection, Birmingham, UK, 1998.

- Injection of triggered lightning current into several configurations at Camp Blanding.

- Review of tests reported in earlier papers and preview of forthcoming test reports.

- 3 references

FERNANDEZ, M.I., RAKOV, V.A., and UMAN, M.A., "Transient currents and voltages in a power distribution system due to natural lightning," Proceedings, 24" International Conference on Lightning Protection, Birmingham, UK, 1998

- Opportunistic natural flash events at the triggered lightning facility of Camp Blanding.

- One flash event struck earth away from the line: electromagnetic coupling and injection via ground connections.

- One flash event struck the directly the overhead distribution line, equipped with MOV arresters at the time.

- 4 references

GAIBROIS, G.L., MASHIKIAN, M.S., and JOHNSON, K., "Study of Lightning Current Magnitude Through Distribution Arresters," EPRI Report No. EL-1140, Sept. 1979.

- Citation of long duration current in arresters.

- 8 references

GOEDBLOED, J.J., “Transients in Low-Voltage Supply Networks," IEEE Transactions EMC-29, No. 2, May 1987

- Shows rates of rise up to $30 \mathrm{kV} / \mu \mathrm{s}$, peaks exceeding $3 \mathrm{Kv}$.

- Contains extensive analysis of data.

- Avoids the use of 'energy in the surge' but defines 'energy measure' based on integral of $v^{2} d t$.

- 13 references

GOEDDE, G.L. DUGAN, R.C., ROWE, L.D, HARTANA, R., SKLIUTAS, J., and WALLING, R., "Full Scale Lightning Surge Tests of Distribution Transformers and Secondary Systems," IEEE Transactions PWRD-7, No.3, July 1992.

- Low-side surges are known to cause failures of low voltage distribution transformers.

- Tests on low-side surges were found to consist of two basic components:

- The natural frequency of the system, responsible for corona discharge spots at secondary bushings.

- The inductive response of the system to the stroke current, responsible for transformer failures.

- 11 references

GOLDSTEIN, M. and SPERANZA, P.D., "The Quality of U.S. Commercial AC Power," Intelec Conference Proceedings, 1982.

- Monitoring with Dranetz 606-3 at Bell Telephone sites.

- Statistical discussion of relative percentages of disturbances based on arbitrary thresholds.

GREBE, T.E., "Application of Distribution System Capacitor Banks and Their Impact on Power Quality," IEEE Transactions IA-32, No.3, May/June 1996.

- Discussion of capacitor switching transients and magnification effects.

- Provides several examples of recordings with the "PQNode" instrument.

- Points out the need to evaluate energy considerations if MOVs are applied for mitigation.

- 6 references 
HAHN, G.J. and MARTZLOFF, F.D., "Surge Voltages in Residential Power Circuits," IEEE Conference Paper, Summer Power Meeting, Portland OR July 1967.

- First publication of the GE surge monitoring project, later upgraded as IEEE Transactions PAS-89, No.6, July/Aug 1970 - See listing under [83] Martzl off \& Hahn.

HAIRABEDIAN, B. "A survey of Power Line Disturbances at Typical IBM Computer Installations in the U.S. for the Period 1988-1992." Document Number TR 21.1507, IBM Corporation, Kingston NY, June 1992.

- The survey logged 22201 monitor-days at 25 IBM computer sites.

- Frequency-distribution tables, Weibull profiles, histories of monthly events, and chronologies of vents.

- The composite results of the survey are compared with those of the 1972 and 1982 IBM surveys.

- 93 pages, 5 references

HARUKI, H., SUNAGA, M., KIMATA, R., and KATOH, J., "Development of a Lightning Current Waveform Measuring System for 500 kV Overhead Transmission Lines," IEEE Transactions, PWRD-4, No. 3, July 1989.

- Reports submicrosecond rise times of lightning current and differences in winter and summer lightning in Japan.

- 7 references

HASLER, R. and LAGADEC, R, "Digital Measurement of Fast Transients on Power Supply Lines," Proceedings, Third Symposium on EMC, Rotterdam, May 1979.

- Results of monitoring with a digital system show ring waves and nanosecond rise times near switching devices.

- 1 reference (in German)

HUGHES, M.B. and CHAN, J.S., "Canadian National Power Quality Survey Results," Proceedings, EPRIPQA'95 Conference 1995.

- Reports results of monitoring surge occurrences (only as part of a power quality survey).

- Three-year period at 550 sites classified as industrial, commercial, and residential, each for 1 month.

- 8 references

KEY, T.S. "Diagnosing Power Quality-Related Computer Problems," IEEE Transactions, IA-15, No. 4, July/Aug. 1979.

- Records of disturbances and general discussion.

- Early version of the computer susceptibility curve that became "The CBEMA Curve."

- 10 references

LENZ, J.E., "Basic Impulse Insulation Levels of Mercury Lamp Ballasts for Outdoor Applications," Illuminating Engineering, Feb. 1964.

- Reports (in the discussion) oscilloscope recordings at pole-mounted transformers with $\mathbf{5 . 6} \mathbf{k V}$ peaks, the maximum surge recording in $120 \mathrm{~V}$ circuits found in the literature.

MacGORMAN, D.R., MAIER, M.W., and RUST, W.D., "Lightning Strike Density for the Contiguous United States From Thunderstorm Duration Records," Report NUREG/CR-3759, U.S. Nuclear Regulatory Commission, 1984.

- Lightning strike density computed from aviation stations observations, presented as maps and tables.

- 16 references

MARTZLOFF, F.D., Surge Suppression in a Typical Home Wiring System," Declassified GE TIS Report 63GL97, 1963.

- Injection of surges and their propagation in a residential power system.

- Examples of suppression achieved by selenium cells before the advent of metal-oxide varistors.

- 2 references

MARTZLOFF, F.D. and HAHN, G.J., "Surge Voltages in Residential and Industrial Power Circuits," IEEE Transactions PAS-89, No. 6, July/Aug 1970.

- Oscilloscope recordings show ring waves; peak detector recordings yield statistics.

- Documents the anecdotal story of clock motor failures.

- 9 references 
MARTZLOFF, F.D., "Transient Overvoltages in Secondary Systems," Unclassified GE TIS Report 81CRD121, 1981.

- Capsule summary of data collected in the survey over the period of 1963-1970.

- Large-size reproductions of oscillograms contributed to IEEE Std C62.41

- 6 references

MARTZLOFF, F.D., "Varistor Versus Environment: Winning the Rematch," IEEE Transactions PWRD-1, No. 2, April 1986.

- Staged test of capacitor switching on remote MV side produces ring waves on low-voltage load.

- Coordination between $3 \mathrm{kV}$ and $480 \mathrm{~V}$ varistor-based SPDs.

- 5 references, 1 discussion

McEACHERN, A. Handbook of Power Signatures. Foster City, CA: Basic Measuring Instruments Publisher, 1989.

- Reports generic types of disturbances.

- Procedures on conducting a site survey.

MEISSEN, W., "Überspannungen in Niederspannungsnetzen" [Overvoltages in low-voltage networks], ETZ Bd. 104, 1983.

- The seminal paper proposing long waveform with extremely high energy-deposition capability (leading to the development of German Standard DIN 0160, but no longer acknowledged by the IEC TC77).

- Documents the effects of fuse blowing in industrial environments.

MELLITT, B., "Transient Voltages Generated by Inductive Switching in Control Circuits," Proceedings IEE, vol. 121, No. 7, July 1974.

- Shows field and laboratory recordings of bursts such as those involved in the IEC EFT specifications.

- 11 references

MINEGISHI, S., ECHIGO, H., and SATO, R., "Frequency Spectra of the Arc Current Due to Opening Electric Contacts in Air," IEEE Transactions, EMC-31, No. 4, Nov. 1989.

- Reports measurement in megahertz range of contact opening sequences.

- 11 references

ODENBERG, R. and BRASKICH, B.J., "Measurements of Voltages and Current Surges on the AC Power Line in Computer and Industrial Environments," IEEE Transactions, PAS-104, No. 10, Oct. 1985.

- Reports long-duration surges (1000 $\mu \mathrm{s})$.

- 5 references, 2 discussions

ORVILLE, R.E., HENDERSON R.W., and PYLE, R.B., "Lightning Flash Characteristics: 1987, Interim Report," EL-6413, Electric Power Research Institute, August 1989.

- Statistics and maps of lightning ground flashes for Eastern United States.

- 13 references

PELLETIN, J. and LEROY, J. "Expérimentation réseaux témoins - Résultats de la campagne d'investigations 1973. Enregistrement de surtensions atmosphériques affectant les postes MT/BT et les dérivations d'abonnés d'artères de distribution rurales - Analyse statistique des enregistrements.

[Experiments on sample networks - Results from the 1973 investigation. -EDF - DER - M15-375 - May 1974. (In French)

- Recordings of atmospheric overvoltages on MV/LV stations and rural distribution lines

- Statistical analysis of the recordings

PFEIFFER, W, and SHEERER, F., “Überspannungen in Niederspannungsnetzen” [Overvoltages in lowvoltage networks], ETZ Bd.113 (1992) pp 578-584. (In German)

- Reports measurements conducted in Germany in the late eighties.

- Source of several figures illustrating switching surges included in this Guide. 
POPOLANSKY, F., PROCHAKZKA, F., and SCHLAMP, M., "Frequency distribution of peak values of lightning overvoltages in a rural low-voltage network," Proceedings, $21^{\text {th }}$ International Conference on Lightning Protection, Berlin, 1992.

- Statistics of the recording of lightning-induced surges in an overhead line.

RAKOV, V.A. and UMAN, M.A., "On the Duration of Time Intervals Between Lightning Return Stokes, Proceedings, $22^{\text {nd }}$ International Conference on Lightning Protection, Budapest, 1994.

- Electric field measurements and TV records of multiple strokes.

- Time intervals between two stroke can be less than one millisecond.

- 25 references

RAKOV, V.A., UMAN, M.A., FERNANDEZ, M.I., THOTTAPPILLIL, R., EYBERT-BERARD, A., BERLANDIS, J.P., RACHIDI, F., RUBINSTEIN, M., GUERRIERI, S., and NUCCI, C.A., "Observed electromagnetic environment close to the lightning channel," Proceedings, $23^{\text {th }}$ International Conference on Lightning Protection, Florence, litaly, 1996.

- Measurements at Camp Blanding of electric and magnetic fields at distances of tens to hundreds of meters from point of strike.

- Comparisons with data from Kennedy Space Center and Fort McClelland.

- 9 references

RHOADES, W.T., "Characteristics of Unusual Power Mains Transients," Proceedings, 1985 Zurich EMC Symposium, 1985.

- Transients associated with UPS operation and CRT flashover.

- 5 references

SABIN, D.D., “An Assessment of Distribution System Power Quality,” EPRI Report TR-106294-V2, 1996.

- Comprehensive statistical data base of power quality measurements collected during the EPRI Distribution Power Quality (DPQ) Project.

- 15 references

SPERANZA, P.D., "A Look at the Quality of AC Power Serving the Bell System," Bell Lab Record, July/Aug. 1982.

- Generic report of recordings and statistical discussion.

STANDLER, R.B., "Transients on the mains in a residential environment," IEEE Transactions EMC-31, No.2, May 1989.

- A digital oscilloscope was used to measure transients on the single-phase $120 \mathrm{~V}$ RMS mains in a residential environment.

- Waveforms are shown for transient overvoltages on the mains caused by three nearby lightning strikes and one unknown source. Statistical summaries are presented for all naturally occurring transients.

- Waveforms are presented for the transient caused by switching on various loads, resulting in rates of rise ranging from $6 \mathrm{kV} / \mu \mathrm{s}$ to $17 \mathrm{kV} / \mu \mathrm{s}$.

- 6 references

TRUEBLOOD, H.M. and SUNDE, E.D., “Lightning Observations in Buried Cables," Bell System Technical Journal, XVIII, April 1949.

- Presents the concept of "stroke factor".

WERNSTRÖM, H., BROMS, M., and BOBERG, S., "Transient Overvoltages on AC Power Supply Systems in Swedish Industry," Report FOA E 30002-E2, Foorsvarets Forskningsanstaldt, Huvudavdelning 3, Sweden, 1984.

- Shows rise times in the range of $60 \mathrm{~ns}$ to $600 \mathrm{~ns}$.

- Contains a graph of number of occurrences versus peaks.

- 12 references 



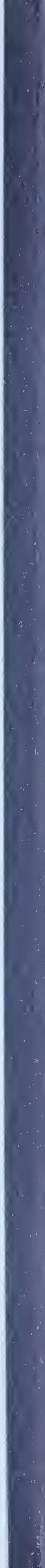

